\title{
Managerial Accountability in the Western Balkans
}

\author{
A comparative analysis of the barriers and \\ opportunities faced by senior managers in \\ delivering policy objectives
}

SIGMA Paper No. 58

Authorised for publication by Karen Hill, Head of the SIGMA Programme 


\section{Table of contents}

Executive summary ........................................................................................................................................ 3

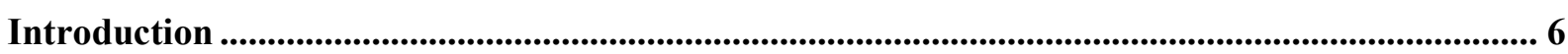

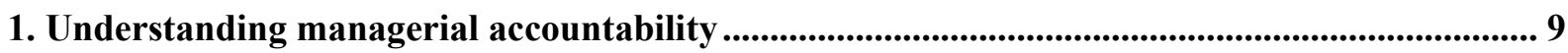

1.1. Definitions and key ingredients: responsibility, authority and autonomy ……......................... 9

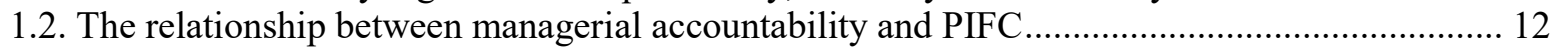

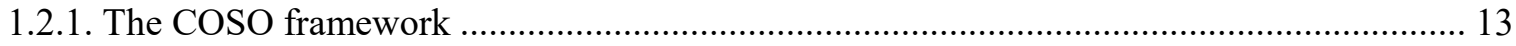

1.2.2. Managerial accountability and the Principles of Public Administration............................. 14

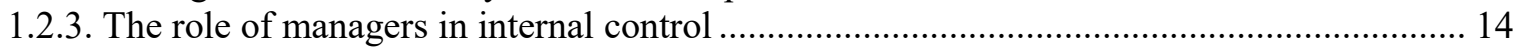

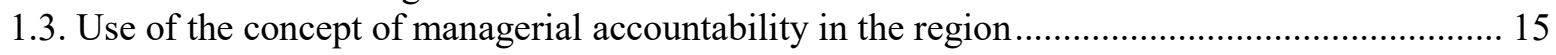

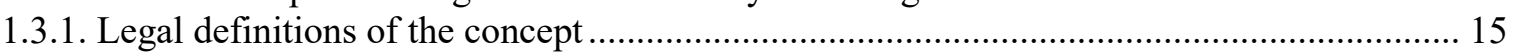

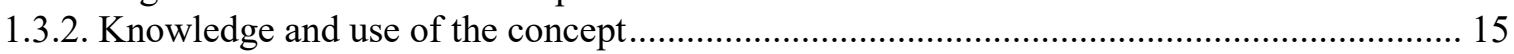

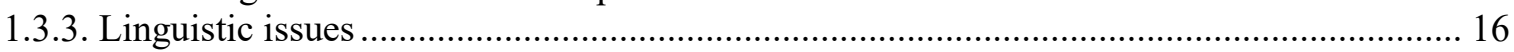

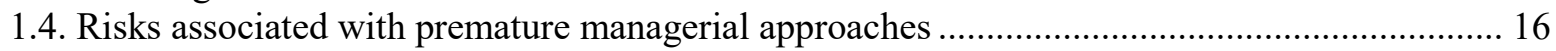

1.5. Factors determining the level of managerial accountability .................................................... 18

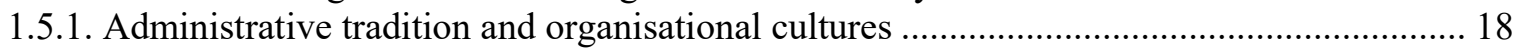

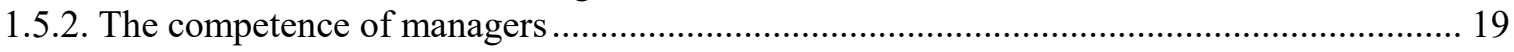

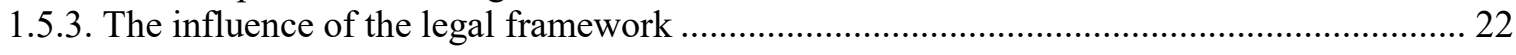

2. Analysis of barriers to managerial accountability and key recommendations............................. 23

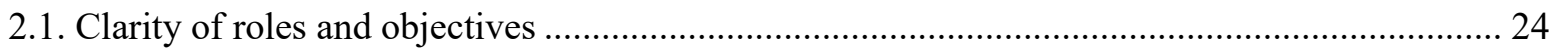

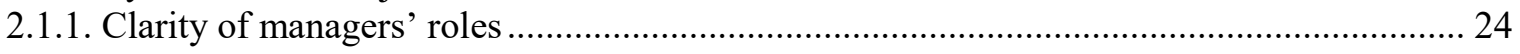

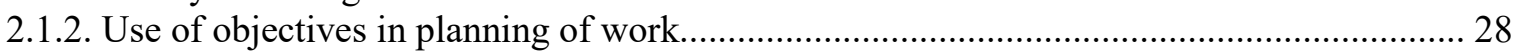

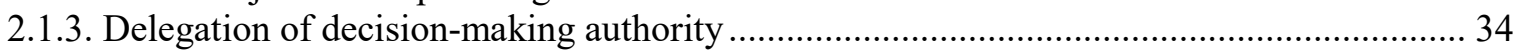

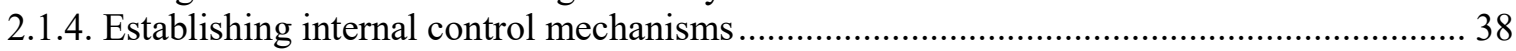

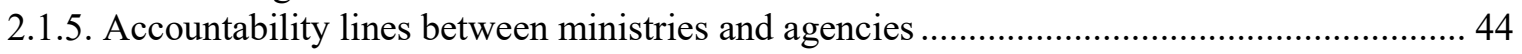

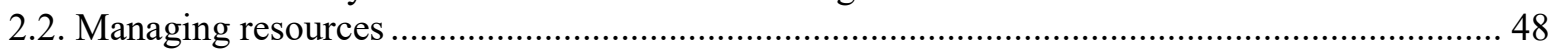

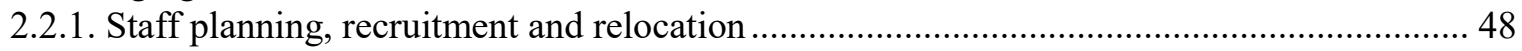

2.2.2. Staff appraisals, objectives and links to promotion and salaries ....................................... 55

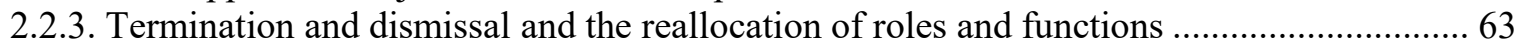

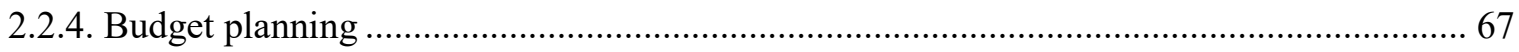

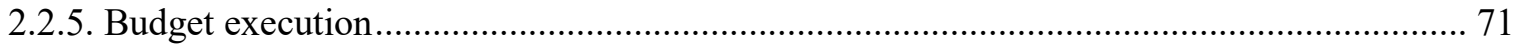

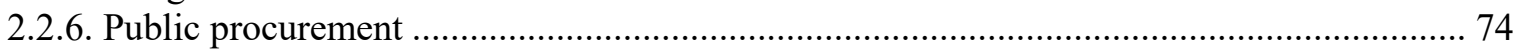

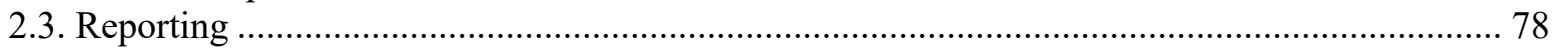

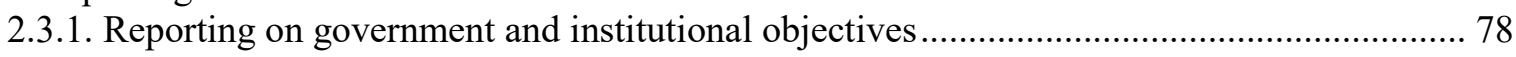

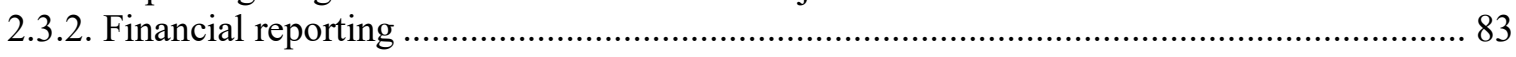

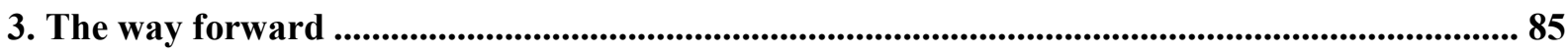

Annex A. Management hierarchy of ministries in the region ..................................................... 89

Annex B. Delegation matrix - a generalised approach to the delegation of decision-making authority .......................................................................................................................................................... 94 


\section{Tables}

Table 1. The state of play on key accountability mechanisms between ministries and subordinated

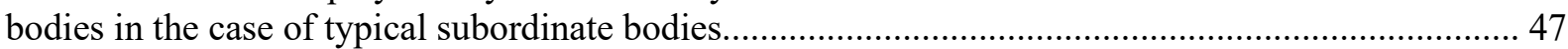

Table 2. National legislation on key aspects of autonomy of the subordinate bodies ........................... 48

Table 3. Decision matrix in the procedure for recruiting civil servants (non-senior levels) in

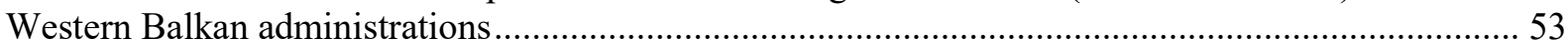

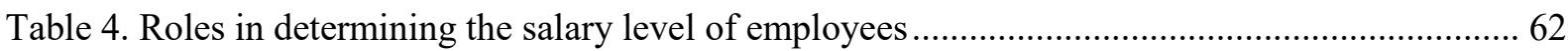

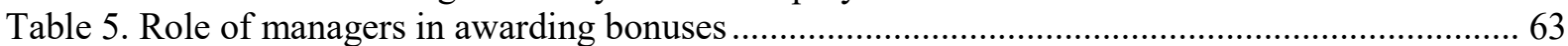

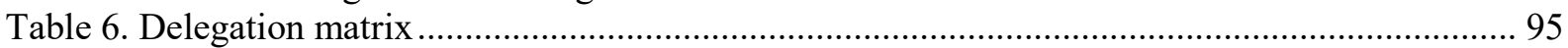

\section{Figures}

Figure 1. Managerial hierarchy of a classical ministerial system...................................................... 7

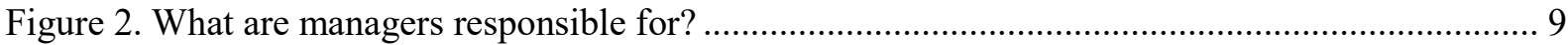

Figure 3. Key building blocks for managerial accountability ......................................................... 12

Figure 4. Topics covered in the analysis of barriers to managerial accountability in the Western

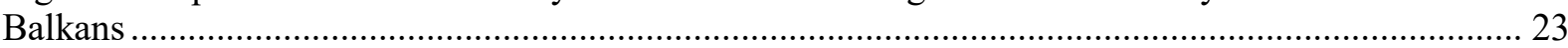

Figure 5. Delegation of formal decision-making authority in administrations across the Western

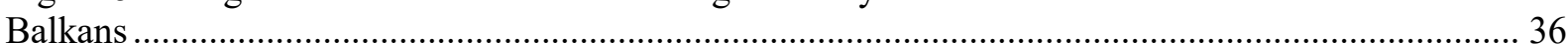

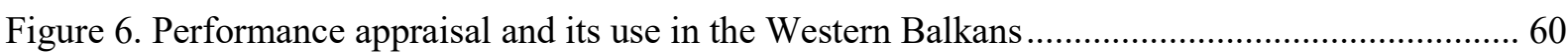

Figure 7. Points received in a SIGMA's assessment for objective criteria for the termination of employment in civil service legislation

\section{Boxes}

Box 1. Explanation of key terms used in this Paper for public sector managers................................... 8

Box 2. Delegation of decision-making authority in the management of IPA-funded programmes ...... 38 


\section{Executive summary}

This Paper looks at managerial accountability in the public administrations of the Western Balkan candidates for EU membership: Albania, Bosnia and Herzegovina, the former Yugoslav Republic of Macedonia, Kosovo*, Montenegro and Serbia. Managerial accountability is not well-rooted in the Western Balkans. Managerial accountability consists of both a clear focus on performance and compliance with rules. It requires holding managers accountable for results by assigning them responsibility, delegating authority for decision making, and giving them the autonomy and resources necessary to achieve the expected results. Without managerial accountability, starting with senior managers, Western Balkan governments will fail to achieve the reforms required for European Union (EU) accession, particularly those referred to under public internal financial control (PIFC) policy in Chapter 32 of the EU's accession negotiations.

In practice, most senior managers in the Western Balkans do not have the authority and autonomy to be accountable for the results of the organisation or unit that they supervise. There tends to be a greater focus on compliance with rules and procedures than on getting things done.

There are a number of universally recognised conditions for strengthening managerial accountability in an institution, namely a clear organisational structure and mandate for each department; internal decision-making processes and reporting lines; managers' involvement in budget planning and execution; the availability of information; managers' involvement in human resource management and procurement processes; and the use of performance targets and an effective system of performance reporting. In most public sector organisations in the Western Balkans, a variety of barriers to managerial accountability exist within each of these areas.

The roles and responsibilities of public sector managers are not clear. Senior managers face frequent changes in administrative structures, unclear reporting and accountability lines and the practice of assigning tasks without regard for formal responsibility.

Decision-making authority in public sector organisations is kept within the highest, often political, level of management, and there is a lack of adequate procedures and instruments to enable its delegation to senior civil servants or to lower-level managers. In many cases, heads of organisation (including ministers) are formally making even the most insignificant decisions on behalf of their organisation. Where some delegation of decision-making authority does take place, it is still mostly centralised to one single person in the organisation and not to the relevant managers, such as department directors or assistant ministers responsible for sectors.

* This designation is without prejudice to positions on status and is in line with United Nations Security Council Resolution 1244/99 and the Advisory Opinion of the International Court of Justice on Kosovo's declaration of independence. 
Objectives are not clear or measurable; the lack of focus on objectives is one of the key challenges for the development of managerial accountability. Objective-setting is perceived as a formal exercise and its value in management is not widely recognised, either by managers or political leaders. Many organisations do not have any systematic work planning besides their general plans, linked to the annual work plan of the government.

Senior managers have very little control or operational discretion over the use of assigned resources. Managers in the ministries do not have a complete picture of the budget they may expect to use during the year. Their responsibility in budget execution is limited to initiating expenditure (with insufficient control over or ability to predict outcomes) and to specific verifications of the supplies and services received. Public procurement procedures promote a focus on compliance; delays and cancellations are common, and managers are not formally responsible for the results of the procurement process.

In human resource management, the key barriers to managerial accountability relate to the lack of managers' influence in the recruitment of their staff, in terms of timing, the competencies required and the final selection decision, which is often made at the political level or by a single central government body. Nor can most managers easily, yet legally, reallocate or dismiss underperforming staff. Performance objectives for staff are insufficiently robust, and there is a tendency for managers to routinely award high grades and conduct completely formalistic, and thus meaningless, staff appraisals. As a consequence, performance appraisal is perceived as a burden, with little value, and does not contribute to developing managerial accountability.

Administrative support services in public organisations do not provide a modern service for the core departments and their managers. In the Western Balkans, most human resource (HR) units have yet to transform into a modern HR function that supports managers in hiring, developing and retaining the right employees to the right positions at the right time. In a similar manner, the finance departments in ministries are neither skilled nor mandated to provide an adequate financial management advisory service to the management teams, and managers do not generally see the need for such support.

Reporting on progress is not used to improve management. Reports by public organisations are not always published, and internal reporting within organisations is based on ad hoc needs in most cases. Even where regular reporting is established and implemented, the lack of reporting against objectives and targets remains another key challenge to developing managerial accountability. Furthermore, there is a lack of connection between reporting on progress and financial reporting.

Centrally devised government rules and procedures do not support the development of managerial accountability. The central procedures for planning, financial management and reporting are not designed to provide managers with the necessary tools and responsibility. At the same time, organisations lack the resources and training required to establish their own internal control systems and there is no incentive for managers to design and implement an internal control system. In addition, internal audit is being developed in all administrations but it does not yet support management sufficiently to develop or improve the internal control systems.

External oversight institutions could do more to support the development of resultsoriented accountability for managers. While performance audit is still in the early stages of development, the supreme audit institutions in the Western Balkans often reinforce the emphasis on compliance. Legally established rules and procedures tend to be very detailed and prescriptive. The inspection services also focus on compliance. Concentrating purely 
on compliance, particularly if the rules are very detailed, leaves little room for rethinking current policy or experimentation, both of which are necessary for developing managerial accountability.

In this environment, providing public sector managers with more autonomy and holding them accountable for results is difficult. To change these conditions, many public governance reforms have been launched by the governments in the region, but a focus on managerial accountability is usually not visible. Most reforms to modernise public administration first address the needs of the central HR services, ministries of finance or other central authorities that design the reforms. The perspective of managers and their needs is not usually taken into account.

To promote greater managerial accountability, governments need to manage reform accordingly, and politicians need to let go of operational management. Managerial accountability cannot develop or thrive on its own: in addition to favourable conditions, it needs concrete instruments and mechanisms, such as objectives and reporting against the objectives, as well as persistent demand for accountability by politicians and citizens. 


\section{Introduction}

The objective of this Paper is to advise key state authorities in the Western Balkans on how favourable conditions for managerial accountability can be developed. The Paper analyses the state of play regarding managerial accountability in the region and explains many of the current barriers to the development of results-oriented accountability of managers.

The Western Balkan governments are all committed to the improvement of PIFC $^{1}$ and reforms in public administration more generally ${ }^{2}$. Achieving genuine progress with the financial management and control (FMC) element of PIFC has proven especially difficult in the absence of good conditions for management. The 2018 European Commission (EC) progress reports make explicit reference to the importance of managerial accountability ${ }^{3}$, but the Western Balkan administrations are struggling to operationalise the concept.

Public sector managers play an important role in shaping the way their organisation works in order to be more effective in delivering public services. To be held fully accountable for results, managers need clarity about the results they are expected to achieve, the resources available to them and the extent to which authority has been delegated to them, and they need to be competent. In addition, there needs to be an environment of trust within and between organisations. While their accountability can be linked to specific outputs, the overall focus of the government machinery should be on achieving the best possible outcomes.

In other words, conditions for managerial accountability matter. Without managerial accountability, reforms to improve PIFC, and public administration in general, will not succeed. This is why the EC is increasingly focusing on the current challenges for managerial accountability in the Western Balkans and why DG Budget invited SIGMA to prepare this regional paper.

The relationship between the political leaders and senior civil servants is vital in shaping managerial accountability in practice. Ministers and governments are politically accountable, but within an institution, other types of accountability are needed to ensure that policy objectives are pursued and delivered. The political leadership benefits from managerial accountability, as this essentially supports their political accountability.

The analysis in this Paper focuses primarily on senior managers, namely public sector managers at the first and second management levels below ministers and the heads of agencies and other subordinate bodies. While structures vary, these levels of public sector management are common to all administrations and are expected to carry responsibility for the achievement of the objectives of public administration organisations.

\footnotetext{
${ }^{1}$ As part of Chapter 32 of the EU accession negotiations, on financial control.

${ }^{2}$ Within the framework of the Principles of Public Administration, OECD (2017), SIGMA, The Principles of Public Administration, OECD, Paris,
} http://sigmaweb.org/publications/Principles-of-Public-Administration_Edition-2017_ENG.pdf.

32018 reports within the EC Enlargement Package 2018. 
Figure 1. Managerial hierarchy of a classical ministerial system

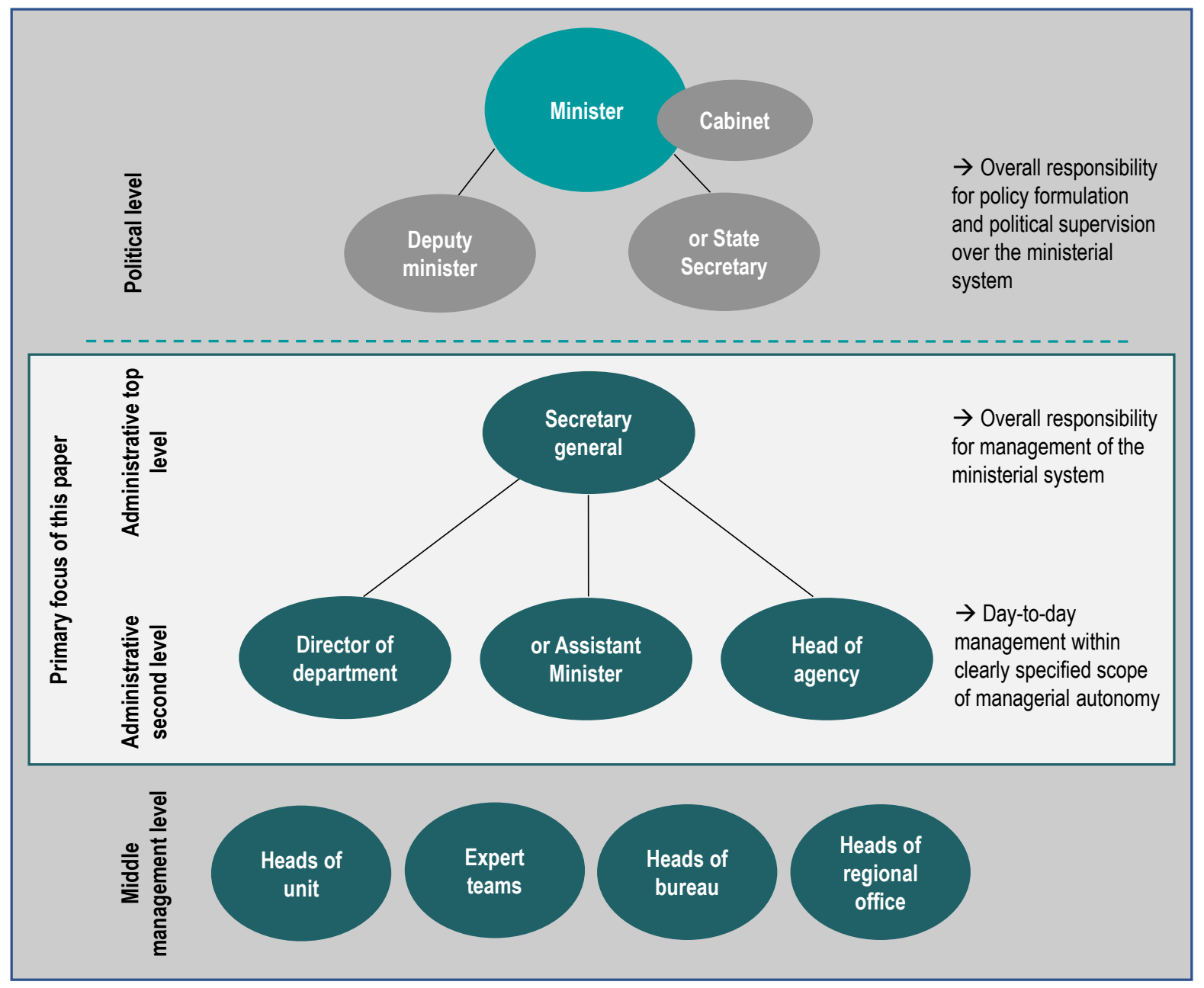

See Annex A for illustrations of the Western Balkan public sector management hierarchies.

Chapter 1 of this Paper explains the concept of managerial accountability, summarising how it is used in the Western Balkans and discusses its general enablers, such as tradition, the competence of managers and the role of legal frameworks.

Chapter 2 analyses the ability of managers to be and to feel accountable for the work and results of their teams. While tradition and organisational culture, along with the skills and ability of managers would all merit deep analysis, this Paper starts by analysing the procedures and practices by which central government organisations work. It reviews the state of play, identifies barriers to managerial accountability in the region and offers recommendations, providing insight into all the key topics that managers deal with on a regular basis. The analysis is presented in three thematic clusters:

- Clarity of roles and objectives

- Managing resources

- Reporting 
Chapter 3 sets out a way forward for reform-minded administrations to manage their development towards increased managerial accountability.

\section{Box 1. Explanation of key terms used in this Paper for public sector managers}

Heads of organisation are politicians, politically appointed managers or professional civil servants leading the work of a ministry, agency or other separate public sector organisation.

Senior managers are the primary focus of this Paper. This term refers to the key management positions within ministries (two levels of management below the minister) and within agencies and other bodies subordinate to ministries (heads of these organisations are both heads of organisation and senior managers for the purposes of this Paper).

Managers are all managers, including those responsible for sectors, directorates, departments or other structural units within a ministry or another public organisation. Managers at higher levels (director generals or assistant ministers) are part of the senior managers' group.

This Paper is fully in line with the Principles of Public Administration and draws on the previous work of SIGMA, notably the 2017 monitoring reports, previous analyses of managerial accountability in Montenegro and Serbia, and the SIGMA Paper No. 55: "Analysis of the Professionalisation of the Senior Civil Service and the Way Forward for the Western Balkans"4. Two focus group meetings were carried out with public sector managers from the region. To complete the existing data and evidence, SIGMA asked for further information from the Central Harmonisation Units (CHUs) for PIFC in Albania, Bosnia and Herzegovina ${ }^{5}$, the former Yugoslav Republic of Macedonia, Kosovo, Montenegro and Serbia.

The Paper was drafted by Klas Klaas and Lech Marcinkowski from SIGMA and Milena Lazarević from the European Policy Centre, Belgrade. The authors received input from SIGMA colleagues and substantial expert contributions from Noel Hepworth and Dawid Sześciło. We extend our gratitude to Jolanda Trebicka, Simonida Kacarska, Suad Music, Ruzhdi Halili, Marko Sošić, Miloš Đinđić and Dušan Protić for their invaluable contributions to data collection and for sharing their first-hand insights into practices in the Western Balkan administrations. Finally, we would like to thank the government officials, as well as colleagues in the OECD Governance Directorate, DG Budget and DG NEAR of the EC, who provided very useful feedback during the various phases of this Paper's development.

${ }^{4}$ OECD (2018), "Analysis of the Professionalisation of the Senior Civil Service and the Way Forward for the Western Balkans”, SIGMA Paper No. 55, OECD Publishing, OECD, Paris, https://doi.org/10.1787/8535b60b-en

${ }^{5}$ In the case of Bosnia and Herzegovina (State level), the Federation of Bosnia and Herzegovina, and the Republika Srpska, their respective central harmonisation units provided separate inputs. 


\section{Understanding managerial accountability}

Managerial accountability is not a familiar notion in the Western Balkan public administrations. It is, however, regarded as a crucial issue in many discussions on PIFC and a precondition for all FMC-related reforms. Despite its use in policy dialogue, there is no commonly agreed definition of the concept, even among the EU member states.

Managerial accountability refers to the answerability of managers for the work and results of their organisation. It implies responsibility for all aspects of management, from planning to reporting and from delegation to control. Managerial accountability means both conformity to rules and procedures (compliance) and a clear focus on results (performance).

Figure 2. What are managers responsible for?

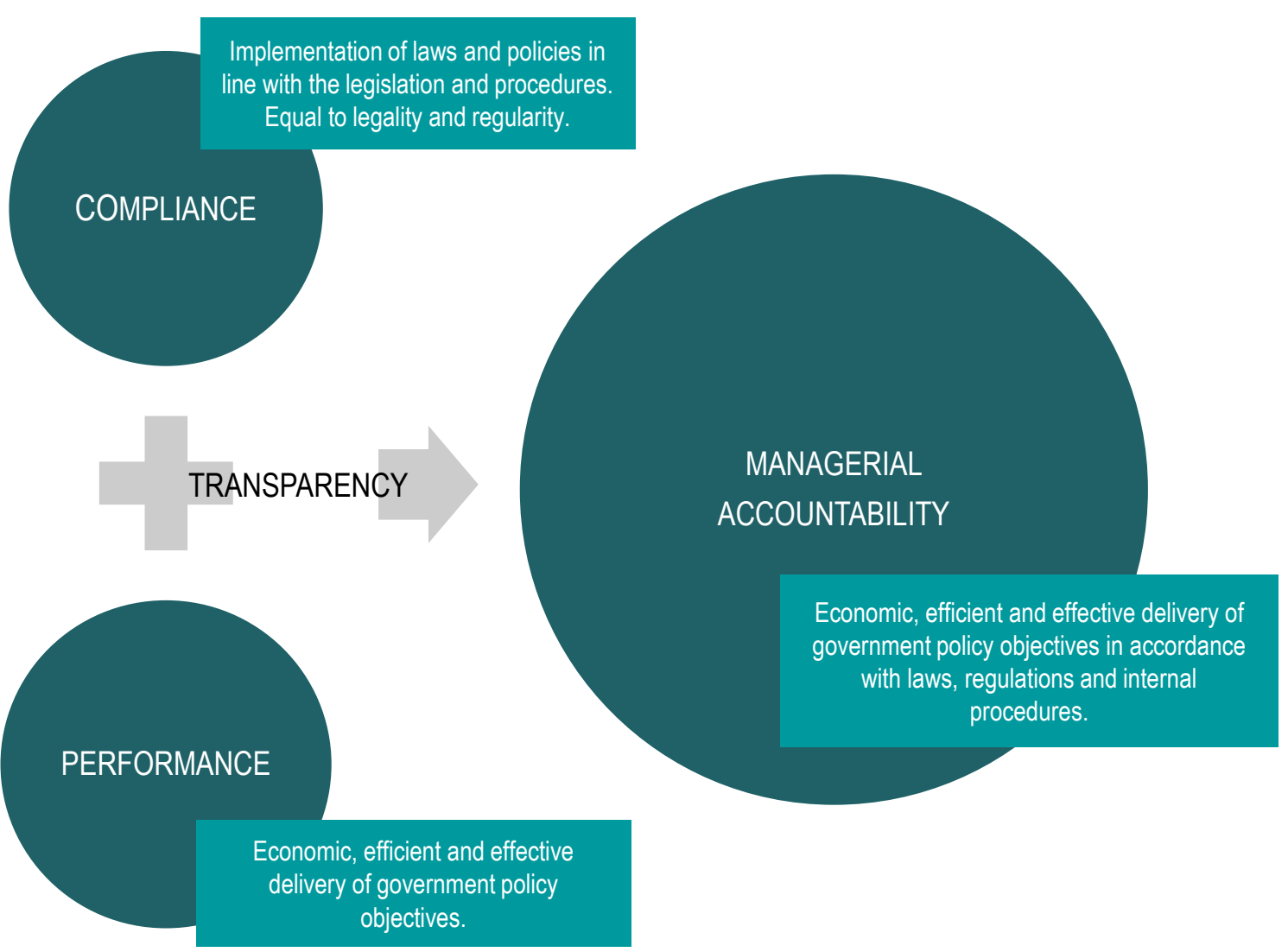

\subsection{Definitions and key ingredients: responsibility, authority and autonomy}

There is no universal definition of managerial accountability. This Paper will explain its content by referring to a number of interlinked ideas of responsibility, authority and 
autonomy (sometimes called in this context the "strategic space" of managers). First and foremost, it is important to underline that managerial accountability is not simply the accountability of managers.

The EC's Compendium of the public internal control systems in EU Member States ${ }^{6}$ presents managerial accountability as "a process whereby managers at all levels are responsible for, and may be required to explain, the decisions and actions taken to meet the objectives of the organisation they manage. Managerial accountability implies responsibility for sound financial management at all levels, i.e. the adequate organisation, procedures and reporting of the results of the organisation".

Accountability is the obligation to account and answer for the execution of responsibilities, for decisions taken and their consequences, to those who entrusted those responsibilities. In the context of public administration, the definition of public accountability given by the International Organisation of Supreme Audit Institutions (INTOSAI) is relevant, namely: "The obligations of persons or entities, including public enterprises and corporations, entrusted with public resources to be answerable for the fiscal, managerial and program responsibilities that have been conferred on them, and to report to those that have conferred these responsibilities on them"'.

In a strict sense, accountability refers to the requirement that an agent, be it an individual or an organisation, renders some account of their actions (report) to an independent authority (such as the parliament or the supreme audit institution). This reporting may occur regularly in a form defined by regulation (e.g. an annual report) or when requested by superiors or external authority (e.g. when a problem arises) ${ }^{8}$.

Two main forms of accountability are most often mentioned in academic studies on the subject: political, and administrative, although others are also discussed (professional, public, democratic, legal, social, moral/ethical) ${ }^{9}$. Administrative accountability takes place in vertical and horizontal dimensions. The former is the relationship that links inferior administrative positions with superior political or administrative positions. The latter links the individual civil servant and the public administration as a whole with the citizen and with oversight bodies ${ }^{10}$.

${ }^{6}$ The EC's Compendium of the public internal control systems in the EU Member States 2012 provides an overview of member states' definition of and approach to managerial accountability. European Commission (2011), Compendium of the public internal control systems in the EU Member States 2012, Publications Office of the European Union, Luxembourg.

7 INTOSAI GOV 9100 - Guidelines for Internal Control Standards for the Public Sector, http://www.intosai.org/issai-executive-summaries/view/article/intosai-gov-9100-guidelines-forinternal-control-standards-for-the-public-sector.html.

${ }^{8}$ Peters, B. G. (2014), “Accountability in public administration”, in M. Bovens, R. E. Goodin, and T. Schillemans (eds), The Oxford Handbook of Public Accountability, Oxford University Press, Oxford, http://dx.doi.org/10.1093/oxfordhb/9780199641253.013.0032.

9 Christie, Natasha V. (2017), “A comprehensive accountability framework for public administrators", Public Integrity, 20:1, pp. 80-92, http://dx.doi.org/10.1080/10999922.2016.1257349.

10 Bar Cendón, A. (2000), "Accountability and public administration: Concepts, dimensions, developments", in M. Kelly (Ed.), Openness and transparency in governance: Challenges and 
Under administrative accountability, public officials and administrative units are subject to a set of constitutional, legal and administrative rules and procedures issued by officials and bodies higher up the hierarchical order that govern their performance. Possible consequences of administrative accountability include revision of the administrative act, compensation to mistreated persons, sanction or reward of the public official involved. Evaluation of public officials and administrative units is based on their fulfilment of the provisions and procedures set by formal rules and regulations and their correct use of public resources ${ }^{11}$.

The focus of administrative accountability is therefore on doing things correctly, while for managerial accountability what also matters is doing the right things to achieve the desired results efficiently and effectively. Authority, delegation of power and autonomy all play an important role in this type of accountability ${ }^{12}$.

This Paper takes as a basis that managerial accountability is an approach to public management in which managers are held accountable for results by assigning them responsibility, accompanied by delegated authority for decision making, and the autonomy and resources necessary to achieve the expected results.

Managerial accountability assumes correlation and consistency between responsibility, authority (the right to make decisions), and a degree of autonomy throughout all levels within the public entity. No responsibility should be accepted without authority, as responsibility without adequate authority leads to dissatisfaction among managers and employees. On the other hand, authority without responsibility may lead to misuse of authority, and responsibility should go hand in hand with accountability. In practice, there is always a balancing act to decide how much authority and autonomy is appropriate.

Responsibility needs to be properly distributed inside the organisation to use organisational resources efficiently. Three aspects are crucial to this end: a clear division of all tasks within the organisation, a delegation framework where both responsibility and authority in respect of those tasks are delegated to the lowest competent level in a clear and formalised manner, and finally a reporting system providing both financial and performance information to the higher levels of management.

The final chapter of the description of managerial accountability comprises some level of autonomy (or at least influence) for managers during the process of deciding how to achieve objectives and to deliver tasks and services. Managers should be able to make decisions on exactly how to use budgets and resources within the rules. The strategic space, created by autonomy, is a space where a public sector manager can also be a creator and not merely an executor. Some managers may have almost no strategic space, being obliged to follow detailed regulations, standards and procedures with little or no ability to influence them. Managers with broader strategic space will have greater autonomy to determine the best way to achieve the results expected from them. Autonomy is indeed perceived

opportunities, NISPAcee, Bratislava, p. 34, http://www.nispa.org/files/publications/ebooks/nispace e-opennes2000.pdf.

${ }^{11}$ Idem, pp. 38-39.

12 European Commission (2015), Principles of Public Internal Control, Position Paper No. 1 of Public Internal Control: An EU approach, Ref. 2015-1, http://ec.europa.eu/budget/pic/lib/docs/2015/CD02PrinciplesofPIC-PositionPaper.pdf. 
sometimes as "primacy of managerial practices over bureaucracy"13. One can refer to administrative accountability where there is very little strategic space, and to managerial accountability when autonomy increases.

Figure 3. Key building blocks for managerial accountability

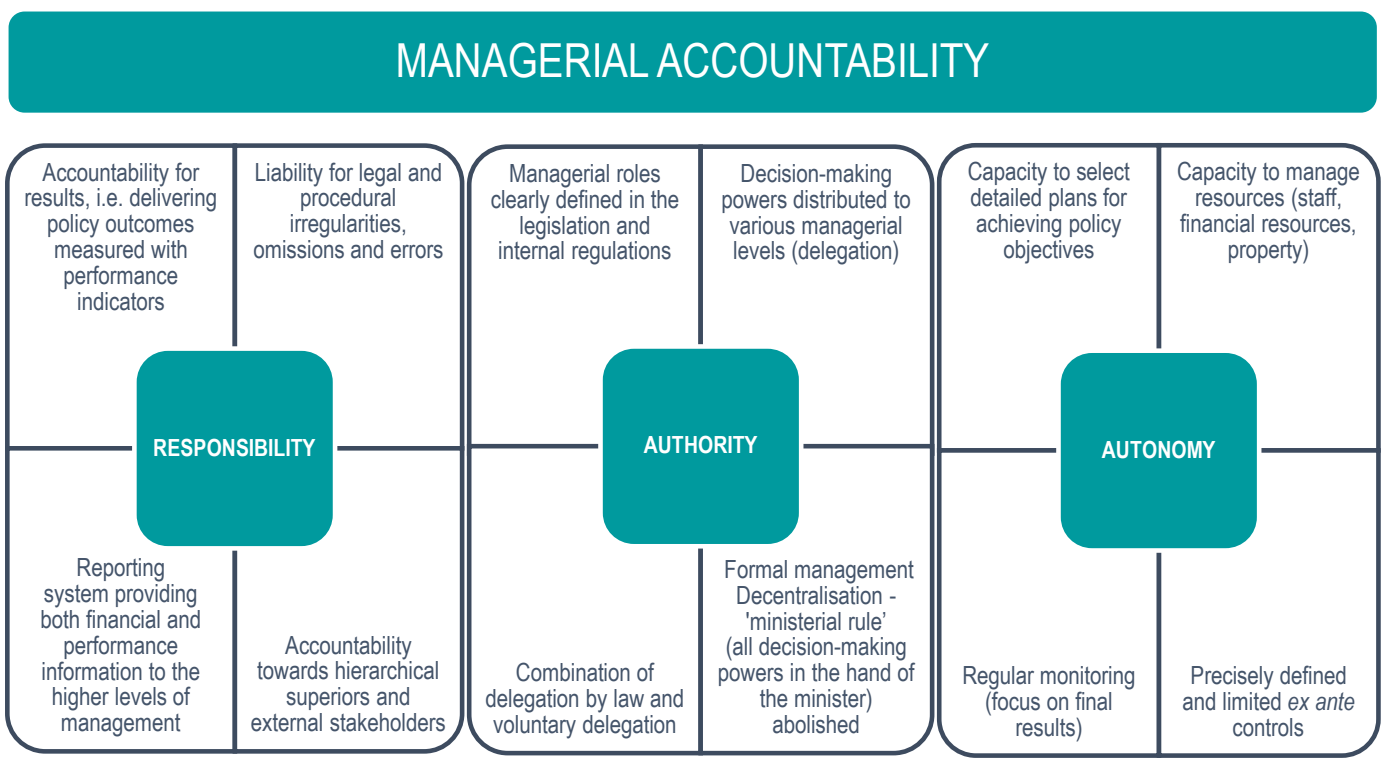

In practice, public sector managers are faced with a mixture of administrative and managerial accountability. Wherever the legal requirements, regulations, procedures and standards are examined by various control and audit services, they are usually treated as a priority. If this is a fair description of the management environment in an organisation, then it may be that only administrative accountability exists. Performance issues become more important - and managerial accountability present - once managers are judged primarily on their achievement of policy objectives.

\subsection{The relationship between managerial accountability and PIFC}

The successful implementation of EU policies, management of EU Structural Funds and other financial instruments, and the protection of the EU's financial interests, depends largely on the ability of the future EU member states and their public organisations to plan well and to ensure plans are implemented on time and in compliance with rules and procedures. Having strong internal control systems in place is therefore in the interest of all EU tax payers.

Achieving the objectives of PIFC has proved difficult without managerial accountability. Therefore, managerial accountability is critical for the successful implementation of the EU acquis and a subject for accession negotiations.

The objectives of internal control are to ensure that there is:

1. A managerial structure capable of delivering the objectives of the organisation;

${ }^{13}$ Van de Walle, S. (2018), "Explaining variation in perceived managerial autonomy and direct politicization in European public sectors", International Review of Administrative Sciences, 26 March 2018, p. 3, https://doi.org/10.1177/0020852317748357. 
2. A strategic planning process linking organisational objectives to the government's overall vision;

3. Operational planning linking operational objectives to budgetary, personnel and other resource requirements;

4. A system of controls to prevent losses arising from misuse of or damage to the assets and other resources of the organisation;

5. Communication leading to accurate, relevant and timely internal and external information about the organisation's financial and operational performance;

6. A monitoring and reporting process showing the level of achievement towards objectives linked to resource utilisation.

While there is a panoply of public internal control models among the EU member states, the concept of PIFC has been developed by the EC for the candidates for EU membership. It provides a structured model to assist national governments in re-engineering their internal control environment in line with international standards and EU best practice. The control environment should be designed to deliver objectives - a positive approach rather than a defensive one.

\subsubsection{The COSO framework}

In order to deliver results, organisations need internal control systems that ensure they execute operations in an orderly, ethical, economical, efficient and effective manner; can fulfil their accountability and reporting obligations; will comply with applicable laws and regulations; and can safeguard their resources against loss, misuse and damage. To ascertain whether they meet these objectives, organisations generally use international benchmarks. The most important of these are the 17 component principles of the Committee of Sponsoring Organizations (COSO) standards ${ }^{14}$, which are explained in more detail for public sector entities through the INTOSAI GOV 9100 guidelines ${ }^{15}$.

Principle 3 of the COSO Framework, sets out the obligation of management to establish structures, reporting lines and appropriate authorities and responsibilities in the pursuit of objectives. For each entity, an organisational structure needs to be established with managers at the different levels having clear objectives. Each subordinate manager should have clear responsibility, the delegated authority and sufficient autonomy (supported by the required information and resources) to deliver those objectives. Accountability arrangements then need to be established so that top management is provided with the necessary information about progress in achieving the objectives.

The INTOSAI guidelines also refer to the need for delegation when explaining the role of the organisational structure, stating: "The organisational structure defines the entity's key

\footnotetext{
${ }^{14}$ Committee of Sponsoring Organizations of the Treadway Commission http://www.coso.org/IC.htm; COSO Framework, 2013 edition, https://www.coso.org/documents/COSOOutreachDeckMay2013.pptx.

${ }^{15}$ The Guidelines for Internal Control Standards for the Public Sector (INTOSAI GOV 9100), INTOSAI.
} 
areas of authority and responsibility. Empowerment and accountability relate to the manner in which this authority and responsibility are delegated throughout the organisation" 16 .

\subsubsection{Managerial accountability and the Principles of Public Administration}

The concept of managerial accountability cuts across many of the Principles ${ }^{17}$ and is referred to explicitly in several. For example, Accountability Principle 1 states that "the overall organisation of central government (...) provides for appropriate internal, political, judicial, social and independent accountability". It is further explained that management units should report through clear lines of accountability, and managerial accountability should be enhanced by empowering managers and supervisors and delegating decision making to them. Furthermore, Policy Development Principle 8 refers to the organisational framework necessary for developing policies. It requires that the management of policy development and legislative drafting within ministries, the managerial levels responsible for these functions and the manner in which responsibility is delegated, are all clearly established.

The development of managerial accountability is explicitly mentioned under Public Financial Management Principle 6, which states: "The operational framework for internal control defines responsibilities and powers, and its application by the budget organisations is consistent with the legislation governing public financial management and the public administration in general". One of the sub-principles states that, to this end, the laws and regulations governing budgetary and treasury arrangements, EU fund management, public accounting and other public financial management (PFM) arrangements facilitate the development of managerial accountability through appropriate delegation and reporting.

\subsubsection{The role of managers in internal control}

Even in environments where the key elements of PIFC/COSO have been more or less successfully implemented (at least on paper), attempts to transform traditional centralised public administration systems into results-driven and PIFC-compliant environments sometimes fail. A lack of managerial accountability is often indicated as one of the main reasons why newly introduced control mechanisms do not operate as intended ${ }^{18}$.

An objective of delegation and managerial accountability is to create an environment where the skills and knowledge of managers at all levels can contribute to improvements in the functioning of their organisations and the delivery of results for citizens.

In the transitional and pre-accession context, PIFC, covered by Chapter 32 of the accession negotiations, is normally placed within the PFM portfolio and thus led by ministries of finance. Nevertheless, when understood as the concept of holding the individuals within public service organisations responsible for their decisions and actions, including their stewardship of public funds, fairness, and all aspects of performance, managerial accountability clearly extends much further than its financial management aspects.

\footnotetext{
${ }^{16}$ Ditto.

${ }^{17}$ OECD (2017), SIGMA, The Principles of Public Administration, OECD, Paris.

18 "Good financial governance and public internal control towards more value-added management: the House of PIFC", National Academy for Finance and Economics, The Hague, 2017, p. 5.
} 


\subsection{Use of the concept of managerial accountability in the region}

\subsubsection{Legal definitions of the concept}

In most of the Western Balkans, the concept of managerial accountability within the public administration is defined in the existing legislation ${ }^{19}$.

In Serbia, Albania and the Federation of Bosnia and Herzegovina, the concept of managerial accountability is defined in a legal act but also applicable in areas and activities other than those covered by this particular piece of legislation. All these definitions rightly extend accountability beyond the financial area, underline the principles of sound financial management of actions in terms of economy, efficiency and effectiveness, and indicate the fact that managers have been appointed and have been given responsibility. Since they refer to "all levels", they presumably include the heads of institutions. However, none of the definitions refer to the autonomy of managers, to the link between responsibility and authority, or to the obligation of delegation of responsibilities to lower levels.

\subsubsection{Knowledge and use of the concept}

Despite legal definitions being in place, the lack of a proper understanding of the term "managerial accountability" is often mentioned as a substantial reason for problems with its implementation. Its development in the Western Balkans until now has not been "organic"; it has not arisen from the inherent need of managers for more tools and authority to exercise their competencies, but mainly from the external pressure coming from the EC. The use of the concept is currently restricted to PIFC laws and it is promoted mostly by the CHUs, whose political weight is limited. A natural challenge also comes from the fact that numerous definitions and explanations of the concept have been elaborated at different points in time, by different authors and based on different source documents, and therefore they are not consistent with each other, which adds to users' confusion. However, because it is such an overarching concept, it demands aligned and co-ordinated approaches to reforms in almost all segments of public administration reform (PAR).

The responses to the questionnaires sent to the CHUs of the former Yugoslav Republic of Macedonia, Bosnia and Herzegovina (BiH) State level and Montenegro assert that the concept of managerial accountability is "widely known" in the central government administration, while other respondents indicate that it is "somewhat known".

Montenegro illustrated their statement with excerpts from the speech of the Prime Minister Duško Marković, who emphasised the topic in his exposé to the Parliament in 2016, explicitly mentioning the need for "greater accountability for delegated tasks, starting from managers downwards, to administration".

Albania's response to the survey admitted that although the legal framework, manuals, guidelines etc. are in place and many training opportunities on managerial accountability are organised, there can still be a lack of understanding of managerial accountability among managers or it can be wrongly interpreted as meaning the organisation can only be under control if a manager personally controls every financial and business decision.

More than any legal definitions, it is the guidelines and instructions explaining what managerial accountability is and how it can be implemented that will eventually render the concept understood, accepted and put into practice. Government strategies, such as the

${ }^{19} \mathrm{CHU}$ responses to SIGMA questionnaire. 
PIFC Strategy and the Public Finance Management Reform Strategy, can also be an important source of information on the concept, although managers rarely use them directly. Within the framework of the 2017 monitoring against the Principles of Public Administration, SIGMA checked whether formally adopted policy planning documents in the area of internal control included reforms and changes to enhance managerial accountability (including accountability mechanisms and objective setting), and this was the case for all of the administrations.

From limited references in policy documents in Albania ${ }^{20}$ ("increase the awareness of public units about the benefits of implementing the concept of managerial accountability") 21 , to specific objectives in Kosovo ("Managerial accountability on inputs and management of resources in place, verified by dedicated reports prepared by the managers of public funds by 2017-2018") 22 and Montenegro ("Financial management and control establishment and improvement based on principles of managerial accountability in all institutions regardless of their size and number of employees" ${ }^{23}$, national strategies specifically refer to managerial accountability and include plans for its development.

\subsubsection{Linguistic issues}

In all Western Balkan administrations there are linguistic issues related to the concept of managerial accountability. The most common problem stems from the fact that the Bosnian, Croatian, Serbian and Montenegrin languages do not recognise the distinction between "accountability" and "responsibility". Therefore, most often "managerial accountability" is translated as "managerial responsibility". Secondary legislation, rulebooks and manuals are indicated as a means to overcome these problems through a more descriptive approach. Although Albania and Kosovo share the same language, they translate the term differently ${ }^{24}$.

When the term "responsibility" is used, it does not communicate what it means to be accountable, answerable, liable, obliged, and so on. When "managerial accountability" is translated into "managerial responsibility" or when just "accountability" is used instead, the key concepts of autonomy and delegating of responsibility and authority are missing.

\subsection{Risks associated with premature managerial approaches}

Managerial accountability is not a silver bullet that will immediately solve the problems faced by Western Balkan administrations. On the contrary, the experience of other administrations in a similar situation provides evidence of risks associated with its premature introduction which are not negligible.

${ }^{20}$ In Albania legal provisions for managerial accountability are already set out in legislation, with Chapter 2 of the FMC law explaining the requirements at different levels within organisations.

${ }^{21}$ Public Financial Management Strategy 2014-20.

22 Public Internal Financial Control Strategy 2015-19.

${ }^{23}$ Strategy for Further Development of Public Internal Financial Control in Montenegro 2013-17.

24 In Albania the expression "Përgjegjshmëria menaxheriale" is used, while in Kosovo it is "Llogaridhenja menaxheriale". 
Questions of the right sequencing of reforms, or the maturity of the administration and its internal control mechanisms, are of paramount importance. Although managerial accountability should not be confused with managerial discretion, greater managerial autonomy assumes also greater flexibility - still within the law and regulations. However, when internal controls and tools for monitoring are weak, when managers have not yet internalised the values of the rule of law, and when transparency is limited, opportunities arise for unethical or even illegal behaviour ${ }^{25}$. This leads to an aspiration to tighten internal controls, to reduce managers' discretion in decision making and eventually to regulate their activities extremely closely or deprive them of power altogether by re-centralising decision making. This vicious circle can be broken if the risks and limitations associated with managerial accountability are understood and properly addressed.

There are not many studies on the effects of reforms introducing managerial approaches to public administration in the region ${ }^{26}$. The approach towards reforms in the area of the civil services of most of the 2004 and 2007 EU accession countries may provide a good illustration of this cautious approach. It clearly prioritised the minimisation of both political and managerial discretion in order to reduce the risks of "informalism", discretionary governance and politicisation. The reform discourse at the time suggested that administrations would have to first follow the Weberian model before considering a greater dose of reforms inspired by the new public management ${ }^{27}$.

The OECD states that the delegation of human resource management (HRM) decisions in such areas as employee selection, recruitment, remuneration, working conditions and dismissal, empowers and enables public managers to better direct their staff, providing it is done under appropriate framework conditions and minimum standards ${ }^{28}$. Delegation without some level of common HRM standards and central oversight often leads to undesired consequences, including political interference in staffing decisions. Although the above statement refers to the decentralisation of decisions from central HRM authorities to line ministries, departments or agencies, the same is true for the delegation of some decision-making authority by the head of the institution to senior managers.

In order to prevent these negative consequences, yet without imposing tight regulatory controls limiting managerial autonomy, managers are requested to demonstrate they are acting in the right way by providing data on performance indicators, quality improvement schemes, or audits. This may result in undesirable side effects such as increased internal

${ }^{25}$ OECD (2017), Recommendation of the Council on Public Integrity, OECD, Paris, p.10, http://www.oecd.org/gov/ethics/OECD-Recommendation-Public-Integrity.pdf

26 The following studies are available for reference: Matei, L. and S. Flogaitis (eds) (2011), Public Administration In The Balkans: From Weberian Bureaucracy To New Public Management, Economica Publishing House; Drechsler, W. (2014), The Rise and Demise of the New Public Management: Lessons and Opportunities for South East Europe, http://uprava.fu.unilj.si/index.php/IPAR/article/download/131/128.

${ }^{27}$ Meyer-Sahling, J. (2009), "Sustainability of civil service reforms in Central and Eastern Europe five years after EU accession", SIGMA Paper No. 44, OECD Publishing, Paris, http://dx.doi.org/10.1787/5kml60pvjmbq-en.

${ }^{28}$ OECD (2017), Government at a Glance 2017, OECD Publishing, Paris, http://dx.doi.org/10.1787/gov_glance-2017-en. 
scrutiny and paperwork ${ }^{29}$, but without systematic provision of data on decisions and progress, governments will not be able to monitor the behaviour of individual managers, and transparency, in general, will remain limited.

\subsection{Factors determining the level of managerial accountability}

\subsubsection{Administrative tradition and organisational cultures}

Although the legal framework remains important, it needs to be underlined that managerial accountability also depends on 'soft' factors that cannot be regulated by laws. The elements of social and administrative tradition and organisational culture can either enhance managerial accountability or form a serious obstacle to progress.

The most general framework for developing managerial accountability is the level of social capital within the society. Social capital ${ }^{30}$ is the value (in economic terms) of social connections and networks. The more people trust and support each other, the higher the value of social capital. This is a key factor for delegation, collaboration and information sharing. The delegation of responsibilities is more likely to take place in an environment with higher social capital. The excessive-control approach will be applied in an environment with little trust (with "trust" defined as a person's belief that another person will act consistently with their expectations of positive behaviour ${ }^{31}$ ). It does not mean that delegation of authority and responsibility cannot occur, but that the transaction costs of a complex control system may be a serious obstacle.

Different administrative traditions result in diverse perceptions of what managers are accountable for and what their main obligations are. The Yugoslav administrative tradition is generally regarded as being more compatible with the objectives of post-communist administrative transformation and placing greater emphasis on legalism ${ }^{32}$. However, the old legalist bias performs a very negative role in PAR, as there is a strong tendency to regard this process in terms of law adoption, while deeper re-structuring of the system does not receive sufficient attention ${ }^{33}$.

If government administration is to achieve the results expected by citizens, practices which allow a focus on the overall public value should not be discouraged. This can also be achieved within an administrative tradition that is centred on legal accountability, as long

${ }^{29}$ Lægreid, P. (2014), “Accountability and new public management”, in M. Bovens, R. E. Goodin, and T. Schillemans (eds), The Oxford Handbook of Public Accountability, http://dx.doi.org/10.1093/oxfordhb/9780199641253.013.0008.

${ }^{30}$ To read more about social capital consult: Scrivens, K. and Smith, C. (2013), "Four interpretations of social capital: An agenda for measurement", in OECD Statistics Working Papers, No. 2013/06, OECD Publishing, Paris, http://dx.doi.org/10.1787/5jzbcx010wmt-en.

${ }^{31}$ More on the concept of trust, including a review of available literature, can be found in Chapter 2 of OECD (2017), OECD Guidelines on Measuring Trust, OECD Publishing, Paris, http://dx.doi.org/10.1787/9789264278219-en.

32 Meyer-Sahling, J. (2012), SIGMA, "Civil service professionalisation in the Western Balkans", SIGMA Paper No. 48, OECD Publishing, Paris, p. 79, http://dx.doi.org/10.1787/5k4c42jrmp35-en.

${ }^{33}$ Mihajlovic, M. (2006), Public Administration Reform and European Integration processes: on the same or parallel tracks? (case study of the Republic of Serbia), NISPAcee, Bratislava, http://unpan1.un.org/intradoc/groups/public/documents/nispacee/unpan024311.pdf. 
as those involved understand that legal requirements are not an end in themselves but a means to streamline behaviour towards the desired outcomes. Thus, moving the responsibility towards better societal outcomes could empower public sector managers to also find ways to improve the regulation as needed.

Organisational cultures are the unwritten rules and expectations based on the shared attitudes and values of individuals within an organisation. They are extremely difficult to change, as they include basic assumptions that have been proven to work in the past and are therefore accepted as common sense within the organisation. They include values, behavioural norms and behavioural patterns and are heavily determined by the leadership ${ }^{34}$. This is one of the reasons why delegation of decision making, though legally possible, will not take place unless it is practised at the top of the organisation.

Not only organisational culture but also even personal preferences can play a role in shaping managerial accountability in individual institutions. Ministers and other heads of organisation will always be, at least theoretically, in a position to centralise authority and limit the "strategic space" of senior civil servants. This centralisation, being a consequence of a lack of trust in subordinates and in the internal control systems and availability of managerial skills, is likely to be detrimental to the organisational objectives.

On the other hand, staff may also be reluctant to take on more autonomy and authority as this implies more responsibility. In a traditional administration, where the higher levels of the organisation are charged with taking key decisions, this allows managers to remain in their comfort zone and loyally execute decisions without being held responsible for them. This is true especially when increased responsibility does not come with proper training or incentives, or where there are practical disincentives in the form of administrative and budget inspection services and external oversight institutions which focus predominantly on compliance aspects of management. The personal preferences and ambition of individual managers may help in some cases, especially in the short term, but managerial accountability will not develop systematically unless the administrative environment is supportive and sufficient incentives are established for all public sector organisations.

\subsubsection{The competence of managers}

As well as a favourable administrative tradition and organisational culture, competent managers are a further prerequisite for improving managerial accountability. For this, the process for recruiting senior civil servants needs to be competitive and merit-based ${ }^{35}$. Competitions for the top public sector jobs should be genuinely competitive and they should attract potentially strong managers, people who want to make a difference and accept accountability for their area of work. When factors such as seniority or technical knowledge, rather than merit, determine promotion to managerial positions, newly appointed managers may feel insecure and thus reluctant to use their managerial capacities even if their strategic space is enlarged.

${ }^{34}$ OECD (2015), The Innovation Imperative in the Public Sector: Setting an Agenda for Action, OECD Publishing, Paris, http://dx.doi.org/10.1787/9789264236561-en, p. 26.

${ }^{35}$ In line with OECD (2017), Recommendation of the Council on Public Integrity, OECD, Paris, p. 11, http://www.oecd.org/gov/ethics/OECD-Recommendation-PublicIntegrity.pdf. Promote a merit-based, professional, public sector dedicated to public-service values and good governance. 
Unless institution heads (in many cases the political leaders) are personally convinced that managers subordinate to them are sufficiently competent to exercise these powers properly, they will remain unwilling to delegate - after all, accountability ultimately rests with them. At the same time the more authority and autonomy the lower level managers are given, the more their level of competence will influence the achievement of government policy goals and, ultimately, trust in the government.

There is plenty of evidence showing that the presence of competent and experienced managers in senior positions is associated with greater organisational performance and lower levels of corruption, compared with organisations where senior positions are filled by political appointees selected on the basis of partisan loyalty ${ }^{36}$. SIGMA has recently published a comprehensive comparative study on the professionalisation of the senior civil service in the Western Balkans ${ }^{37}$ and the following sub-sections are based on these findings.

Since senior civil service positions function at the junction of the civil service and political spheres, one of the biggest challenges in building a professional senior civil service is maintaining the balance between political responsiveness ${ }^{38}$ and trust on the one hand, and neutral professionalism on the other. It means that the public sector managers are committed to the professional implementation of the sitting government's policies, which express the preferences of the electorate. The political responsiveness of the senior civil service is needed for a functioning and trusting relationship between ministers and senior administrative managers. The more trust politicians have and the more they believe in the professionalism, skills and abilities of managers, the more willing they are to share their authority with them.

\section{Recruitment and selection of senior civil servants}

Recruitment and selection systems are critical for establishing a professional senior civil service that can be entrusted with increased autonomy and responsibilities. The ultimate purpose of a well-functioning recruitment and selection system is to deliver managers that possess a high level of professional competence, a prerequisite for receiving delegated authority and decision-making powers.

SIGMA found that current recruitment systems and practices in the Western Balkans are not sufficiently capable of delivering professional competence for the SCS positions. The application process is well designed in most Western Balkan administrations and is not discriminatory, so the legal preconditions for merit-based selection are met. However, at

\footnotetext{
${ }^{36}$ Lewis, D. (2008), The Politics of Presidential Appointments: Political Control and Bureaucratic Performance, Princeton University Press, Princeton, NJ; Meyer-Sahling, J.H. and K.S. Mikkelsen (2016) "Civil service laws, merit, politicization, and corruption: The perspective of public officials from five East European countries”, in Public Administration, 94(4), pp. 1105-1123.

37 OECD (2018), "Analysis of the professionalisation of the senior civil service and the way Forward for the Western Balkans”, SIGMA Paper No. 55, OECD Publishing, Paris.

38 "Political responsiveness means that the senior civil service is committed to the professional implementation of the sitting government's policy. Senior officials work closely with politicians, so it is important to establish constructive working relationships that maintain the neutrality of the civil servants, while achieving the acceptance and trust of the politicians. As constructive working relationships between ministers and senior civil servants result in personal trust, they also contribute to the smooth management of government organisations. Political responsiveness does not in any way mean that the senior management has partisan tendencies or is subject to party patronage, favouritism or politicisation".
} 
the same time, it is too burdensome and, in some cases, too costly. Moreover, in most administrations the number of eligible candidates per position is low, indicating low competition for and attraction to positions in the SCS.

The testing systems are not sufficiently designed to screen competence levels and to meet the needs of open competition, as they mostly assess knowledge and formal requirements rather than the skills and abilities needed for a senior management position. Moreover, there are no comprehensive competency models or minimum professional requirements in place to inform potential applicants and to provide a basis for the testing of candidates.

\section{Professional development and training}

While the recruitment and selection system is crucial in ensuring that the people with the right set of competencies are appointed, it is rare that the selected candidate fits the job requirements entirely. Given the constant change within today's public sector, civil servants need to acquire new skills to address the increasingly complex problems of increasingly pluralistic societies, using new tools available to governments ${ }^{39}$. A solid foundation of professional development and training is therefore needed in order to address the development needs of individual senior civil servants and to contribute to the collective ethos and joint working culture of all senior civil servants.

SIGMA found that the professional development of senior civil servants is not well developed in the Western Balkans. It has no systematic basis, as competency models are still lacking in most administrations and there are no other tools in use to draw up a comprehensive training needs analysis at the senior level.

The lack of any systematic assessment of the professional development needs of senior managers and the lack of tailored development programmes are given as reasons for low levels of participation of managers in training. Curricula shaped around knowledge rather than competencies development are not recognised as useful. The traditional classroomstyle delivery of training programmes is also unattractive to managers who rather seek appropriate forums for the sharing and exchange of experiences at managerial level.

There is little evidence of the effective use of performance appraisal for the senior managers. Senior civil servants' appraisals are not linked to professional development activities and in some cases are even not carried out in practice or are conducted only formally. In the context of managerial accountability, performance appraisal could provide feedback on the extent to which the authority and autonomy given to managers have served their purpose.

When performance appraisal refers to individuals' objectives which are also linked with organisational objectives, either of the department they lead or of the whole organisation, clear accountability lines can be established. In most Western Balkan administrations, even where individual performance appraisals include annual objectives, the link between the performance of senior civil servants and the annual performance report of their organisation is not clear.

\footnotetext{
${ }^{39}$ OECD (2017), Skills for a High Performing Civil Service, OECD Publishing, Paris, p. 14, http://dx.doi.org/10.1787/9789264280724-en.
} 


\subsubsection{The influence of the legal framework}

Managerial accountability is not a concept that can be introduced by a legal act and written procedures. Legal provisions may, nevertheless, promote or hamper its successful implementation and sometimes prevent the introduction of the first steps. An example of the latter is where administrations specifically make delegation of authority impossible (e.g. requiring that certain documents must be signed personally by the minister) or render important tools useless (e.g. making progress reports confidential).

One specific area where regulatory arrangements influence accountability lines is the delineation between heads of institution - political appointees in the case of ministries and senior public managers, who in most cases are senior civil servants. Defining the senior managers as a special group in terms of composition, responsibilities, accountability lines and employment conditions not only reinforces the boundaries between neutral, professional, senior-level officials and political positions but also safeguards their accountability. Clear lines of accountability are a precondition of proper oversight and control of the work of senior civil servants.

There are a number of universally recognised prerequisites to the introduction and strengthening of managerial accountability in an institution, namely a precise mandate for the organisation; a clear organisational structure, internal decision-making processes and reporting lines; managers' influence over procurement processes and HRM; managers' involvement in budget setting, planning and execution; the availability of financial information; and the use of performance targets and an effective system of performance reporting. In most parts of the world, certainly in the Western Balkans, all these matters are regulated and supported by laws, procedures and guidelines and are covered in detail in Chapter 2 of this report. 


\section{Analysis of barriers to managerial accountability and key recommendations}

Managerial accountability can thrive in a well-developed public administration, and almost all aspects of public sector management are important. In this study, the topics listed in Figure 4 have been analysed in detail to identify barriers and other aspects hindering the development of managerial accountability in the public administrations in the region. For each of the topics that follow, this Paper seeks first to explain its relevance to managerial accountability, then to summarise the overall findings and provide recommendations for reform directions, and finally to present further detailed regional analysis. Aspects of responsibility, authority and autonomy remain important within all of those topics.

Figure 4. Topics covered in the analysis of barriers to managerial accountability in the Western Balkans

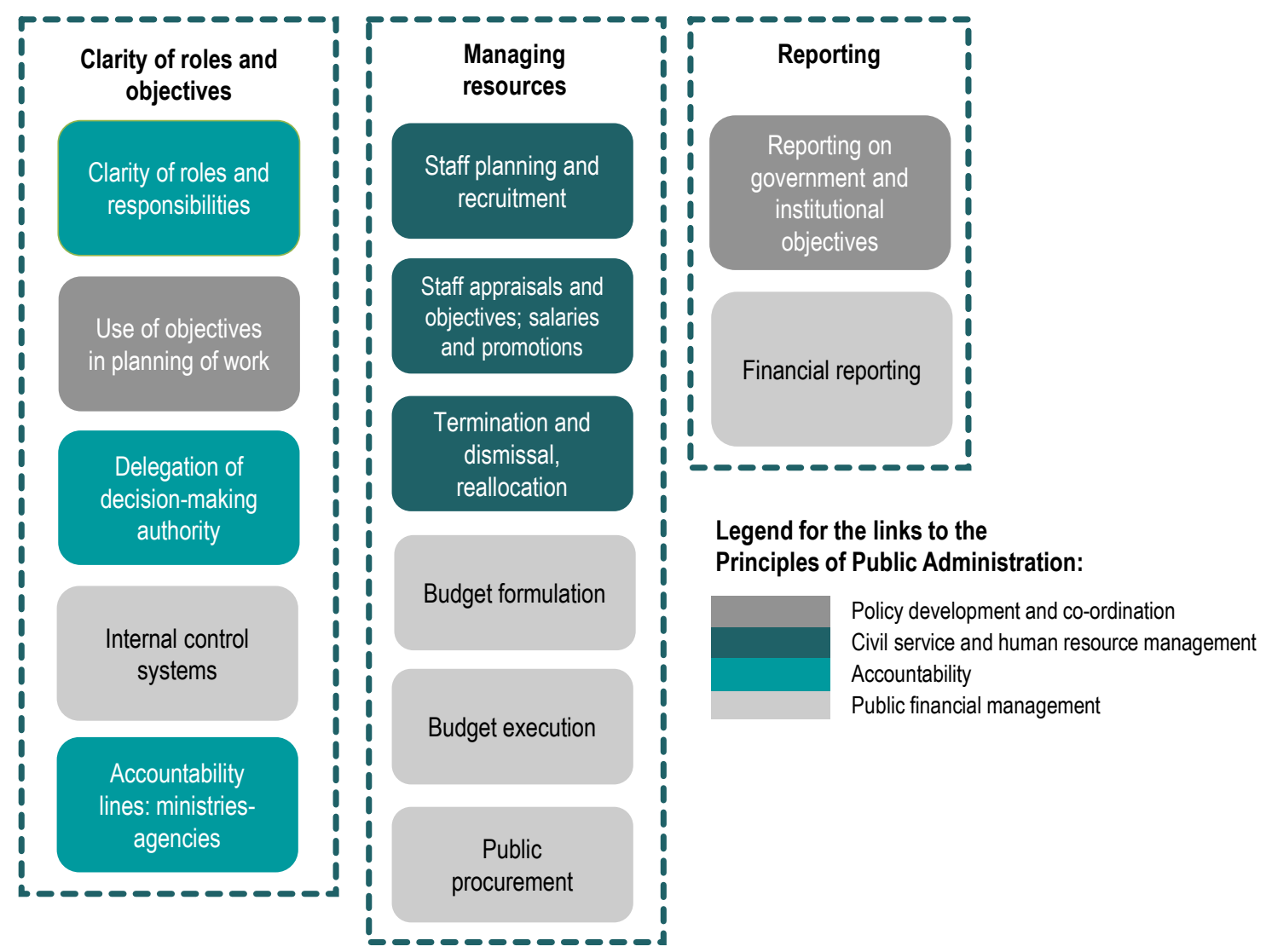




\subsection{Clarity of roles and objectives}

Before managers can be given resources to manage and asked to report on their use, a number of conditions need to be met. Managers' roles and responsibilities need to be clear, and objectives need to be set for both the organisation and its managers. Appropriate authority must have been delegated to them and internal control mechanisms must be set in place. Finally, where two distinct institutions are involved, such as a ministry and a subordinate agency, lines of accountability must be established.

\subsubsection{Clarity of managers' roles}

\section{Why it is important}

Clarity of the scope of responsibility is among the most basic conditions for accountability ${ }^{40}$. The focus of an individual manager is bound by the scope of responsibility of the organisation they work in. Unless the specific area of responsibility is defined, a person cannot take responsibility for it. Overlaps between the responsibilities of different colleagues will also result in confusion about who should do what. At the same time co-operation and co-ordination are needed to reduce the "silo" effect, i.e. the lack of crossdepartmental co-ordination, in the work of public administration.

In a similar way, the functional responsibilities of the managers need to be clear both in terms of the authority and autonomy an organisation and a manager has. The manager also needs to know the timelines by which the key responsibilities need to be delivered.

The importance of the internal division of tasks forming a clear scope of responsibility is particularly emphasised by the COSO model, which recommends that it should include:

1. Links between the general tasks of an entity and the tasks of its operational units, in order to demonstrate the connections between the operational level and the entity's mission.

2. The identification of connections between the tasks of individual internal units, to enhance their ability to co-operate.

3. The identification of outputs for tasks at every level of the organisation, thus allowing the effectiveness and efficiency of operations to be measured (and reported), and resources to be assigned rationally ${ }^{41}$.

\footnotetext{
${ }^{40}$ On the importance of clear roles and responsibilities see: OECD (2017), Recommendation of the Council on Public Integrity, OECD, Paris, p.8, http://www.oecd.org/gov/ethics/OECD-Recommendation-Public-Integrity.pdf.

${ }^{41}$ OECD (2016), SIGMA, “Managerial accountability in public administration: Practical aspects of the concept and its implementation", Discussion paper, 4th Regional Conference on Public Internal Financial Control for EU Enlargement Countries, 29-30 September 2016, https://www.slideshare.net/SIGMA2013/discussion-paper-4th-regional-pifc-conference-for-euenlargement-countries-montenegro-2930-september-2016.
} 


\section{Summary of SIGMA analysis}

The main organisational barriers to managerial accountability in the Western Balkans are related to the lack of coherence in the administrative and therefore also in the management structure, frequent changes in the administrative structures, shortcomings in the preparation and application of the systematisation acts, unclear reporting and accountability lines where there is more than one manager below the minister with equal rank, and the practice of assigning tasks regardless of formal responsibility.

The areas of responsibility of individual organisations, including ministries, are regulated by central laws or decrees of the governments. Within the ministries and other central government institutions, the roles are set in the systematisation acts ${ }^{42}$ or similar documents. These reflect a traditional and rigid approach to organisational hierarchy. Almost all managerial authority at the level of the organisation as a whole is concentrated in the hands of the minister.

Finally, in all of the Western Balkans administrations, clarity of roles and responsibilities is further lessened by the fact that many formal legal rules and procedures are not followed in practice. There is a significant mismatch between the formal procedures and obligations and the work that is actually carried out by the administration.

\section{Recommendations}

1. The roles of each key public sector management position, both political and senior non-political, should be clearly defined within the hierarchy of executive organisations ${ }^{43}$. A clear split between the political and senior administrative levels is needed ${ }^{44}$. This should be established in legislation for the highest-level civil servants in the ministry and for the heads of bodies subordinate to the ministry. This will help to eliminate multiple overlapping accountability lines in order to ensure that everyone in the hierarchy is accountable for the decisions they take ${ }^{45}$.

2. The systematisation acts should be reviewed with the aim of increasing their relevance and adequacy. They should be more in line with the available budgets and more truly reflect the purposes and tasks of the different structural units within the organisations. To prevent them becoming out of date too quickly, fewer details of individual positions should be included, the exact profiles of staff positions being left to each organisation to decide, within the approved budget and other more general central limits.

3. To help make all government organisations accountable under established rules and procedures, governments should provide the necessary practical mandate and resource investment to the units that set government standards and monitor

\footnotetext{
${ }^{42}$ In some of the administrations these are called the rulebooks on organisation and systematisation of job positions.

43 OECD (2018), "Analysis of the professionalisation of the senior civil service and the way forward for the Western Balkans”, SIGMA Paper No. 55, OECD Publishing, Paris.

${ }^{44}$ OECD (2017), SIGMA, The Principles of Public Administration, OECD, Paris, Public Service and Human Resource Management (PSHRM) Principle 1, on the scope of public service, and Principle 4, on the senior managerial positions in the public service.

${ }^{45}$ Idem, Accountability (ACC) Principle 1, sub-principle 3, on clear lines of accountability.
} 
compliance with those standards, in the areas of policy-making ${ }^{46}, \mathrm{HRM}^{47}$ and public financial management (PFM). Gatekeeping and quality control over regulatory impact assessment, costing, consultation and other similar procedures need to be substantial and poor-quality work needs to be pushed back ${ }^{48}$.

4. Changes to structures should not be the first remedy for every problem. There need to be clear procedures for deciding major changes to organisations, and these should encourage the movement of clearly distinguishable structural units, if needed, rather than making frequent changes to responsibilities and mandates.

\section{Detailed regional analysis}

The areas of responsibility of individual organisations, including ministries, are regulated in all Western Balkan administrations by central laws or decrees of the governments. Although some potential overlaps exist, the division of responsibility between organisations is in most cases very clear and adhered to by the institutions.

The division of roles between different levels of central government institutions, i.e. between the centre of government ${ }^{49}$ institutions and ministries, as well as between ministries and agencies, is in most cases also clear. Problems do arise in individual cases, however, where agencies operating in a ministry's area have a high level of independence, such as separate budget planning or independent authority to prepare laws and bylaws. This topic is covered in more detail in Section 2.2.

Within the ministries and other central government institutions, the roles are set in the systematisation acts or similar documents. While the systematisation acts are descriptive guides on internal organisation and roles, they reflect a traditional and rigid approach to organisational hierarchy and do not respond well to the contemporary challenges and needs of institutional management. Lines of responsibility and reporting are not established. In practice ministers often assign individual tasks to members of their management team based on personal trust, cutting across the formal and expected responsibilities. It is not uncommon for a director general or an assistant minister to receive law-making assignments that fall under the policy area of another line manager within the ministry ${ }^{50}$. There have been occasions where longer-term assignments, such as chairing an EU accession negotiation chapter, have been given to officials who are not foremost in terms of formal responsibility in that area.

In most administrations the systematisation acts are approved by the government and provide the detailed framework for all organisations, determining the details of the staff positions and even generic job descriptions. Together with other centrally driven ${ }^{46}$ Idem, Policy Development and Co-ordination (PDC) Principle 1, on a well-organised, consistent
and competent policy-making system.

${ }^{47}$ Idem, PSHRM, Principle 2, sub-principle 6 on a central co-ordination unit.

${ }^{48}$ See more context in OECD (2012), Recommendation of the Council on Regulatory Policy and Governance, OECD, Paris, https://www.oecd.org/governance/regulatorypolicy/49990817.pdf

49 'Centre of government' is a broad term to cover the key horizontal functions of the government in policy making. It typically includes the general secretariats, offices of the prime minister, ministries of finance, and ministries of justice or secretaries for legislation.

${ }^{50}$ SIGMA focus group meetings with managers from the Western Balkans. 
procedures, this places more burden on managers needing to adjust their internal work arrangements. In many cases the systematisation acts describe a desired situation in the organisation, not reflecting the budgetary realities or functions carried out in practice. This limits their practical value in practice.

The organisational model of the ministries is based on a solid monocratic principle: almost all managerial authority at the level of the organisation as a whole is concentrated in the hands of the minister. The roles among the levels of management below the minister are the least clear in those particular ministries that have multiple lines of accountability between the political leadership (ministers and the government) and the senior management positions. Only in Albania, Kosovo and the former Yugoslav Republic of Macedonia is the administrative management model below the minister relatively monocratic. In other administrations there are multiple accountability lines between political and senior civil service (SCS) positions, which blurs the boundary between them, obscuring their roles, and makes effective management of ministries and their subordinate agencies more difficult ${ }^{51}$. See Annex A for illustrations of the management structures of the Western Balkan ministries.

In administrations where each ministry has several state secretaries (Montenegro and Serbia) the clarity of roles between the managers is reduced since the actual authority of individual state secretaries depends heavily on the particular person in the position and the mandate she or he receives from the minister. Moreover, the director general or assistant minister positions (the highest civil service positions in these administrations) are accountable to the minister, but in many cases need to report also to one of the state secretaries. The role of the secretaries of ministries is clearer, but this is predominantly focussed on administrative matters such as accounting and basic HRM.

The role of cabinets of ministers, while relevant for supporting the minister, in practice also hinders accountability among senior civil servants in many cases ${ }^{52}$. There is some merit in the minister having a strong cabinet, but this brings a risk of lower levels of accountability among senior civil servants and reduces the likelihood of a good level of trust between the minister and the senior civil servants. In such cases, the chief of cabinet, in fact, becomes a senior manager in the ministry, with ad hoc powers over senior civil servants. The issue has been noted also for the OECD administrations: although the political advisers sometimes issue instructions to the senior civil servants on behalf of the ministers, they often act without a clear delineation of their roles and responsibilities and are not answerable for their actions to anyone but their minister ${ }^{53}$.

The roles and responsibilities for policy development processes (typically for preparation of legal changes) are in some cases supported by internal rules and procedures, but actual practices in implementation among the analysed institutions are inconsistent ${ }^{54}$. Often it depends on a specific regulative proposal and the individuals involved as to whether the drafting of legal amendments is led by the relevant policy department or taken forward by

51 OECD (2018), "Analysis of the professionalisation of the senior civil service and the way forward for the Western Balkans", SIGMA Paper No. 55, OECD Publishing, Paris.

52 SIGMA focus group meetings.

${ }^{53}$ OECD (2011), Ministerial Advisors: Role, Influence and Management, OECD Publishing, Paris, http://dx.doi.org/10.1787/9789264124936-en.

54 OECD (2017), SIGMA, Monitoring Reports, OECD, Paris, http://www.sigmaweb.org/publications/monitoring-reports.htm. 
the legal department of a ministry (or another horizontal department, e.g. the European Integration department).

The Western Balkan administrations are in a long phase of different reforms, some internally, some externally driven. Most reforms also result in changes to administrative structures within or between organisations, making it difficult to compare their effectiveness over the time and establish accountability for results. There is a clear example of this in the Serbian state administration, where changes to individual organisations' status and mandate are a common occurrence, making the state administration's structure "permanently provisional". These frequent modifications cause institutional instability and unpredictability, with negative effects on internal organisation and the individual positions of managers ${ }^{55}$.

According to managers who attended a SIGMA focus group meeting, the things that are important for ministers and the prime minister always get done. There is, however, a significant mismatch between the formal obligations (including objectives outlined in planning documents, covered in the next section) of institutions and individual departments, and the work that is actually expected by the administration. Implementation rates of formal plans are low, and often the things that get priority are not even part of the plans disclosed to the public.

In all of the Western Balkan administrations, clarity of roles and responsibilities is further blurred by the fact that many formal legal rules and procedures are not followed in practice. Public consultations are a case in point since the legal obligation to carry out written public consultations on draft laws and bylaws is not consistently respected in any of the Western Balkan administrations. Often the formal requirements are too demanding for the existing resources of the ministries and agencies and, combined with tight deadlines, they leave the institutions having to cut corners where they can get away with it. Whatever the root cause of this unpredictable implementation of formal procedures, it does not help to keep public sector managers accountable for agreed procedures, and it also reduces clarity about the things operational managers are expected to carry out.

\subsubsection{Use of objectives in planning of work}

\section{Why it is important}

Along with regulations to ensure legality in the work of the administration and a clear framework for responsibility and the delegation of decision-making authority, objectives represent a further key ingredient in the managerial accountability framework. The use of measurable objectives in the management of an organisation constitutes the difference between administrative and managerial accountability, as it allows the organisation to move from a compliance orientation to responsibility for performance and results of the managers' work. The autonomy of managers to pursue objectives implies responsibility for delivering results, framed by relevant laws and internal rules and regulations.

There is a strong emphasis on PIFC and the COSO framework on the role of objectives. Managerial accountability requires not only the existence of organisational objectives, but also their cascading through an organisation, with the widest possible distribution of

\footnotetext{
${ }^{55}$ SIGMA focus group meetings.
} 
responsibilities ${ }^{56}$. Cascading objectives down within an organisation means that high-level, more strategic objectives (usually found in relevant sectoral strategies) need to be made concrete through operational (shorter-term) objectives, not only at the level of the organisation (i.e. the ministry or agency) but also of individual organisational units. These objectives will ideally then translate into the individual objectives of the managers themselves, which sets a good environment for the delivery of both organisational and individual results.

\section{Summary of SIGMA analysis}

All of the Western Balkan administrations have formally introduced some kind of work planning processes, albeit using diverging methodologies and approaches. The lack of use of objectives and indicators in organisational management is, however, one of the key challenges for the development of managerial accountability in the administrations of the region. Throughout the region, whether objectives are set in one or in several competing planning processes, they are perceived as a formal exercise and their value in management is not widely recognised, either by managers or the political leaders.

The low quality of the objectives is, at least in part, both a result and a cause of this lack of interest in management by objectives. If objectives simply repeat the scope of the competencies of an institution, or if indicators and targets are missing, or are vague and unclear, accountability for results will not be possible. If objectives are not measurable (e.g. through indicators and targets), their value is limited to general statements of intent. Lack of consolidated and standardised data leads to unavailability of baseline information for setting objectives and targets. As stated in the conference discussion paper, "if targets are unclear or unknown there is no basis for being accountable for results" ${ }^{57}$. Moreover, the number and diversity of typology of objectives and indicators in some administrations worsen this picture. Where there are numerous objectives from various documents, managers can hardly be expected to focus on them in their everyday practice. Having too many objectives makes it impossible to prioritise and focus on delivering against them ${ }^{58}$.

Furthermore, a failure to cascade objectives down the organisational structure indicates a poor connection between organisational and individual work objectives. This results in a missing link within the performance management system, making it practically impossible for managers to connect their own performance and the individual performances of their staff to the organisational objectives.

\section{Recommendations}

1. In order to serve their intended purpose, objectives should be - to the maximum extent possible - specific (concrete), measurable (i.e. targets are set), achievable, relevant (to the organisation and to the government's plans) and time-bound. Governments need to set minimum criteria for objectives and indicators (including baselines and targets), at least for the most common planning documents.

\footnotetext{
56 OECD (2016), SIGMA, “Managerial accountability in public administration: practical aspects of the concept and its implementation", Discussion paper, 4th Regional Conference on Public Internal Financial Control for EU Enlargement Countries, 29-30 September 2016.

${ }^{57}$ Idem, p. 6.

${ }^{58}$ Idem, p. 7.
} 
2. Political-level prioritisation decisions and political and strategic steering of objectives should be encouraged, but not at the expense of managerial involvement in these processes. Managers must participate in their formulation, in collaboration with their political superiors, and they need to have the responsibility and means to deliver the objectives.

3. In order for objectives to become a vehicle for developing managerial accountability and pursuing and achieving results, the governments should consolidate the planning systems and procedures and ensure a clear hierarchy of strategic/policy and planning (organisational) documents ${ }^{59}$.

4. Policy objectives should be clearly distinguished from the internal objectives of individual organisations, which need to operationalise them.

5. An optimal number of objectives should be stipulated in order to avoid proliferation of objectives.

6. Quality assurance for formulating objectives (by a central unit in a ministry and/or central unit of the government) should be put in place and implemented. This should not, however, lead to central formulation of objectives.

7. Consolidation of financial/budgetary and organisational work planning should be consolidated, ideally by merging them into a single process.

8. A further step would be to extend planning to the level of individual units within the institutions, corresponding with the delegation of authority to the level that holds the responsibility.

9. Progress towards the attainment of these objectives should be checked and fed back into the development of subsequent plans on a regular basis ${ }^{60}$. The use of the conclusions of progress monitoring should be a key step in any required adjustment of policy plans.

10. Awareness-raising and training of managers on strategic and operational planning need to be embedded in the compulsory training programmes for managers, as it represents the very basis of management and of managerial accountability.

An important caveat to keep in mind is that in the transition and reform context, each new reform wave or even a new technical assistance project may bring new methodologies and new approaches to the processes which have already undergone certain reforms, with more or less success in the past. This also results in fragmented reforms and partial successes, which is probably one of the causes of competing objectives and planning processes. Therefore, when new performance management systems and projects are introduced (for example, through the work of the delivery units, which currently exist in Albania and Serbia), care should be taken to ensure that they complement and improve existing processes. Alternatively, new performance management initiatives can completely overhaul the old processes, but they should not simply create new, duplicated layers, which overburden and confuse managers.

At the same time, processes should not oversimplified either, for example by merging all planning and objective-setting processes into one. It is important to differentiate between

${ }^{59}$ OECD (2017), SIGMA, The Principles of Public Administration, OECD, Paris, PDC Principle 3, on harmonised policy planning.

${ }^{60} \mathrm{Idem}$, PDC Principle 5, on regular monitoring of the government's performance. 
longer-term, strategic planning and shorter-term operational (work) planning. Higher-level, strategic priorities and objectives are still needed to set the broader context of policy processes, whereas organisational objectives need to operationalise them. That is, they should clarify what an institution needs and plans to do and achieve in the short to midterm, in order to achieve these longer-term, more strategic objectives. "The interlinkage between long- and short-term planning should be visible not only at the level of objectives but also at the budgetary level" ${ }^{61}$.

A risk identified in the context of more advanced managerial accountability systems is the possibility of managers becoming too focused on their existing objectives, losing sight of the wider goal of delivery of public services. As stated in the SIGMA regional PIFC paper, "managers think about products, not necessarily about the result of delivering public services" ${ }^{2}$. It recommends that in this context it is better to define sets of objectives rather than single targets and that objectives should occasionally be changed so that the complexity of activities can be monitored.

\section{Detailed regional analysis}

All of the Western Balkan administrations have formally introduced some kind of work planning processes, albeit using diverging methodologies and approaches. In some cases, there are competing planning and objective-setting processes, which hinder managers' ability to use the objectives in their work. This may be the cause of the prevailing sentiment, recorded in focus group discussions with senior managers, that objectives are a mere formality and even a burden in addition to the managers' already excessive workload.

In Albania, the main annual central planning document is the analytical programme of government (the legislative plan) which captures all legislative measures planned for approval during the year. Operational plans, once prepared by the Office of the Prime Minister, are no longer being prepared. They used to endeavour to operationalise government priorities and increase alignment between various strategic planning documents. As their role in the system was not regulated - and they were not formally approved by the Government - this practice was abandoned from September 2017. The Albanian FMC Law and the FMC manual envisage that all public authorities develop annual work plans for their respective institution. Strategic goals and objectives, contained in sectoral strategies, are also reflected in the Medium-Term Budget Programme, where they are broken down further into concrete outputs and activities to be achieved in line with the approved budget limits for three years ${ }^{63}$.

In Serbia, ministries and other state administration bodies are required to enter their objectives into the online software for the preparation of the Government Annual Work Plan (GAWP), though these objectives are not subsequently published. The requirement was introduced as part of the mid-term planning methodology, which is currently not being

${ }^{61}$ OECD (2016), SIGMA, “Managerial accountability in public administration: practical aspects of the concept and its implementation", Discussion paper, 4th Regional Conference on Public Internal Financial Control for EU Enlargement Countries, 29-30 September 2016.

62 Ibid.

${ }^{63}$ Information received from the Albanian Central Harmonisation Unit through an online questionnaire. 
fully implemented ${ }^{64}$. At the same time, ministries prepare priority objectives in the process of developing the Action Plan for the Implementation of the Government Programme, which is not a public document but, in theory, should contain priorities of a higher order than the GAWP. Moreover, objectives are set as part of the programme budget development - at the level of individual programmes of the organisations. According to the Budget System Law, this is done in line with the mid-term objectives of the organisations, but as the objectives entered in the GAWP software are not published, it is difficult to assess if these are the same objectives.

In $\mathrm{BiH}$, due to the complex state structure, each level and entity has its own planning and objective-setting processes, which have been criticised for lack of prioritisation and reference to specific objectives, measurable performance indicators and targets ${ }^{65}$. At the same time, in Kosovo, annual objectives are set in the work plans, and three-year objectives in the medium-term budgetary framework (MTBF) document, but SIGMA 2017 Monitoring Report states that the "framework for policy planning consists of too many short- and medium-term plans, and there are several inconsistencies involving planned commitments and their deadlines in central planning documents"

All of these examples illustrate the problems of insufficient coherence and lack of streamlining of the planning processes, which is fundamentally detrimental to managers' ability to plan and measure the quality of their units' work.

The government work planning in Montenegro has been primarily annual on the basis of the GAWP, which does not include outcome-level objectives that would enable the achievement of priority objectives to be monitored ${ }^{67}$. The Government adopted its first Medium-Term Work Programme for 2018-20 in February 2018. The document contains 44 outcome-level goals and indicators for monitoring progress towards some, but not all, of them. At institutional level "there are rare examples of organisations that produce annual work plans", as confirmed by the Central Harmonisation Unit (CHU).

In contrast, the former Yugoslav Republic of Macedonia is the only country in the region with a fairly coherent and unified planning system, in which a basic form of strategic planning at organisational level is done simultaneously with financial planning, as confirmed by a senior manager during a focus group meeting ${ }^{68}$. According to the CHU responses, individual organisations' objectives are set for a three-year period within the strategic plans, which are aligned with the whole-of-government priorities as set out in the Government Programme, covering a government's entire mandate. However, objectives

\footnotetext{
${ }^{64}$ Although in 2009 the mid-term plans were introduced also as part of the Budget System Law, in the meantime, the practice of developing them has been abandoned and is only pro forma mentioned in the General Secretariat's Instruction for developing the annual government's work plans. The provision of the Budget System Law is still there. The reinstatement of the practice is expected with the enforcement of the Law on the Planning System.

${ }^{65}$ OECD (2017), SIGMA, Monitoring Report: Bosnia and Herzegovina, OECD, Paris, pp. 38-40.

${ }^{66}$ OECD (2017), SIGMA, Monitoring Report: Kosovo, OECD, Paris, p. 31.

${ }^{67}$ OECD (2017), SIGMA, Monitoring Report: Montenegro, OECD, Paris, p. 30.

${ }^{68}$ SIGMA focus group meeting, 24 November 2017, Paris.
} 
are not always cascaded further down within organisations, and the responsibility of individual units is sometimes recognised only for specific activities ${ }^{69}$.

The content of sector strategies, and even the actual procedures for their preparation and adoption, vary greatly within all the administrations due to a failure to set minimum requirements for sector strategies. These sector policy planning documents typically include objectives but very often these are neither measurable nor supported by indicators. Fewer than half the strategies are costed, consistency with government work programmes is not ensured and, in some cases, no clear action plans for the responsible institutions or managers are prepared, or they are not updated regularly. It is rare that objectives stipulated in sector strategies are linked to specific managers in the ministries, but it is more common for actions to be the clear responsibility of certain structural units or managers. This reinforces the notion of responsibility for carrying out tasks and actions rather than for achieving objectives and good outcomes.

The quality of the objectives is a widespread problem across the region, and is another probable reason for managers' poor opinion of them. According to the CHU in the Federation of Bosnia and Herzegovina $(\mathrm{FBiH})$, objectives are primarily based on the legal competencies of the individual institutions. In Serbia also, for example, ministries often use their legal mandates as formulations for their objectives, though this problem is more difficult to analyse in Serbia, due to the fact that the objectives are not published as part of the GAWP adopted by the Government. As part of the work done by the external stakeholders who have been supporting the new planning exercises, there has been an increased insistence on quantifying objectives ${ }^{70}$. In the Republika Srpska, according to an interviewed senior manager, all objectives are set at output level, thus making it impossible to use them as a results-based management tool. An Albanian senior manager explained that objectives are sometimes in conflict with one another, which creates problems for managers. Competing sectoral strategies, from which institutional objectives are derived, have also been recognised as a problem in Kosovo.

Within the current planning processes and procedures throughout the region, senior managers are commonly involved or even have a key role in the setting of the objectives (i.e. ministers often simply confirm the proposed objectives). However, the managers' impression is that this is often simply a result of the fact that their political superiors do not care enough about plans and objectives ${ }^{71}$.

A shared problem among the Western Balkan administrations is that objectives are not cascaded down to the level of organisational units, but rather are set at the level of the institution as a whole (although in some cases, such as $\mathrm{BiH}$, responsibility for activities

\footnotetext{
${ }^{69}$ From three analysed ministerial strategic plans (2018-20), of the Ministry of Health, Ministry of Interior and Ministry of Economy, one had internal units recognised for specific objectives (programmes), one had internal units recognised for individual activities, while one only included the responsibility of the institution as a whole in the document.

${ }^{70}$ However, according to an interview with a senior manager, this has been without properly understanding which processes and outcomes can be quantified. An example was given where the experts insisted that objectives would be set in terms of the number of EU negotiation chapters opened, without taking into consideration that this number is not determined by the performance of the co-ordinating ministry.

${ }^{71}$ Based on focus group discussions with senior managers, Paris, November 2017.
} 
does refer to specific units). This means there is no link between the managers' own results and the organisational objectives. Programme-based budgeting, where implemented, could correct this deficiency, but since these new procedures and practices are not designed from the perspective of senior managers, and there is no active pressure to use the procedures well, they have not been recognised by managers as a useful practice ${ }^{72}$.

In the end, as several managers from the region agreed in the focus group discussions, the problem is that there are no consequences following the realisation of objectives or lack of it. Managers are not commonly asked by their ministers to report on performance against the objectives. This issue is tackled in more detail in Section 2.3.

\subsubsection{Delegation of decision-making authority}

\section{Why it is important}

The right level of delegation of responsibility and decision-making authority is associated with a higher level of efficiency and effectiveness within an organisation. In large private sector organisations, contracts with clients are typically signed by operational-level staff backed up by appropriate internal decision-making procedures. Top management is rarely engaged with the regular authorisation of decisions or transactions. In public administration organisations, it is not uncommon that the head of the organisation has a formal (and often substantial) role in endorsing decisions related to regular and even minor transactions of the organisation.

Without some delegation of decision-making authority, the resources of the organisation (in terms of both the talents and time of officials) are not used to the best possible effect, and the organisation heads (including the ministers) do not have time to focus on the strategic management of the organisation.

\section{Summary of SIGMA analysis}

Delegation of decision-making authority is permitted by legislation but implemented only rarely. A high degree of centralisation, both at the government level and within individual institutions, makes the development of managerial accountability unrealistic. The centralisation of responsibility and authority, and a lack of adequate procedures and instruments to enable its delegation to operational managers, lead to an insufficient or unclear level of delegation of authority. In practice, authority is mostly kept within the political positions and is often exercised through informal instructions and co-ordination, resulting in blurred lines of individual managerial accountability. Organisation heads (including the ministers) are in many cases formally making even the smallest decisions on behalf of their organisation, which is a totally inefficient use of time and resources. Where delegation of decision-making authority does happen, it is still mostly centralised to one single person, such as the secretary general or secretary of the ministry, rather than being passed down to managers, such as directors or assistant ministers responsible for sectors.

\footnotetext{
${ }^{72}$ Based on focus group discussions with senior managers, Paris, November 2017.
} 


\section{Recommendations}

1. Ensure that the opportunities for delegation within general legislation are supported by tangible procedures and guidelines, to enable organisations to make use of the legally defined delegation opportunities ${ }^{73}$.

2. Key legislation should be reviewed in order to identify any explicit requirements that ministers and other heads of organisation take decisions or are held responsible for taking specific decisions. Where reasonable and feasible, the legal texts should be adjusted to encourage organisation heads to delegate decision-making authority to lower levels of management, ideally to the level closest to that of the delivery of the public services in question, providing that reporting and information flows allow the use of delegation to be monitored.

3. Current practices for less strategic decisions should be analysed and consideration given to whether, for certain specific decisions, the legislation should provide rules limiting those decisions to lower levels of management. This means a detailed analysis of what it is appropriate to delegate and what not. Where the legislation already provides sufficient opportunities to delegate decision-making powers, these should be used in practice to delegate relevant managerial responsibilities directly to the senior civil service positions, to avoid overburdening the political level with administrative matters, and to equip senior civil servants with proper managerial roles with corresponding rights and responsibilities ${ }^{74}$.

4. Dedicated training and coaching on effective delegation should be included in existing or planned management training programmes. Delegation is a skill that is developed with practice, but training and guidance can provide the motivation and confidence needed to practice more frequent and better delegation.

Delegation can only occur when staff are sufficiently informed and competent to carry out the delegated authority and when monitoring of the use of the authority is possible either through reporting or other forms of data and information. Delegation is appropriate where there are clear objectives and performance can be measured in some way.

\section{Detailed regional analysis}

Although individual ministries are responsible for their own policy areas, a high number of decisions are taken at the level of the government. At the organisational level, the dominant perception is that all key decisions, and even most routine decisions, are centralised to the top political level. In effect, there is a high degree of centralisation which makes the development of decentralisation at the individual organisation level and hence the development of managerial accountability more difficult.

${ }^{73}$ OECD (2017), SIGMA, The Principles of Public Administration, OECD, Paris, PFM Principle 6, sub-principle 3, on laws and regulations and other PFM arrangements facilitating the development of managerial accountability through appropriate delegation.

${ }^{74}$ Idem, ACC Principle 1, sub-principle 3, on empowering managers and supervisors and delegating decision making to them. 
Figure 5. Delegation of formal decision-making authority in administrations across the Western Balkans

Number of instances in 34 ministries questioned, dark colour indicates "yes" and light colour "no"
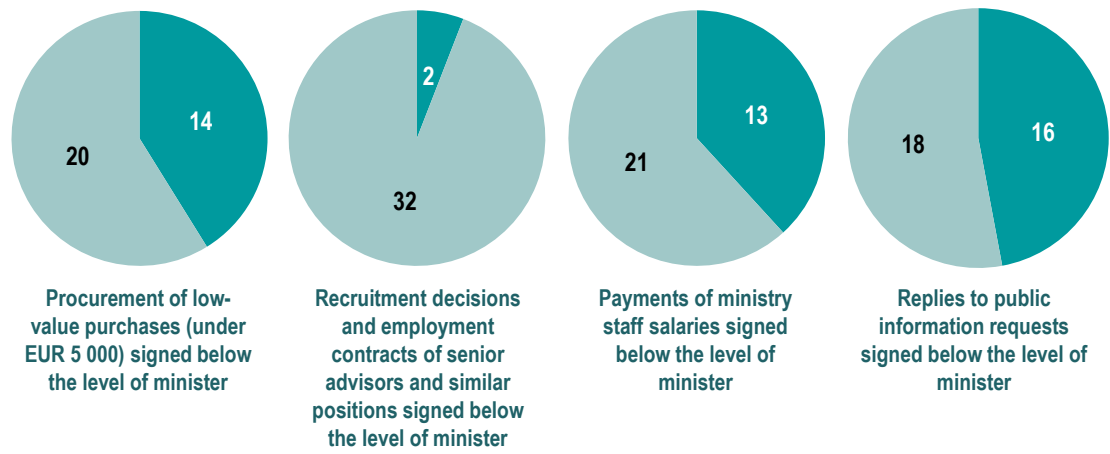

\section{Payments of ministry staff salaries signed} below the level of minister

Replies to public information requests signed below the level of EUR 5 000) signed below positions signed below minister

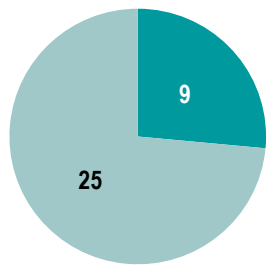

Annual leave requests formally approved below the level of permanent secretary or equivalent

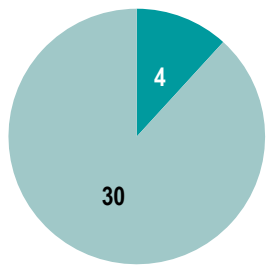

Business trips of staff members formally approved below the level of permanent secretary or equivalent

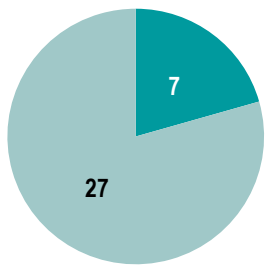

Training participation for staff members approved below the level of permanent secretary or equivalent

Source: Data collected for the 2017 SIGMA monitoring.

In 2017 SIGMA analysed the practices of delegating specific regular decisions to lower levels of management across the Western Balkan administrations. It was found that most routine decisions of public administration organisations are still formally signed off at the highest levels of management. Even such simple decisions as providing a response to a public information request are in many cases left to the minister to sign and thus take formal responsibility for.

A closer analysis reveals that in some administrations the level of delegation depends on the organisation in question and in some administrations, there are specific functions that are systematically delegated.

In the former Yugoslav Republic of Macedonia and in Serbia, the level of delegation varied between the reviewed ministries indicating that these ministries use the right to delegate freely and differently between organisations. The ministries responsible for interior affairs have made more use of delegation, showing that in larger organisations the need for delegation is seen and also used in practice. In Kosovo, and to a lesser extent in Albania, the level of delegation depended on the functions reviewed, illustrating the effect of central rules for delegation or decision-making levels for the entire central government. For example, in Kosovo, in all sample cases reviewed the annual leave requests were delegated to the level of directors of departments, and in Albania small-scale procurement was always delegated to a level lower than the minister. 
Overall, public administration organisations in the Western Balkans do not make sufficient use of delegation for routine decisions, with less than half of the cases displaying the minimum expected level of delegation.

At the same time, many managers tend to avoid responsibility. They move problems and responsibility for solving them to a higher-level authority and are used to asking their superiors for permission for minor issues. When forced to act, many run formal procedures documenting every action, regardless of whether such procedure and documentation are really needed or proportional to the case. These patterns of behaviour are then replicated by their staff, overwhelming the organisation with a flood of purposeless e-mails and internal documents.

A key instrument across the region for delegating responsibilities and tasks within state administration authorities is the 'act on internal organisation'. Despite being a key document for defining the structure of the individual bodies, including the internal relationships and job descriptions, this act is not used to formally delegate specific decisionmaking authority, but simply to indicate the scope of responsibilities. As such, these acts on internal organisation form a necessary ingredient for developing managerial accountability, as these define the framework of responsibilities and accountability lines, but do not formally authorise managers to decide on specific matters.

The legal framework for delegation of specific decision-making authority is not clear in all administrations. There are explicit provisions on delegation of powers in the $\mathrm{FBiH}^{75}$, while more general provisions are applied to the Bosnia and BiH State level institutions and the RS, with the exception of financial management and control (FMC) (i.e. the Law on Financing of $\mathrm{BiH}$ Institutions, Article 33e). A lack of clear legal provision and supporting forms that organisations can use for delegation hinder the practice.

Delegation is a skill that needs to be learned, ideally through a combination of training and practical experience. Public sector managers (as well as ministers) do not receive any training on delegation and how to organise simple monitoring.

\footnotetext{
${ }^{75}$ Law on the Organization of the Management Bodies in the Federation of Bosnia and Herzegovina
} (Official Gazette of the Federation of Bosnia and Herzegovina, No. 35/05). 
Typical reasons for the low level of delegation are ${ }^{76}$ :

1. A lack of trust by political leaders and fear of being held responsible for what others have done.

2. A lack of competent and motivated staff to whom they can delegate.

3. Staff who are not motivated to take on more responsibility.

4. The time required to monitor whether the delegated role is handled well.

5. A lack of strong and performance-oriented reporting rules and practices.

\section{Box 2. Delegation of decision-making authority in the management of IPA-funded programmes}

The decentralised management and control systems set up in most of the administrations in the region for programmes funded from the Instrument for Pre-accession Assistance (IPA) have established procedures whereby decision-making authority is delegated by default to the competent predefined managerial roles. These externally imposed rules demonstrate from a delegation point of view a good case of modern management where decisions are taken at the level of operational management.

In practice, this means that decisions are formally and to a large extent also in practice entrusted to lower levels of management than in the case of similar national procedures. Launching public procurement, signing contracts and authorising payments to contractors are decisions typically made two levels below the minister, which are all civil service management positions. This practice, however, affects only a limited group of civil servants and has not been developed or applied to other management positions, even within the same organisation.

\subsubsection{Establishing internal control mechanisms}

\section{Why it is important}

Delegated managerial accountability can only work where there are strong management and control systems in place to give organisation heads the assurance that they can confidently delegate decisions to informed, empowered and competent lower-level managers. Effective internal controls set boundaries to the strategic space that managers enjoy and unless these controls are purposefully overridden, provide assurance to institution heads that the delegated powers will not be misused.

In this section, we will focus on one specific aspect of establishing internal control, namely the setting of internal regulations by senior managers who are not institution heads. The role of the heads of institutions is indisputable, but when they delegate responsibility to their subordinates, the question arises as to whether this delegated responsibility also includes authority to set procedures and specific control activities.

\footnotetext{
${ }^{76}$ Survey among public sector managers in Serbia (CEP 2016).
} 
Authority delegated to empowered managers should include the right to adapt existing control mechanisms to their specific needs. This adjustment will typically comprise the setting up of additional controls, not superseding the ones that are binding for the entire institution. Unless senior managers can obtain reasonable assurance that control mechanisms in place are effective, consenting to additional responsibilities would mean taking risks that are unacceptable both for them and for their superiors.

To make sure the internal controls work effectively, managers may use internal audit, the second main pillar for PIFC. Internal audit, by bringing a systematic, disciplined approach to evaluating and improving the effectiveness of risk management, control and governance processes, can assure the managers - at least to some extent - that the risks are mitigated, governance processes are effective and efficient, and organisational goals will be met even if heads of organisation are no longer solely responsible for them.

In the context of managerial accountability, internal audit has a special role to play. Heads of institution will be more willing to delegate their responsibilities to their subordinates only if they have been assured there are proper internal control mechanisms. Internal audit can provide such assurance. By providing assurance to heads of organisation, effective internal audit helps mitigate the risks associated with delegating authority. For these reasons, development of managerial accountability and the strengthening of internal audit should go hand in hand.

However, internal audit will not be an ally of managers, i.e. will not enable them to improve their management and control systems, if it focuses solely on compliance and ex post inspections. The same is true for supreme audit institutions, which, if they focus on a compliance approach, can effectively lower managers' appetite for risk. It is managerial autonomy that permits innovation in public administration along with its beneficial effects, though within overall standards, and some experimentation and occasional failures need to be tolerated and accepted.

\section{Summary of SIGMA analysis}

In most Western Balkan administrations, line managers are permitted to develop internal rules and procedures, including additional reporting obligations, within their sectors/departments; it is therefore no longer a role unique to financial units or heads of organisation. Despite a permitting legal framework, there is a lack of horizontal awareness among senior managers in ministries of their role and its importance within this process, resulting in a formalistic approach to the setting up of internal control mechanisms and to the internal control system more broadly.

The lack of adequate competencies for designing and implementing internal controls, the formal and technical application of risk management and the poor understanding of what internal audit is for constitute a significant challenge. PIFC in general and COSO framework requirements in particular are rarely the subject of training sessions for senior civil servants. With no tradition of decentralised management systems, very few managers have professional experience in this area. 
The internal audit function is established throughout the public sector in the region and internal audit work is basically carried out according to international standards. However, audits in the region focus more on compliance issues than performance/effectiveness, and audit recommendations are generally poorly implemented. This does not sufficiently help the managers in the organisation to focus on better internal control systems.

\section{Recommendations}

1. Governments should continue the development of the internal audit function into a professional advisory service to provide managers with the necessary advice for better internal control77.

2. All cases where senior managers have successfully developed internal rules and procedures of adequate quality should be identified, and a repository of such documents built, to be shared among interested managers during dedicated workshops. Such cases should also be reviewed and commented on by the CHU in order to add value.

3. The theoretical description of PIFC or COSO principles and cases from administrations with a different management tradition should be replaced by a more beneficial type of training session, where real-life examples from managers' own administrations are presented, explained and discussed at length.

There is a risk that managers will request internal audit units, who are traditionally and rightly associated with expertise in internal controls, to assist with or even take over the development of the internal regulations they intend to introduce within their area of responsibility. It should be remembered that, in accordance with international standards ${ }^{78}$, directly referred to by the Principles of Public Administration, in Public Financial Management Principle 8, the internal audit activity must be independent, and internal auditors must be objective in performing their work. Taking an active part in operational activities, or designing the internal control systems for an area, would effectively bar them from performing audits in that area.

Internal rules and procedures may create additional red tape, which may also affect citizens and businesses. A balance must, therefore, be achieved between the costs of such additional controls and the benefits they bring to the process. More internal reporting will not translate into better supervision if the manager is unable to digest the information provided and act upon it. Like the heads of institution, senior managers need to learn to delegate, to trust their employees and understand that they can be in control of their remit even though they do not take all decisions personally and do not sign all documents. Otherwise, they will become a new bottleneck, overloaded with tasks and unable to effectively deliver the expected results.

77 OECD (2017), SIGMA, The Principles of Public Administration, OECD, Paris, PFM Principle 8 , on the operational framework for internal audit and on its application, and Principle 9, on public organisations' implementation of internal audit.

78 The Institute of Internal Auditors, International Standards for the Professional Practice of Internal Auditing - International Professional Practices Framework, the Institute of Internal Auditors. 


\section{Detailed regional analysis}

\section{Internal control}

In all Western Balkan administrations, line managers are formally permitted to develop internal rules and procedures for internal control in their sectors/departments; it is therefore no longer a role unique to financial units or heads of organisation. The only exception seems to be Kosovo, where the approval of the general secretary or a general director of an agency is required for such additional internal procedures. Senior civil servants may also set up additional reporting obligations for their staff that go beyond what is required from other staff in the organisation ${ }^{79}$. Such additional obligations often make up for reporting arrangements that are lacking at the organisational level and are indispensable for the adequate management of resources.

A comprehensive approach in this regard exists in Albania, where, in accordance with the Law on Financial Management and Control ${ }^{80}$, all line managers are responsible for developing internal rules and procedures for internal control in their sectors/departments. Specifically, the rules provide that they are responsible and accountable to their superior in the hierarchy for:

1. The effective supervision and management of the structure, employees and their professional standards.

2. The identification, assessment and control of risks that endanger the successful completion of activities and attainment of objectives.

3. The development and maintenance of the risk register.

4. Ensuring that the internal control system within their units is functioning according to the rules set by the head of the public unit and reporting any weaknesses that need to be addressed to the respective authorising officer.

5. Safeguarding the unit's assets, information and documentation against loss, misuse and unauthorised use.

6. Reporting in a timely and proper manner any major structural risks and serious shortcomings identified during the execution of an activity and any measures taken to correct these shortcomings.

The Law on PIFC in Montenegro, Articles 13-14, states that it is the head of the entity who is responsible for the "establishment and development of an adequate system of financial management and control". They may delegate authority for certain tasks and assignments within the entity's remit to lower levels of management, but this would not negate their own accountability. However, the actual establishment, implementation and development of FMC are the responsibility of a person specifically appointed to this end.

In practice, the FMC manager (often the secretary of the ministry) seems to be the only person engaged in shaping internal controls in the institution. This is despite the fact that according to the Guidelines for Preparation of the FMC Plan, managers of all internal organisational units should participate in this process. When the task of preparing the FMC

${ }^{79}$ For example, internal forms required for expenditure or additional internal reports related to sensitive or otherwise special assignments or projects.

${ }^{80}$ Law No. 10296, 08 July 2010, amended by Law No. 110/2015, 15 October 2015, Chapter II. 
Plan is delegated to the finance department, its elaboration becomes a formality, with managers not even knowing such a document exists. This is particularly true when internal control systems are perceived as purely financial issues, which do not require the involvement of operational managers. Outside of the narrow circle of those whose job it is to understand it, such as internal auditors and, to some extent, FMC managers, a low level of awareness of PIFC remains omnipresent, with the institution heads and managers considering it an additional technical obligation.

In Serbia, according to the Law on the Budget System, responsibility for establishing and updating internal control systems belongs to the heads of the administrative bodies ${ }^{81}$. They may delegate certain responsibilities pertaining to the establishment, maintenance and updating of the internal system to another person within the administrative body. ${ }^{82}$ The scope of the delegation is not entirely clear since the provision of the bylaw issued by the Minister of Finance ${ }^{83}$ stipulates that only some of the functions related to the system of FMC may be delegated, while the Law does not provide for such restraints ${ }^{84}$. Unlike the Law on the Budget System, which leaves some room for interpretation, the Rulebook is explicit that despite the delegation of this authority, the head of the administrative body remains accountable ${ }^{85}$.

Within the $\mathrm{FBiH}$, it is the head of the institution who is responsible for issuing internal regulations, but the Law on Financial Management and Control in the Public Sector permits the delegation of this task. In practice, internal procedures are proposed by the competent organisational unit and issued (signed) by the head of the institution.

Despite a favourable legal framework, there is a lack of horizontal awareness (and sometimes disinterest) among senior managers in ministries of their role and its importance within this process, resulting in a formalistic approach to the setting up of the internal control system. Hence, assessments of the state of development in PIFC are often done as a bureaucratic exercise, and the opportunity to promote internal control processes and outputs (such as risk assessment information) as tools for improving the internal control systems and overall performance of the institution is often missed.

\section{Internal audit}

In 2017 SIGMA reviewed the state of internal audit in the region and assessed it against the relevant key requirement of the Principles of Public Administration, namely that the internal audit function is established throughout the public sector and internal audit work is carried out according to international standards. However, only in Serbia and the former Yugoslav Republic of Macedonia were internal audit functions established in more than $90 \%$ of the government organisations required by law to do so (too often, however, staffed

${ }^{81}$ Article 81, paragraph 3 of the Law on Budget System.

82 Idem, articles 80 and 81 .

${ }^{83}$ The Rulebook on common criteria and standards for the establishment, operation and reporting on the financial management and control in the public sector (Official Gazette of Republika Srpska, Nos. 99/2011 and 106/2013).

${ }^{84}$ Article 11, paragraph 2 of the Rulebook in relation to Article 81, paragraph 3 of the Law on Budget System.

${ }^{85}$ Article 11, paragraph 3 of the Rulebook. 
with just one auditor) ${ }^{86}$. Most of the administrations made the application of internationally recognised audit standards mandatory.

Within the framework of the 2017 Assessment, SIGMA verified whether audit reports were prepared according to a methodology that addressed weaknesses in internal control systems and in achieving value for money. Out of 24 audit reports reviewed, only 8 (these were all in Albania and $\mathrm{BiH})$ met the first criterion and only $2(8 \%)$ met the second ${ }^{87}$. Audits in the region focus more on compliance issues than performance/effectiveness, and audit recommendations are generally poorly implemented. This does not sufficiently help the managers in the organisation to focus on better internal control systems.

In the context of managerial accountability, it should be noted that audits in the region are based on strategic and annual audit plans, although the quality of these plans varies and they are not always based on a risk assessment covering all parts of the organisation. Managers are not, therefore, meant to simply ask internal audit to review control mechanisms within the area of their responsibility, although this may explain the large number of ad hoc audits (i.e. outside the audit plan) noted by SIGMA in its 2017 monitoring.

In addition in their daily work internal auditors work in excessive isolation from other units within their organisation. Careful to guard their independence, they do not regularly cooperate and communicate with line managers, apart from the head of institution or the most senior civil servant to whom they report. Once managerial accountability is developed within their organisation, this may prevent them from understanding the new roles of managers, now operating with less regulatory guidance and within an enlarged strategic space.

\section{Management of risk}

An additional tool that can be used to improve the quality of management and to achieve better outcomes is risk management, although its effective implementation is a real challenge. In most ministries and large agencies, risk assessment is carried out and updated at least annually. This is normally done using the templates and guidance provided by the CHUs. In most cases, however, risk assessment does not follow all the key objectives of the organisation. Risk mitigation measures exist more frequently but are not systematic. Kosovo and the former Yugoslav Republic of Macedonia stand out as having a more systematic approach to risk management ${ }^{88}$. In $\mathrm{BiH}$, risk management requirements are only just being rolled out, as the relevant regulation was first introduced in 2016. The role of operational managers varies between organisations. Risk management initiatives are typically led or organised by one co-ordinator within an organisation and in some cases, the necessary tables are merely filled in by any available staff members of the relevant structural units, without the personal involvement of operational managers.

\footnotetext{
${ }^{86}$ OECD (2017), SIGMA, Monitoring Reports, OECD, Paris, sub-indicator 6.8.1.2 Organisational capacity for internal audit.

${ }^{87}$ Idem, sub-indicator 6.9.1.2 Quality of audit reports.

${ }^{88}$ OECD (2017), SIGMA, Monitoring Reports, OECD, Paris, sub-indicator 6.7.1.7 Regularity and completeness of risk management practices.
} 


\subsubsection{Accountability lines between ministries and agencies}

\section{Why it is important}

Although the concept of managerial accountability is mostly applied to individual managers, it can also be applied to relations between institutions, in particular between a parent ministry and its subordinate bodies (agencies) ${ }^{89}$. Relations between institutions influence senior managers' accountability for policy and results, so it matters also for the individual managers.

In the traditional setup, ministries plan and monitor policies and the agencies focus on implementation. In practice, of course, the situation is not this clear cut, with agencies sometimes contributing to legislation, and ministries retaining some of the actual implementation and inspection functions. In any case, agencies are key to the successful implementation of government policy, and the accountability of senior managers in the ministries is dependent on the agencies' co-operation and results.

The relationships between the ministries and their subordinate bodies have two different overall dimensions for managerial accountability. First, the ministries and the key officials in the ministry have an overall responsibility for a policy area. In many cases, the implementation of the policy is within an agency or several other bodies. It is therefore important that the ministry has the opportunity to steer the design and key parameters of implementation of the policy. Otherwise, it cannot be fully accountable for good results in the area.

Likewise, the agencies and other subordinate bodies need to have sufficient operational independence, to allow them to be responsible for the successful implementation of agreed programmes and other commitments ${ }^{90}$.

\section{Summary of SIGMA analysis}

The Western Balkan administrations have a system where line ministries are responsible for policy areas right from design through to implementation. None of the administrations have clear criteria in place for establishing agencies and other subordinate bodies. The horizontal rules, where in place, are general in nature and a high number of institutions have been established through separate laws, many having their own unique governance and accountability systems. Responsibility for the monitoring of subordinate bodies is often not clearly placed within a ministry and the rules do not systematically require the subordinate bodies to submit their plans and reports to the parent ministry.

Annual plans and annual reports are nevertheless in most cases prepared, although in practice subordinate bodies do not have objectives and measurable targets as part of their

\footnotetext{
${ }^{89}$ SIGMA is referring to classical agencies, directorates and administrations that typically implement the policies defined by the ministries. Semi-autonomous regulatory agencies, stateowned companies and other specific organisations are not referred to, although these often also execute government policy.

90 On the "management autonomy" of such bodies see: OECD (2005), Modernising Government: The Way Forward, OECD Publishing, Paris, page 117, http://dx.doi.org/10.1787/9789264010505en.
} 
annual plans and therefore the annual reports do not focus on results related to their objectives.

\section{Recommendations}

1. The number of agencies that do not report to any ministry should be reduced in most administrations by subordinating these to the ministries that govern their relevant policy areas, starting with those who are directly involved in the implementation of government policies ${ }^{91}$. This would allow the ministries to take greater responsibility for their policy area and manage the relevant resources to the best effect.

2. Ministries should strengthen the responsibility of the relevant structural units and the senior managers charged within the ministries with supervising the subordinate bodies working within their policy area ${ }^{92}$. The practice whereby only the minister is responsible for the results of the agency does not foster sustainable management of subordinate bodies and reduces the accountability of managers within the civil service.

3. The rules should establish the requirement for the subordinate bodies to present their annual plans, including objectives and measurable targets, to the ministries, and to report against these at least annually.

4. In situations where the ministries apply detailed ex ante controls on many management decisions of the subordinate bodies, the CHUs or other relevant bodies should advise and guide the ministries to review the existing practices and find ways to remain in control while leaving more operational independence to the subordinate bodies ${ }^{93}$.

\section{Detailed regional analysis}

The situation varies across the region, but the systems do have certain things in common. The Western Balkan administrations have a system where line ministries are responsible for policy areas right from design through to implementation. Although formal decisions are largely taken at the government level, the role of the centres of government (i.e. the general secretariats or even the prime ministers' offices) is not dominant.

None of the Western Balkan administrations have clear criteria in place for establishing agencies and other subordinate bodies or independent regulatory agencies. The horizontal rules, where in place, are general in nature and a high number of institutions have been established through separate laws, many having their own unique governance and accountability systems.

${ }^{91}$ OECD (2017), SIGMA, The Principles of Public Administration, OECD, Paris, ACC Principle 1 , on the rational organisation of central government, with clear accountability lines.

${ }^{92}$ Idem, ACC Principle 1, sub-principle 5 on assigning responsibilities for steering and controlling the subordinated agencies/bodies and availability of specialised professional capacities.

93 Idem, PFM Principle 7, sub-principle 2, on internal control requirements and the clear definition of the relationship of subordinate organisations with ministries. 
In the Western Balkans, it is usual for a large number of organisations to propose and negotiate their budgets directly with the Ministry of Finance (MoF), and the number of first-level budget holders is high. In Montenegro there are 29, in Kosovo and Albania 30 and in the former Yugoslav Republic of Macedonia 73 agencies and other institutions that are not ministries or constitutional bodies can negotiate their budgets directly without the steering of a ministry ${ }^{94}$.

In a similar manner, the number of agencies reporting directly to parliament is high. Without counting the constitutional bodies such as the supreme audit institutions, judiciary institutions and ombudsman offices, the number of agencies reporting directly to the parliament ranges from 10 in Montenegro to 31 in Kosovo ${ }^{95}$. While it is understandable that constitutional bodies are not part of the government's general accountability framework, independent agencies need to be the exception if the government and ministries are to take full responsibility for the design and implementation of public policies.

SIGMA's review of the regulation of all the administrations shows that responsibility for the monitoring of subordinate bodies is often not clearly set within a ministry (it is often the responsibility of the minister) and the rules do not systematically require the subordinate bodies to submit their plans and reports to the parent ministry. This limits the ability of line managers in the ministries responsible for the relevant policy areas to feel accountable for pursuing better outcomes in those areas.

For instance, in Serbia, the Business Registry Agency is a subordinate body of the Ministry of Economy, but it is obliged to report directly to the Government and negotiates its annual budget directly with the MoF. Since this agency is key to delivery in a policy area that the Ministry of Economy's senior managers ought to be responsible for, those managers will feel less accountable in the absence of control over the plans and public sector resources in their area of work.

Annual plans and annual reports are in most cases prepared and provided by the subordinate bodies. Albania, Kosovo and Montenegro stand out for having a more consistent approach. In each of them, at least six out of the eight reviewed subordinate bodies had prepared both the plans and the reports and these were communicated to the parent ministry ${ }^{96}$. In the case of Montenegro, most reviewed bodies had their annual plans and annual reports integrated into the plans and reports of the ministry.

Looking at each administration's legislation relating to subordinate bodies, SIGMA also found that while the key aspects of accountability between the ministries and subordinate bodies were covered by the legislation in Kosovo and Montenegro, in other administrations the picture was more mixed, with only some subordinate bodies having the requirements set out.

\footnotetext{
94 OECD (2017), SIGMA, Monitoring Reports, OECD, Paris.

${ }^{95}$ Ditto.

${ }^{96}$ Analysis of the number of central government bodies reporting to a parent ministry. The measure is based on a sample of eight bodies in total. Two bodies were selected from each of four different ministries: 1) the ministry of interior, 2) the ministry of finance, 3) the ministry of justice, 4) the ministry of economy. Subordinated bodies with the highest number of staff were selected for each ministry.
} 
Table 1. The state of play on key accountability mechanisms between ministries and subordinated bodies in the case of typical subordinate bodies

\begin{tabular}{|c|c|c|c|c|c|c|}
\hline & Albania & $\begin{array}{l}\text { Bosnia and } \\
\text { Herzegovina }\end{array}$ & Kosovo & $\begin{array}{l}\text { The former } \\
\text { Yugoslav } \\
\text { Republic of } \\
\text { Macedonia }\end{array}$ & Montenegro & Serbia \\
\hline $\begin{array}{l}\text { Responsibility for monitoring the } \\
\text { subordinated body is clearly assigned to } \\
\text { the relevant organisational unit of the } \\
\text { ministry }\end{array}$ & & $\checkmark$ & $\checkmark 97$ & & $\checkmark$ & \\
\hline $\begin{array}{l}\text { The ministry has the right to appoint and } \\
\text { dismiss the management of the } \\
\text { subordinated body (or the government } \\
\text { makes the decision based on the } \\
\text { proposal of the minister) }\end{array}$ & $\checkmark$ & $\checkmark$ & $\checkmark$ & $\checkmark$ & $\checkmark$ & $\checkmark$ \\
\hline $\begin{array}{l}\text { The ministry has the right to request any } \\
\text { documents produced and collected by } \\
\text { the subordinated body }\end{array}$ & $\checkmark$ & $\checkmark$ & $\checkmark$ & $\checkmark$ & $\checkmark$ & $\checkmark$ \\
\hline $\begin{array}{l}\text { The regulations include a requirement for } \\
\text { an annual plan and annual activity report } \\
\text { to be submitted to the ministry }\end{array}$ & $\checkmark$ & & $\checkmark$ & & $\checkmark$ & \\
\hline $\begin{array}{l}\text { The budget proposal is required to be } \\
\text { submitted to the parent ministry (not } \\
\text { directly to the MoF, parliament or similar) }\end{array}$ & $\checkmark$ & $\checkmark$ & $\checkmark$ & $\checkmark$ & $\checkmark$ & $\checkmark$ \\
\hline
\end{tabular}

Source: Data provided by the national authorities during the 2017 SIGMA assessment process.

The regulations hardly set any requirements for setting objectives and measurable targets for the work of subordinate bodies. Of the 30 institutions reviewed, it is only for the Directorate of Metrology in Albania that the legislation sets out specific requirements regarding ministerial approval of specific work targets and indicators and annual reporting.

In practice, subordinate bodies do not have objectives and measurable targets as part of their annual plans and therefore the annual reports do not focus on results related to the objectives. Kosovo alone stands out for having a more consistent approach towards performance information in the annual plans and reports of the subordinate bodies. Here seven of the eight subordinate bodies reviewed had specific objectives in the annual plans, the annual plans were in most cases agreed with the relevant ministry, and the annual report contained information on results measured against predefined objectives.

Montenegro and Serbia have many administrations within the ministries, as administrative parts of the ministry organisation. They have more authority and autonomy than regular departments but they are not legal entities and therefore legal responsibility is with the minister. This has an effect on their operational independence in managing resources after the budget is approved.

97 This is not universally applied. For example, the MPA has no unit to monitor the work of the Agency for Information Society. 
Table 2. National legislation on key aspects of autonomy of the subordinate bodies

\begin{tabular}{|c|c|c|c|c|c|c|}
\hline & Albania & $\begin{array}{l}\text { Bosnia and } \\
\text { Herzegovina }\end{array}$ & Kosovo & $\begin{array}{l}\text { The former } \\
\text { Yugoslav } \\
\text { Republic of } \\
\text { Macedonia }\end{array}$ & Montenegro & Serbia \\
\hline $\begin{array}{l}\text { Managerial autonomy of the heads of } \\
\text { subordinated bodies is defined in the } \\
\text { regulatory framework. }\end{array}$ & $\checkmark$ & & $\checkmark$ & $\checkmark$ & $\checkmark$ & $\checkmark$ \\
\hline $\begin{array}{l}\text { The heads of subordinated bodies have } \\
\text { operational autonomy to manage financial } \\
\text { resources within the approved budget. }\end{array}$ & $\checkmark$ & & $\checkmark$ & $\checkmark$ & & $\checkmark$ \\
\hline $\begin{array}{l}\text { Recruitment and dismissal decisions } \\
\text { regarding the staff of a subordinated body } \\
\text { can be made by the head of the respective } \\
\text { body independently } 98\end{array}$ & & & $\checkmark$ & & & \\
\hline \multicolumn{7}{|l|}{$\begin{array}{l}\text { For bodies subordinated to a ministry, } \\
\text { requirements for setting specific objectives } \\
\text { and targets are defined. }\end{array}$} \\
\hline $\begin{array}{l}\text { Procurement decisions up to EUR } 100000 \\
\text { can be made by the subordinated body. }\end{array}$ & $\checkmark$ & & $\checkmark$ & $\checkmark$ & & \\
\hline
\end{tabular}

Source: Data provided by the national authorities during the 2017 SIGMA assessment process. ${ }^{99}$

\subsection{Managing resources}

Managerial accountability can be present only if managers have proper means for achieving the objectives for which they are held accountable. This entails having either the basic resources within their control or the opportunity to effectively influence the way these are managed by the organisation. In practical terms, staff and direct budgetary funds are the resources most used and discussed in this chapter. Both types of resources are heavily regulated by the national legislation in order to manage inherent risks associated with their use. Increasing managerial accountability within public administration organisations does not entail dismantling or loosening the legal frameworks but calls for assigning appropriate roles to senior managers in organisational decisions that affect members of their teams and the funds they need to achieve their objectives.

\subsubsection{Staff planning, recruitment and relocation}

\section{Why it is important}

Planning of human resources (HR) (also referred to as human resources planning, workforce planning, staff planning, etc.) is a core HRM function which enables an organisation to link its organisational objectives (set in strategies and plans) to the

\footnotetext{
${ }^{98}$ In cases where the subordinate bodies are not part of the civil service, usually more autonomy is allowed also in HRM.

${ }^{99}$ It should be noted that a few administrations have started reforms to improve their organisation. This may bring changes to the overall assessment of the situation but it also offers an opportunity to make changes that are positive for managerial accountability.
} 
management of the people in the organisation. It can "enable an organisation to assess and anticipate its current and future needs such as the size of the workforce, the deployment of the workforce across the organisation, and the knowledge, skills and competencies needed to pursue its mission" 100 . Managers' capacity to pursue and achieve their objectives depends not only on their own skill set and competencies, but also on the quality of the staff working under them in their department, sector or unit, and on whether the right people are doing the right things. If a manager is made responsible for influencing the planning of the necessary HR in their unit, then they must also think in advance and assume responsibility for how those civil servants will contribute to the achievements of the strategic and organisational objectives. Leaving managers out of HR planning can lead to a decreased sense of responsibility for the results of the staff in their units.

Following on from the planning, the recruitment process also needs some level of central control, especially in the more politicised administrative cultures where the risk of patronage is high, as it has been argued that centralised recruitment helps to ensure that meritocracy reduces politicisation ${ }^{101}$. Yet recent trends in OECD countries lean towards a focus on efficiency and effectiveness, which require that innovative approaches are found. They, in turn, "entail greater delegation of responsibility for HRM to ministries and agencies and to line managers, in order to enable them to develop new ways of working" 102. Therefore, it makes sense for line managers to be involved in the recruitment of the staff within their units, and even to have the final say in the ultimate phase of merit-based recruitment process for medium-level positions. It is important to strike the right balance between the oversight (or even control) needed to curb corruption and nepotism on the one hand - especially when recruiting from outside the civil service - and the strategic space that managers need in order to create a team which can deliver results.

The HRM process can also impact upon the budgetary processes where personnel and training budgets are held centrally within an organisation, and delegation to managers would require changes to those budgetary processes. Central control of personnel budgets can also mean that someone other than the manager takes decisions about personnel, and this causes damage to the processes of delegation and managerial accountability.

\section{Summary of SIGMA analysis}

In the Western Balkans, most governments have formal, and sometimes strict, control of (usually by the MoF) staffing plans, due to general efforts to impose budgetary discipline. The role of senior managers in the planning of human resources is recognised only at the level of providing inputs and making proposals.

Key barriers to developing managerial accountability in the domain of HRM stem either from the prominent role of ministers (and the heads of agencies) in staff recruitment and selection decision making or from the government-level centralisation of recruitment and

${ }^{100}$ Huerta Melchor, O. (2013), The Government Workforce of the Future: Innovation in Strategic Workforce Planning in OECD Countries, OECD Working Papers on Public Governance, No. 21, OECD Publishing, Paris, p. 5, http://dx.doi.org/10.1787/5k487727gwvb-en.

${ }^{101}$ Sundell, A. (2014), "Are formal civil service examinations the most meritocratic way to recruit civil servants? Not in all countries", in Public Administration, 92, pp.440-457, http://dx.doi.org/10.1111/padm.12077.

102 OECD (2015), Building on Basics: Value for Money in Government, OECD Publishing, Paris, p. 218, http://dx.doi.org/10.1787/9789264235052-en. 
selection processes, usually implemented precisely in order to reduce the nepotism associated with the involvement of politicians.

Regardless of the design and implementation of the recruitment procedures, in most administrations ministers (or directors, in the case of agencies) take the final decision on selection. Line managers do not feel empowered in this area, especially when recruitment is centralised to a specific government body. In the administrations with more decentralised recruitment procedures, senior managers are normally entitled to participate in the selection panels, which are in most cases appointed by the minister/agency director. A common problem undermining the role of line managers is the large amount of discretion allowed to the appointing authority (in most cases the minister or agency director) under the legislation.

\section{Recommendations}

1. Political leadership should remove itself from appointment decisions for nonmanagerial and middle-management positions ${ }^{103}$. This can be done through changes in the appropriate legislation.

2. The reforms of public sector recruitment procedures and practices should ensure that the depoliticisation and strengthening of the merit basis of recruitment go hand in hand with the professionalisation of both the procedures and the HRM support services. This can be achieved through more tailoring of the individual recruitment procedures to specific positions, by increasing the responsibility of direct supervisors, by training managers to conduct interviews in the final stages of the selection procedures, and by ensuring that trained and skilled HR (or other properly trained) specialists participate in the selection panels ${ }^{104}$. It is important that the direct supervisor of the recruited person has had a role in the selection procedure.

3. Recruitment and selection procedures should be made as open and transparent as possible, by one or more of the following means ${ }^{105}$ :

a. disclosing publicly the job descriptions, the selection criteria and the final appointment decisions

b. inviting experts and civil society representatives onto selection panels (using open procedures for their nomination and selection)

c. rendering the selection mechanisms transparent and clear enough that recruitment decisions are easily appealed against in the courts ${ }^{106}$.

103 OECD (2017), SIGMA, The Principles of Public Administration, OECD, Paris, PSHRM

Principle 3 , on the recruitment of public servants based on merit and equal treatment, sub-principle 3 , on selection committees with no political interference.

${ }^{104} \mathrm{Ibid}$. The selection committees should include persons with expertise and experience in assessing different sets of skills and competences of candidates for public service positions.

${ }^{105} \mathrm{Ibid}$. Principle 3, on the recruitment of public servants based on merit and equal treatment.

${ }^{106}$ Ibid. Principle 3, sub-principle 4, on the right to appeal against unfair recruitment decisions. 
A strong merit-based procedure is a key precondition for safe decentralisation of the recruitment and selection processes from the central government towards the organisational level. Given the lack of experience of the Western Balkan administrations with merit-based recruitment, it is wise to maintain a certain level of involvement of the central authorities in charge of HRM in the selection of staff. Ensuring that the testing and written selection procedures are of good quality and anonymised is one way to ensure that only high-quality, competent candidates enter the final selection phases, in which there may be more space for managerial decisions.

In these final phases, where recruitments to non-managerial or lower managerial positions are concerned, there is no justification for involving or giving decision-making powers to ministers and agency directors (at least for large agencies such as tax and customs).

Finally, one needs to go back to the importance of objectives and reporting, as key prerequisites for ensuring managers' accountability for results. Only if they are made fully accountable for the results they deliver will managers seek to ethically and correctly enforce any new powers in the recruitment processes - as their results (and their careers) then will depend on the abilities and skills of the staff they bring into their units.

\section{Detailed regional analysis}

\section{HR planning}

Various fiscal consolidation and austerity measures, as well as a general effort to impose fiscal discipline in the transition processes in the Western Balkans, have contributed to significant centralisation of the staff planning processes. Whereas certain bottom-up inputs have been made possible, most governments have formal, and sometimes strict, control (usually by the MoF) of staffing plans. In some administrations, the staffing plans have not even been adopted in the last years (notably Serbia), as specialised legislation with HR targets and limits was enacted to impose top-down controls of staffing levels.

In most administrations in the region, the role of senior managers in the planning of HR is recognised only at the level of providing inputs and making proposals. In those administrations with a tradition of "Acts on Internal Organisation and Job Systematisation" (all administrations except for Albania), the role of managers is slightly higher in the preparation of these acts, although the procedure for their development is not explicitly regulated. The managers' proposals are usually accepted to the maximum extent possible in the design of the sectors and units and in defining the numbers of staff, though some bargaining often takes place between the senior managers, for the distribution of the quota for specific types of positions (this practice is particularly present in Serbia, where the shares of the more senior expert-level civil service positions are limited by legislation for most state administration authorities).

Nevertheless, when it comes to the development of staffing plans, which represent the actual basis for recruitments ${ }^{107}$, the processes are far more top-down enforced, with the individual managers' role appearing tiny in comparison with the big picture of the fiscal controls imposed by the ministries of finance (Serbia, the former Yugoslav Republic of Macedonia, Kosovo) and/or ministries/departments of public administration (Kosovo,

${ }^{107}$ In Kosovo, the implementation of the staffing plans is low. In 2016 , only $42 \%$ of the vacancies included in the staffing plan were filled, although the proportion was higher in the managerial category, as reported in the 2017 SIGMA Monitoring report for Kosovo. 
Albania, the former Yugoslav Republic of Macedonia). The only administration where, despite central controls, the CHU has reported that managers enjoy more freedom to plan within a set budget, is Kosovo. There, senior managers can make changes in staff numbers, in line with government policies and based on the budget manual, during the preparation of budget circulars and the Medium-Term Expenditure Framework.

\section{Recruitment}

According to the senior managers who participated in the SIGMA focus group meetings, recruitment is the one area of HRM in which they do not feel empowered. In most administrations, regardless of the design and implementation of the recruitment procedures, it is ministers (or directors, in the case of agencies) who take the final decision. As stated by one of the senior managers: "the proposals are always ours, but the final decision is not".

Managers have been particularly removed from the process in Albania, where the recruitment procedures have been the most centralised, compared with the rest of the region, in an effort to fight politicisation. The Albanian CHU reports that "the timeline for recruitment, shortlisting of candidates, decision on the appointment etc., are all processes co-ordinated by the Public Administration Department in accordance with the laws and regulations in force."

In the administrations with more decentralised recruitment procedures, senior managers and relevant line managers are normally entitled to participate in selection panels, which are in most cases appointed by the minister/agency director (with the exception of Kosovo, where these appointments in ministries are made by secretaries general $)^{108}$. In the former Yugoslav Republic of Macedonia and Montenegro, participation by the manager of the unit making the appointment (though not necessarily a senior manager) is a requirement, whereas in $\mathrm{BiH}$ and Serbia this is merely an option, though common practice. A particular problem observed in Montenegro is that politically appointed persons can be members of the selection panels ${ }^{109}$. This provision both undermines the merit character of the selection procedure and limits the scope for operational managers to fulfil their role in it (and thus limits their managerial accountability).

\footnotetext{
${ }^{108}$ The composition of the committee is proposed by the HR unit of the institution and approved by the highest administrative authority of the institution. OECD (2017), SIGMA, Monitoring Report: Kosovo, OECD, Paris, p. 65.

${ }^{109}$ Professional composition of selection committees is not fully guaranteed because the CSL does not establish the obligation of the representative of the employment authority to be a civil servant, CSL, article 42. OECD (2017), SIGMA, Monitoring Report: Montenegro, OECD, Paris, p. 62.
} 
Table 3. Decision matrix in the procedure for recruiting civil servants (non-senior levels) in Western Balkan administrations

\begin{tabular}{|c|c|c|c|c|c|c|}
\hline & Albania & $\mathrm{BiH}$ (State) & Kosovo & $\begin{array}{l}\text { Former } \\
\text { Yugoslav } \\
\text { Republic of } \\
\text { Macedonia }\end{array}$ & Montenegro & Serbia \\
\hline $\begin{array}{l}\text { Deciding the criteria } \\
\text { for applicants }\end{array}$ & $\begin{array}{l}\text { 2nd level } \\
\text { managers in } \\
\text { ministries }\end{array}$ & $\begin{array}{l}\text { Minister, } \\
\text { Director }{ }^{110}\end{array}$ & $\begin{array}{l}2^{\text {nd }} \text { level } \\
\text { managers in } \\
\text { ministries } \\
\text { Managers at } \\
1 \text { st level below } \\
\text { agency heads }\end{array}$ & Minister ${ }^{111}$ & $\begin{array}{l}2^{\text {nd }} \text { level } \\
\text { managers in } \\
\text { ministries }{ }^{112} \\
\text { Managers at } \\
\text { 1st level below } \\
\text { agency heads }\end{array}$ & $\begin{array}{l}2^{\text {nd }} \text { level } \\
\text { managers in } \\
\text { ministries }{ }^{113} \\
\text { Managers at } \\
1^{\text {st level below }} \\
\text { agency heads }\end{array}$ \\
\hline $\begin{array}{l}\text { Setting the } \\
\text { recruitment timeline }\end{array}$ & $\begin{array}{l}\text { Department } \\
\text { of Public } \\
\text { Administration }\end{array}$ & $\begin{array}{l}1 \text { st level } \\
\text { managers in } \\
\text { ministries } \\
\text { Managers at } \\
2^{\text {nd }} \text { level below } \\
\text { agency heads }{ }^{114}\end{array}$ & $\begin{array}{l}2^{\text {nd }} \text { level } \\
\text { managers in } \\
\text { ministries }\end{array}$ & $\begin{array}{l}\text { Minister }{ }^{115} \text {, } \\
\text { Director }\end{array}$ & $\begin{array}{l}\text { Minister (signs } \\
\text { the decisions to } \\
\text { start procedure) } \\
\text { Director }\end{array}$ & $\begin{array}{l}2^{\text {nd }} \text { level } \\
\text { managers in } \\
\text { ministries } \\
\text { Managers at } \\
1 \text { st level below } \\
\text { agency heads }\end{array}$ \\
\hline $\begin{array}{l}\text { Shortlisting of } \\
\text { candidates }\end{array}$ & $\begin{array}{l}\text { Department } \\
\text { of Public } \\
\text { Administration }\end{array}$ & $\begin{array}{l}\text { Selection } \\
\text { panel }{ }^{116}\end{array}$ & $\begin{array}{l}2^{\text {nd }} \text { level } \\
\text { managers in } \\
\text { ministries }\end{array}$ & $\begin{array}{l}2^{\text {nd }} \text { level } \\
\text { managers in } \\
\text { ministries } \\
\text { (or lower } \\
\text { managers) }{ }^{117}\end{array}$ & $\begin{array}{l}\text { Human } \\
\text { Resource } \\
\text { Management } \\
\text { Authority }\end{array}$ & $\begin{array}{l}2^{\text {nd }} \text { level } \\
\text { managers in } \\
\text { ministries (or } \\
\text { lower managers) } \\
\text { Managers at } \\
\text { 1st level below } \\
\text { agency heads } \\
\text { (or lower } \\
\text { managers) }\end{array}$ \\
\hline $\begin{array}{l}\text { Participation in } \\
\text { interviews/panels }\end{array}$ & $\begin{array}{l}1 \text { st level } \\
\text { managers in } \\
\text { ministries }\end{array}$ & $\begin{array}{l}1 \text { st level } \\
\text { managers in } \\
\text { ministries } \\
2^{\text {nd }} \text { level } \\
\text { managers in } \\
\text { ministries }\end{array}$ & $\begin{array}{l}1^{\text {st }} \text { level } \\
\text { managers in } \\
\text { ministries } \\
2^{\text {nd }} \text { level } \\
\text { managers in } \\
\text { ministries }\end{array}$ & $\begin{array}{l}2^{\text {nd }} \text { level } \\
\text { managers in } \\
\text { ministries (or } \\
\text { lower managers) }\end{array}$ & $\begin{array}{l}2^{\text {nd }} \text { level } \\
\text { managers in } \\
\text { ministries (or } \\
\text { lower managers) }\end{array}$ & $\begin{array}{l}2^{\text {nd }} \text { level } \\
\text { managers in } \\
\text { ministries (or } \\
\text { lower managers) }\end{array}$ \\
\hline
\end{tabular}

${ }^{110}$ By approving the Rulebook on Internal Organisation and Systematisation.

${ }^{111}$ Approves the Rulebook on Internal Organization and Systematization.

${ }^{112}$ Managers make proposals through the Act on Internal Organisation and Systematisation, though this is rather an informal practice, not a regulated one. The Acts are finally approved by the Government.

${ }^{113}$ Managers make proposals through the Act on Internal Organisation and Systematisation, although this is rather an informal practice, not a regulated one. The Acts are finally approved by the Government.

${ }^{114}$ First-level managers in Ministries just decide on the date of public announcement as the Agency for Civil Service takes over the procedure from that point on.

${ }^{115}$ Signs the decisions for initiating the procedure.

${ }^{116}$ The selection panel is established by the Decision of the Civil Service Agency (CSA) and two members of the panel are appointed by the institution while three members are appointed by the CSA.

${ }^{117}$ The Commission in the Civil Servants Agency is made up of one member from CSA and from the institution. 


\begin{tabular}{|c|c|c|c|c|c|c|}
\hline & Albania & BiH (State) & Kosovo & $\begin{array}{l}\text { Former } \\
\text { Yugoslav } \\
\text { Republic of } \\
\text { Macedonia }\end{array}$ & Montenegro & Serbia \\
\hline & & $\begin{array}{l}\text { Managers at } \\
1 \text { st level below } \\
\text { agency heads }\end{array}$ & $\begin{array}{l}\text { Managers at } \\
\text { 1st level below } \\
\text { agency heads }\end{array}$ & & $\begin{array}{l}\text { Managers at } \\
\text { 1st level below } \\
\text { agency heads } \\
\text { (or lower } \\
\text { managers) }\end{array}$ & $\begin{array}{l}\text { Managers at } \\
\text { 1st level below } \\
\text { agency heads } \\
\text { (or lower } \\
\text { managers) }\end{array}$ \\
\hline $\begin{array}{l}\text { Suggesting a } \\
\text { preferred candidate }\end{array}$ & $\begin{array}{l}1 \text { st level } \\
\text { managers in } \\
\text { ministries }\end{array}$ & $\begin{array}{l}\text { 1st level } \\
\text { managers in } \\
\text { ministries } \\
2^{\text {nd }} \text { level } \\
\text { managers in } \\
\text { ministries } \\
\text { Managers at } \\
\text { 1stlevel below } \\
\text { agency heads }\end{array}$ & $\begin{array}{l}2^{\text {nd }} \text { level } \\
\text { managers in } \\
\text { ministries } \\
\text { Managers at } \\
1^{\text {st level below }} \\
\text { agency heads }\end{array}$ & $\begin{array}{l}2^{\text {nd }} \text { level } \\
\text { managers in } \\
\text { ministries (or } \\
\text { lower managers) }\end{array}$ & $\begin{array}{l}2^{\text {nd }} \text { level } \\
\text { managers in } \\
\text { ministries } \\
\text { (confirmed by } \\
\text { first level) } \\
\text { Managers at } \\
1^{\text {st level below }} \\
\text { agency heads }\end{array}$ & $\begin{array}{l}2^{\text {nd }} \text { level } \\
\text { managers in } \\
\text { ministries } \\
\text { Managers at } \\
1^{\text {st level below }} \\
\text { agency heads }\end{array}$ \\
\hline $\begin{array}{l}\text { Deciding on the } \\
\text { appointment } \\
\text { (including signing the } \\
\text { appointment) }\end{array}$ & $\begin{array}{l}\text { Department } \\
\text { of Public } \\
\text { Administration }\end{array}$ & $\begin{array}{l}\text { Minister, } \\
\text { Director }\end{array}$ & $\begin{array}{l}\text { 1st level } \\
\text { managers in } \\
\text { ministries }\end{array}$ & $\begin{array}{l}\text { Minister, } \\
\text { Director }\end{array}$ & $\begin{array}{l}\text { Decision by } 1 \text { st } \\
\text { or } 2^{\text {nd level lel }} \\
\text { managers in } \\
\text { ministries, but } \\
\text { final formal act } \\
\text { signed by } \\
\text { minister (or head } \\
\text { of agency) }\end{array}$ & $\begin{array}{l}\text { Minister, } \\
\text { Director }\end{array}$ \\
\hline
\end{tabular}

Note: Certain data is not presented in this table, particularly for agencies, as it could not be obtained at the data collection and factchecking stage.

Source: CHUs' responses to questionnaires, combined with SIGMA expert inputs.

Another common problem undermining the role of managers is the large amount of discretion allowed to the appointing authority (in most cases the minister or agency director) under the legislation. In Montenegro, final appointments are made by a minister or head of agency, who signs the final act "rješenje", following interviews with at least three best-ranked candidates, without any obligation to disclose the justification for not selecting the best-ranked candidate. However, the latest amendments to the Law on Civil Servants and State Employees (which had not yet been put into practice at the time of writing) envisage that the authority to decide on the selection is to be delegated to senior civil servants (second-level managers) in the ministries and managers at the first level below the director in the agencies. In Serbia, although ministers do not participate in selection panels or interviews, the procedure leaves them substantial scope to influence recruitment outcomes ${ }^{118}$. Kosovo is an exception when it comes to ministries, as the final decision on recruitment is signed by the general secretary of the ministry (i.e. second-level manager below the minister $)^{119}$.

It should be emphasised that the existing scope for managerial input into the recruitment of staff over the past years has been further hampered in several administrations by recruitment freezes. In Serbia, in the wake of the fiscal consolidation and austerity measures, a central government commission for the approval of recruitments was

${ }^{118}$ OECD (2017), SIGMA, Monitoring Report: Serbia, OECD, Paris, p. 59.

${ }^{119}$ When it comes to agencies, though, this role is performed by the general directors of agencies under ministries. 
established in 2013, and in the former Yugoslav Republic of Macedonia, there was an employment freeze in 2016, due to the political deadlock in the administration. In Montenegro, recruitment procedures are always frozen in the run-up to elections. In the view of one senior manager interviewed, in this kind of a situation one "needs to be a managerial genius to fulfil all requirements".

\subsubsection{Staff appraisals, objectives and links to promotion and salaries}

\section{Why it is important}

The linking of organisational objectives with individual/personal objectives vertically within an organisation is a key element of a performance management system which supports managerial accountability. This is because managers need to be able to properly and correctly assess the performance of their staff in order to be accountable for their own performance. At the same time, "all employees need and deserve to know how they are performing, to motivate them by highlighting their strengths, to help them improve by pinpointing their weaknesses, to help them develop by identifying gaps in their abilities, and to signal when they might be ready for promotion" ${ }^{120}$. HRM tools such as performance appraisal, professional training and development "are needed not only to attract valuable employees to the public service but also to retain them and motivate them to achieve the strategic goals of the state" 121 .

It is important to ensure that senior managers have the key responsibility in setting the objectives for their own staff (in consultation with the staff members rather than top-down) and that those objectives are based on their own individual objectives. The quality of the objectives is of particular importance here, as they need to reflect the scope of work of the unit, but still measure the results of the work of the staff, rather than just repeat the job descriptions. This is important, as only SMART objectives with clearly set targets can serve as a good basis for measuring performance and then show how the performance of the staff in a unit contributes to the performance of the manager.

Performance pay is probably one of the most contested issues with regard to the introduction of managerial accountability systems in pre-accession administrations. On the one hand, "pay is an important management tool, and the strongest motive for decentralised pay setting is that public managers need to have access to and a willingness to use this tool, if they are to be able to pursue performance and result-based goals. Relative differences in pay and pay adjustments can be used to signal expectations and to reward good behaviour and good performances - or to punish bad behaviour" ${ }^{22}$. On the other hand, flexibility

${ }^{120}$ European Commission (2017), Quality of Public Administration: A Toolbox for Practitioners, 2017 edition, Publications Office of the European Union, Luxembourg, p. 91, http://ec.europa.eu/s ocial $/$ main.jsp? catId=738\&langId $=$ en \&pubId $=8055 \&$ type $=2 \&$ furtherPubs $=$ no.

121 OECD (2017), SIGMA, The Principles of Public Administration, OECD, Paris, p. 44. See also: OECD (2011), Public Servants as Partners for Growth: Toward a Stronger, Leaner and More Equitable Workforce, OECD Publishing, Paris, http://dx.doi.org/10.1787/9789264166707-en.

122 Rexed, K. et al. (2007), "Governance of decentralised pay setting in selected OECD countries", OECD Working Papers on Public Governance, No. 3, OECD Publishing, Paris, p. 29,

http://dx.doi.org/10.1787/210083427643. See also: OECD (2005), Performance-related Pay Policies for Government Employees, OECD Publishing, Paris, https://doi.org/10.1787/9789264007550-en. 
pertaining to salaries and bonuses of staff reduces the general predictability and even transparency of the overall salary system in an administration and it can create a risk of cronyism and nepotism. Moreover, if applied in a poor managerial environment, it can be quite counterproductive and lead to a decrease in staff motivation, especially if managers use such powers to financially reward personal or even political favourites. Earlier research found that "performance pay schemes may also introduce an element of political control over a career civil service" and that "even if such schemes are fairly administered, it is next to impossible to prevent the perception of favouritism" 123 .

It is also important to distinguish between flexibility to set salaries on the one hand, and authority to award bonuses or increase civil servants' salary increments (within a prescribed salary category for a civil service rank), on the other hand. Whereas the elements of base salaries of civil servants are normally defined in legislation according to certain ranks/grades of the service ${ }^{124}$, bonuses or pay rank/grade increases can be subject to some managerial discretion. As the Principles of Public Administration require, "managerial discretion in assigning different elements of salary, allowances and benefits to individual public servants [should be] limited, to ensure fairness, transparency and consistency of the total pay" ${ }^{25}$. SIGMA thus proposes limitations to managers' level of discretion in setting bonuses ${ }^{126}$. They need to be tightly regulated and kept to a limited share of total income ${ }^{127}$. as well as being clearly linked to performance.

On the whole, provided that the right preconditions are put in place and that certain caveats are accounted for, allowing managers to take some pay-related decisions is a manifestation of managerial accountability and an important tool for them to stimulate performance of their team. More on those preconditions and caveats is provided below under "Recommendations".

\section{Summary of SIGMA analysis}

The key challenge to managerial accountability in the area of personnel performance measurement is the fact that the appraisal systems and procedures are not properly used to assess actual performance. The common problems across the region are the poor quality of objectives for staff and the tendency to award high grades and conduct either completely formalistic or unrealistic appraisals of staff. As a consequence, performance appraisal is

123 OECD (2007), SIGMA, Performance Related Pay in the Public Service in OECD and EU Member States, OECD Publishing, Paris, http://www.sigmaweb.org/publications/38690351.pdf.

124 Those basic salaries need to be clearly formulated and transparent, based on publicly available primary and secondary legislation. Such a pay system in the civil service is a necessary precondition for the establishment of the general accountability culture in a state and society.

${ }^{125}$ OECD (2017), SIGMA, The Principles of Public Administration, OECD, Paris, PSHRM Principle 5, sub-principle 4.

126 OECD (2017), SIGMA, Methodological Framework for the Principles of Public Administration, OECD, Paris, http://www.sigmaweb.org/publications/MethodologicalFramework-for-the-Principles-of-Public-Administration-November-

2017.pdf, Indicator 3.5.1: Fairness and competitiveness of the remuneration system for civil servants, sub-indicator 6 .

${ }^{127} \mathrm{Ibid}$. Up to $20 \%$, as stipulated under sub-indicator 6 on managerial discretion in the allocation of bonuses. 
perceived as a burden, with little value, and does not contribute to developing managerial accountability.

Although the legal preconditions are largely in place, they do not necessarily enable or stimulate actual implementation. Performance appraisals are not systematically implemented in all of the region's administrations. Managers tend to give the highest grades to their subordinates as a rule rather than as an exception, which is a strong sign of the weak managerial culture in the region.

In such circumstances, it is clear that performance appraisal cannot serve as a management tool for assessing and awarding good performance. Furthermore, the actual integration of the objectives and appraisals into professional development for civil servants is weak in most of the region.

The legislation and practices with regard to salary systems vary considerably across the region. In several administrations, the salary systems are currently undergoing reforms. In the majority of administrations, the salary level is directly linked to the rank/position of a civil servant, which means that essentially senior managers do not have a role in determining salary levels beyond their role in promoting and/or reassigning staff to other positions/ranks.

Most of the administrations have prescribed either the option of awarding bonuses or at least provisions which allow salary incremental steps to be increased as a result of good performance. However, legislation has in some cases not been implemented, and the situation has also been affected by the financial austerity measures of recent years.

\section{Recommendations}

1. The experiences and lessons learned among managers and HRM specialists (including those in the private sector) should be shared in order to find out why performance appraisals are more successful in some organisations than in others and to draw conclusions as to the key reasons why these procedures do not work.

2. Bearing in mind the many problems with performance appraisal systems across EU member states, and the constant quest for new and better solutions128, the proposals for the Western Balkan administrations should be realistic and designed in a way that provides simple but useful information for managers and supports to the maximum extent possible the building of a culture of trust. In line with the emerging EU good practices, innovative solutions might involve performance dialogue, without a performance appraisal focus, in order to strengthen the relations between managers and subordinates at all levels (including between political-level and senior managers).

3. The training programmes for managers should be strengthened across the region and made obligatory. HRM, in particular the setting of objectives for staff and performance appraisals, needs to feature strongly in the management and leadership

\footnotetext{
${ }^{128}$ For a detailed overview of the EU member state practices in performance appraisal, please refer to: Staroňová, K. (2017), Performance Appraisal in the EU Member States and the European Commission, Government Office of Slovakia, Bratislava, and Demmke, C. (2007), Performance Assessment in the Public Services of the EU Member States: Procedure for performance appraisal, for employee interviews and target agreements, Study for the 48th meeting of the Directors-General of the Public Service of the Member States of the European Union, European Institute of Public Administration, Maastricht.
} 
programmes across the region. Moreover, HRM units and central HRM institutions should be charged with providing regular on-the-job training and mentoring for managers on the implementation of these practices.

Increasing managerial accountability through modern (and functioning) HRM practices may need to go hand in hand with the simplification of the performance appraisal procedures, so as to make them less of an administrative burden on managers, and more of a tool for providing feedback to one's staff and pointing them in the right direction in terms of personal and professional development.

Essentially, the most important condition for the avoidance of these negative effects would be to make managers' careers truly dependent on the results of their units, through strong links between individual performance objectives and organisational performance objectives.

Performance pay, despite being an important managerial tool for stimulating the achievement of objectives, is particularly prone to favouritism and even corruption, unless preceded by sound performance measurement tools and skills and coupled with strong monitoring/oversight mechanisms. Therefore, steps towards developing such tools need to be taken with maximum caution and in the proper order. Any future moves towards the introduction of the elements of performance pay would need to start from the development of strong criteria and functional oversight mechanisms, followed by training and coaching for managers on how to properly apply these tools, and only then rolling out performance pay tools in the administration, with the support of HR units.

\section{Detailed regional analysis}

\section{Setting objectives for staff and performance appraisal}

The legal framework for setting the objectives and implementing performance appraisals is largely present and well developed across the region. In all administrations, the basic requirements for a professional appraisal procedure have been reported ${ }^{129}$, although with some deficiencies. For example, in Montenegro, transparent criteria for the appraisals are missing ${ }^{130}$. In Albania, there are no specific guidelines for managers on how to conduct the appraisals, beyond the regulations ${ }^{131}$. In Kosovo, the requirement to record results of the appraisals in written form is not set in the legislation ${ }^{132}$.

Yet despite the largely solid legislative framework, performance appraisals are not systematically implemented in all of the region's administrations. In Kosovo, only $64 \%$ of civil servants were appraised in 2016 (although this is an improvement compared to the previous years), and in Montenegro 69\%. ${ }^{133}$ In the Brčko District in $\mathrm{BiH}$, no performance appraisals are done ${ }^{134}$. Serbia was the only administration which reported over $90 \%$

${ }^{129}$ Data collected by SIGMA for the 2017 SIGMA Monitoring Reports.

${ }^{130}$ OECD (2017), SIGMA, Monitoring Report: Montenegro, OECD, Paris, p. 70.

${ }^{131}$ Based on the data collected by SIGMA for the 2017 Monitoring Report for Albania.

132 Ditto.

${ }^{133}$ Data collected and analysed by SIGMA for the 2017 SIGMA Monitoring Reports.

134 OECD (2017), SIGMA, Monitoring Report: Bosnia and Herzegovina, OECD, Paris, p. 71. 
coverage of the civil service by performance appraisals. Three administrations did not report data for the 2017 assessment on this criterion, including the former Yugoslav Republic of Macedonia, where implementation of the new appraisal system has just started, albeit partially, and in 2016 a freeze on all potentially politically sensitive HR procedures resulted in no appraisals being carried out ${ }^{135}$.

Managers tend to give out the highest grades to their subordinates as a rule rather than as an exception, which is a strong sign of the weak managerial culture in the region. Only in Montenegro and Kosovo was the proportion of employees receiving the two highest categories of grades lower than $60 \%$ (48.5\% in Montenegro and $58 \%$ in Kosovo $)^{136}$. Montenegro, however, has shown a sharply increasing trend in highest grades over the last three years. In other administrations, the figures go as high as $90 \%$ in Serbia, $96 \%$ in Albania and $98 \%$ at the State level in $\mathrm{BiH}$. In such circumstances, it is clear that performance appraisal cannot serve as a management tool for assessing and awarding good performance. In some cases (e.g. Albania), it has been reported that managers have at least started to use performance appraisals to identify training needs in their respective institutions, which is a positive development ${ }^{137}$.

Furthermore, where conducted, the actual integration of the objectives and appraisals into professional development for civil servants is weak in most of the region, with the partial exception of Albania and Kosovo (see Figure 6) ${ }^{138}$. In Albania, performance appraisals are linked by legislation to vertical promotion and to possible dismissals (but not to salary steps). In Kosovo, they are linked to promotions (which are implemented in practice), dismissals (generally not practised) as well as salary steps (however, the legislation on salary steps is not implemented). In Montenegro, Serbia and the former Yugoslav Republic of Macedonia, links are rarely or never practised, whereas in $\mathrm{BiH}$, despite the existence of links in the legislation at all levels, no evidence of such links in practice has been found.

${ }^{135}$ OECD (2017), SIGMA, Monitoring Report: the former Yugoslav Republic of Macedonia, OECD, Paris, p. 50.

${ }^{136}$ Data collected by SIGMA during the 2017 assessment. It should be noted, however, that for Montenegro only the highest grade ("excellent") was awarded, as the next lower grade ("good") is described in the legislation as an average grade (there being only four grade levels in Montenegro). For Kosovo, with 5 grade levels, the two highest levels were awarded. The percentage is still too high considering that, according to the Regulation on performance appraisals, managers may award the 'excellent' grade to only $5 \%$ of their staff and 'very good' to only $15 \%$.

${ }^{137}$ OECD (2017), SIGMA, Monitoring Report: Albania, OECD, Paris, p. 78.

138 The elements of development which were analysed are: training, mobility and promotion; dismissals; financial rewards (e.g. bonuses); non-financial rewards (e.g. public recognition) or specific measures to address negative results. 
Figure 6. Performance appraisal and its use in the Western Balkans

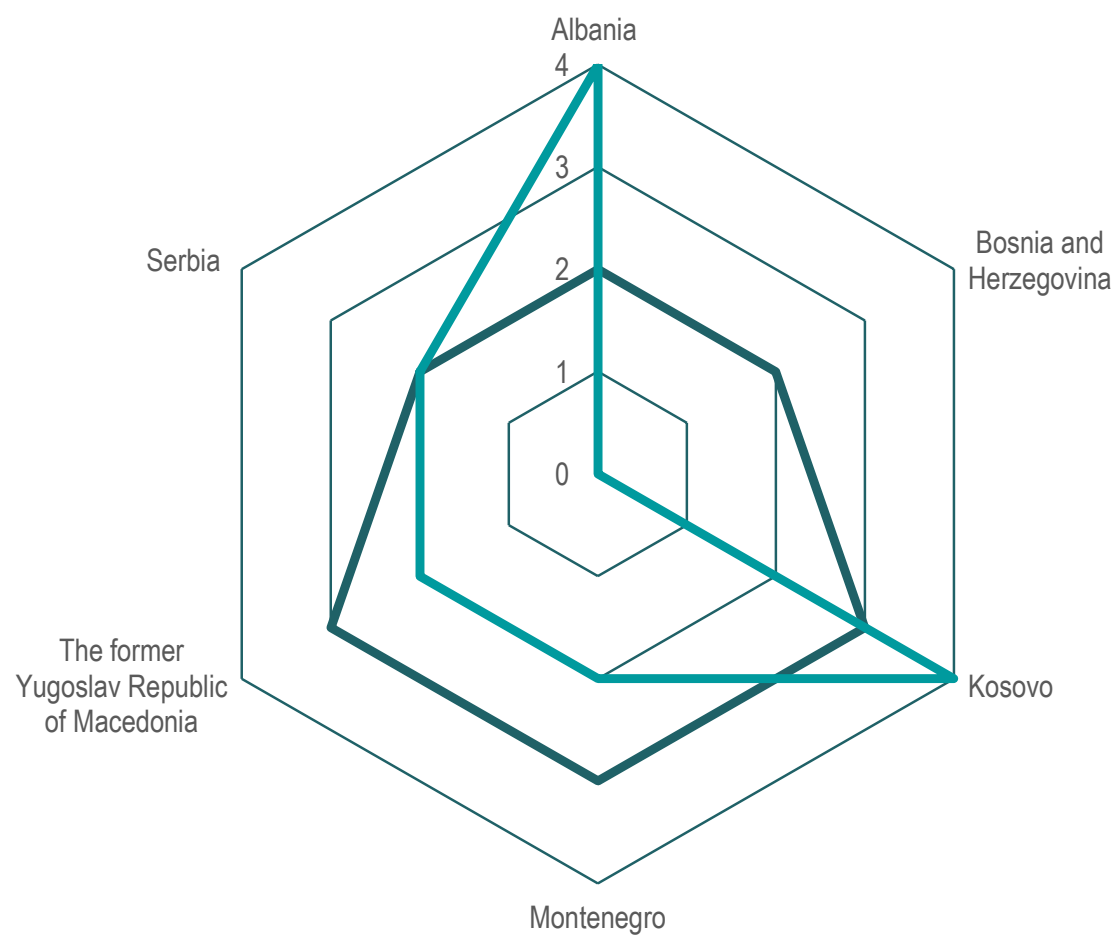

Note: The maximum points for these two sub-indicators is 4 and the minimum 0 .

Source: Collation of indicator values from 2017 SIGMA Monitoring Reports for Albania, Bosnia and Herzegovina, Kosovo, Montenegro, the former Yugoslav Republic of Macedonia and Serbia.

The practical reasons for the poor practices in performance appraisal across the region range from a lack of support provided to managers by HRM units and insufficient training of managers on these issues, to cultural pressures, such as fear of confrontation or a wish to present one's own unit as equally or more successful than other units ${ }^{139}$. Also, performance appraisals can be a time-consuming exercise for managers, especially if they are to do them well, which means that they need to be fully aware of the benefits, as well as being able and permitted to access those benefits. Yet in some administrations in recent years there have been restrictions and freezes on promotions for financial and electionrelated reasons (in Serbia and the former Yugoslav Republic of Macedonia respectively).

${ }^{139}$ Based on SIGMA focus group meetings with senior managers. 


\section{Relationship between performance and salary}

The legislation and practices with regard to salary systems vary considerably across the region. In several administrations, particularly in Albania, Kosovo and Serbia, the salary systems are currently undergoing reforms.

Most of the administrations have prescribed either the option of awarding bonuses or at least provisions which allow salary incremental steps to be increased as a result of good performance. However, this legal possibility has in most cases not been implemented, and the situation has also been affected by the financial austerity measures of recent years. As a result, the progression through salary grades has been stopped in Serbia and in the former Yugoslav Republic of Macedonia, no bonuses were paid in 2016. In Albania, despite a legal framework (Civil Service Law) which foresees performance-related progression, in reality, none of the salary components (except the seniority supplement) allow for salary upgrading without moving to another position. Neither the results of individual civil servants' performance appraisals nor mandatory training programmes are yet connected to the awarding of salary increments ${ }^{140}$.

Whereas in Albania, the FBiH, Kosovo and Serbia no bonuses are paid to civil servants, in Montenegro, they are paid but are based on unclear criteria. In fact, the law includes bonuses for exceptional results and quality of work but does not set any criteria, procedures or ceilings ${ }^{141}$. The former Yugoslav Republic of Macedonia is the only administration in which the system is well regulated, however, it was not implemented in 2016 due to a freeze on payments of bonuses ${ }^{142}$. Bonuses can be awarded in the case of exceptional performance, but it really is an exception in practice, with only $5 \%$ of administrative staff receiving bonuses, and their value is limited to the equivalent of one month of the recipient's salary.

In the majority of administrations, the salary level is directly linked to the rank/position of a civil servant, which essentially means that senior managers do not have a role in determining salary levels beyond their role in promoting and/or reassigning staff to other positions/ranks (which is discussed in other sections of this Paper). In Serbia, however, based on the Law on Salaries of Civil Servants still in force, salary levels are also dependent on performance appraisal in terms of horizontal progression (progression through salary grades). However, that system is no longer implemented as envisaged by the Law, due to the austerity measures of recent years.

The table below, based on the information collected from the administrations' CHUs, shows the weak role of managers in determining the salary levels for their employees, as in most cases they are only informed of them.

\footnotetext{
${ }^{140}$ OECD (2017), SIGMA, Monitoring Report: Albania, OECD, Paris, p. 76.

${ }^{141}$ OECD (2017), SIGMA, Monitoring Report: Montenegro, OECD, Paris, p. 68.

${ }^{142}$ OECD (2017), SIGMA, Monitoring Report: Former Yugoslav Republic of Macedonia, OECD, Paris, p. 65 .
} 
Table 4. Roles in determining the salary level of employees

\begin{tabular}{lllll} 
& Minister & $\begin{array}{l}\text { First level below } \\
\text { minister }\end{array}$ & $\begin{array}{l}\text { Second level below } \\
\text { minister }\end{array}$ & Head of agency \\
\cline { 2 - 5 } Albania & Participates & Consulted & Informed & Informed \\
\hline BiH (State) & Informed & Informed & Informed & Informed \\
\hline BiH (Federation) & Informed & Informed & Informed & Informed \\
\hline BiH (RS) & No data & No data & No data & No data \\
\hline Kosovo & Proposes & N/A & Informed & Informed \\
\hline $\begin{array}{l}\text { The former Yugoslav } \\
\text { Republic of Macedonia }\end{array}$ & Fully decides & N/A & N/A & N/A \\
\hline Montenegro & Informed & Informed & Informed & Informed \\
\hline Serbia & Proposes & Informed & Informed & Participates \\
\hline
\end{tabular}

Source: CHU questionnaire responses.

\section{Managers' role in awarding bonuses and supplements}

According to focus group discussions, senior managers across the region are in agreement that they do not have the means to financially reward/motivate their best-performing staff members. Even where bonuses are legally allowed, recent fiscal restrictions have annulled this possibility (in the former Yugoslav Republic of Macedonia).

In some cases, various salary supplements are used as a substitute for the missing bonuses. In Kosovo, salary supplements can amount to as much as $50 \%$ of the base salary ${ }^{143}$. In addition, in several administrations (Albania, Kosovo and the former Yugoslav Republic of Macedonia) market supplements have been introduced for IT or other specialised jobs, but are reportedly in some cases misused, i.e. allocated to persons working in positions not covered by these regulations ${ }^{144}$. Such misuse of available financial stimulations points to a weakness of control and oversight mechanisms and drives salary policies to become more rigid and less performance-based in an effort to stimulate transparency (through simplicity) and curb nepotism and corruption.

A marked contrast to this tendency is presented by the Montenegrin system, which recognises both bonuses (up to $50 \%$ of the previous year's total salary, performancerelated) and various supplements (up to $45 \%$ of the base salary), without setting clear criteria for their award, therefore allowing a high level of managerial discretion in their allocation $^{145}$, although the decisions are often taken at the highest level.

The table below, based on the responses collected from the CHUs, shows that the role of managers is mainly to propose/nominate, while in no administration do managers decide on the bonuses of their staff (where they exist).

${ }^{143}$ OECD (2017), SIGMA, Monitoring Report: Kosovo, 2017, p. 73.

${ }^{144}$ Based on focus group discussions with senior managers, Paris, November 2017.

145 The secondary legislation sets forth only that the person entitled to make the decision on the variable pay will decide on the fulfilment of conditions and on the amount in each case. OECD (2017), SIGMA, Monitoring Report: Montenegro, 2017, p. 68. 
Table 5. Role of managers in awarding bonuses

\begin{tabular}{lllll}
\hline & Minister & $\begin{array}{l}\text { First level below } \\
\text { minister }\end{array}$ & $\begin{array}{l}\text { Second level below } \\
\text { minister }\end{array}$ & Head of agency \\
\cline { 2 - 5 } Albania & N/A (no bonuses) & N/A & N/A & N/A \\
\hline BiH (State) & Fully decides & Co-decides & Proposes/ & \\
\hline BiH (Federation) & Nominates & Fully decides & & Informed \\
\hline BiH (RS) & Informed & Informed & Informed & No data \\
\hline Kosovo & No data & No data & No data & No data \\
\hline $\begin{array}{l}\text { The former Yugoslav } \\
\text { Republic of Macedonia }\end{array}$ & Proposes/Nominates & No data & No data & No data \\
\hline Montenegro & Fully decides & No data & No data & Fully decides \\
\hline Serbia & Fully decides & Proposes/Nominates & Participates & \\
\hline
\end{tabular}

Source: CHU questionnaire responses.

\subsubsection{Termination and dismissal and the reallocation of roles and functions}

\section{Why it is important}

Having the ability to influence the structure and composition of one's team, and to remove underperformers from the team, is an important ingredient in a manager's space to stimulate and reward performance. The way in which people are allocated to the different roles in a team, and whether the assigned roles are well-aligned with the objectives set for the entire unit, strongly affects a manager's ability to steer the achievement of the whole team. Keeping people in positions where they are obstructing the ability of the manager to get the most out of the team can be just as demotivating, for both the manager and the team, as keeping people in the team who repeatedly show a lack of effort, skills or discipline. In addition to demotivating staff, poor performers hamper the achievement of objectives, which is a major concern for managers with managerial accountability.

Nevertheless, the autonomy in this regard constitutes probably the largest difference between public sector (especially civil service) and private sector managers. Civil service legislation is particularly protective when it comes to termination and dismissal, but reallocation is also often strictly regulated, in order to protect civil servants from undue political pressures. Indeed, the Principles of Public Administration require that "objective criteria for the demotion of public servants and termination of the public service relationship are explicitly established in law" ${ }^{\text {"146. }}$. Moreover, the mobility of public servants, although encouraged, is required to be "established in legislation, based on objective and transparent criteria" ${ }^{147}$.

As a result of tight regulation, civil service laws are often seen by managers as "obstacles" to their work and their ability to maximise the performance of their teams. Nevertheless, public sector managers need to manage their units even in such restrictive environments and to demonstrate skill in managing the composition of their teams despite these circumstances. Essentially, the civil service system needs to strike the right balance between protecting people from undesirable politically motivated interference with their

146 OECD (2017), SIGMA, The Principles of Public Administration, OECD, Paris, PSHRM

Principle 3, sub-principle 6.

${ }^{147}$ Idem. PSHRM Principle 6, sub-principle 6. 
professional work and creating a crippled environment in which people are permanently stuck in their position with virtually no possibility of moving or dismissing them.

\section{Summary of SIGMA analysis}

The rules on reallocating staff within an organisation, and thus its units, are in most administrations thoroughly regulated. The legislative frameworks thus include rules for reassigning staff, particularly to lower-level positions. In some cases, senior managers have reported that it is particularly difficult to remove the heads of lower-level units in cases of poor performance. Other lateral types of reallocations are more flexible and can in most administrations be done either through individual reassignments or through changes of the acts on internal organisation. In most administrations, the decisions on reallocations are formally taken by ministers. Managers from the region are largely in agreement that apart from proposing changes in the assigned roles and functions in their units, they do not have authority in this regard.

Termination of employment or dismissal of civil servants is another thoroughly regulated procedure in all of the administrations' civil service legislation. Involuntary terminations are generally not widely used by managers across the region, except in cases where they are imposed for political reasons. The explanation for this, apart from the excessively demanding legal requirements in some cases, is that they are unpopular within the local administrative culture, or because of the generally improper application of the performance appraisal procedures.

\section{Recommendations}

1. Ministers should be excluded from individual dismissal decisions for nonmanagerial positions ${ }^{148}$. Politicians would continue to take policy decisions on the downsizing of the administration, but not decide on individual dismissals. A strong and fair appeals procedure which is devoid of political interference should be ensured $^{149}$.

2. In order to address a common problem with a lack of dialogue and openness in HR procedures, senior managers should be trained and coached on the use of HR procedures in order to better manage their units and the staff below them, to maintain or increase motivation of staff and to boost the achievement of objectives. If managers are skilled in HRM, termination will be the last resort, used only when the performance appraisal, professional development and other tools have failed. This needs to go hand in hand with the professionalisation of the HRM units or specialists within organisations.

3. In order to assume that an empowered manager would use his/her authority and autonomy to reallocate and dismiss staff within their unit for the purpose of maximising performance rather than to implement "orders from above", one would need to first make a major assumption concerning the managers' motivation. Indeed, managers themselves need to be professionals whose careers depend on the achievement of objectives for them to be driven by such highly ethical motives. Considering that in most of the region, the politicisation of the SCS is one of the

${ }^{148}$ Idem, PSHRM Principle 3, sub-principle 6, on objective criteria established by law for the demotion of public servants and the termination of the public service relationship.

${ }^{149} \mathrm{Idem}$, Sub-principle 7, on the right to appeal against unfair demotion and dismissal. 
major challenges in the area of public service and HRM, one needs to maintain caution and advise that steps towards depoliticisation of the SCS precede any possible steps towards more authority and autonomy for managers in reallocating and dismissing staff (and always in a strictly objective process, and in accordance with a robust legal basis).

\section{Detailed regional analysis}

\section{Reallocation of roles and functions}

The rules on reallocating staff within an organisation, and thus its units, are in most cases thoroughly regulated, as part of the civil service legal provisions. The legislative frameworks thus include rules for reassigning staff, particularly to lower-level positions. In $\mathrm{BiH}$ and Serbia, senior managers have reported that it is particularly difficult to remove the heads of lower-level units in cases of poor performance, even leading in some cases to them creating new units and ignoring/bypassing the unit which is not delivering ${ }^{150}$. Other lateral types of reallocations are more flexible and can in most administrations be done either through individual reassignments or through changes of the acts on internal organisation (except for Albania where acts on internal organisation do not exist).

Apart from in Kosovo, where the decision on reallocations is made by second-level managers below ministers (general secretaries), in the remaining administrations, decisions on reallocations are formally taken by ministers. In this case, the ministers' formal decision-making power is not a mere formality, but a substantively used power. In fact, managers from the region are largely in agreement that apart from proposing changes in the assigned roles and functions in their units, they do not have authority in this regard. In the end, it will depend on the minister's personality (or even on the political momentum in an administration) as to whether the minister will accept the senior managers' proposals or impose their own views and decisions.

\section{Termination and dismissal}

Termination of employment or dismissal of civil servants is another thoroughly regulated procedure in all administrations' civil service legislation. Apart from the former Yugoslav Republic of Macedonia ${ }^{151}$, all of the other administrations' legal frameworks for termination of employment were assessed positively, as can be seen in Figure 7. However, Albania and Serbia did not receive the maximum points either - the former due to the option to dismiss civil servants who fail the regular assessment of additional knowledge of civil servants, and the latter because of the extremely short timeframe for dismissal following a negative performance appraisal ${ }^{152}$.

\footnotetext{
${ }^{150}$ According to a senior manager attending a SIGMA focus group meeting with senior managers from the Western Balkans, held on 24 November 2017, Paris.

${ }^{151}$ The analysis carried out by SIGMA for the 2017 assessment of the former Yugoslav Republic of Macedonia revealed problems with the quality of the legal framework for dismissals due to restructuring and for poor performance.

${ }^{152}$ Data collected by SIGMA during the 2017 assessment.
} 
Figure 7. Points received in a SIGMA's assessment for objective criteria for the termination of employment in civil service legislation

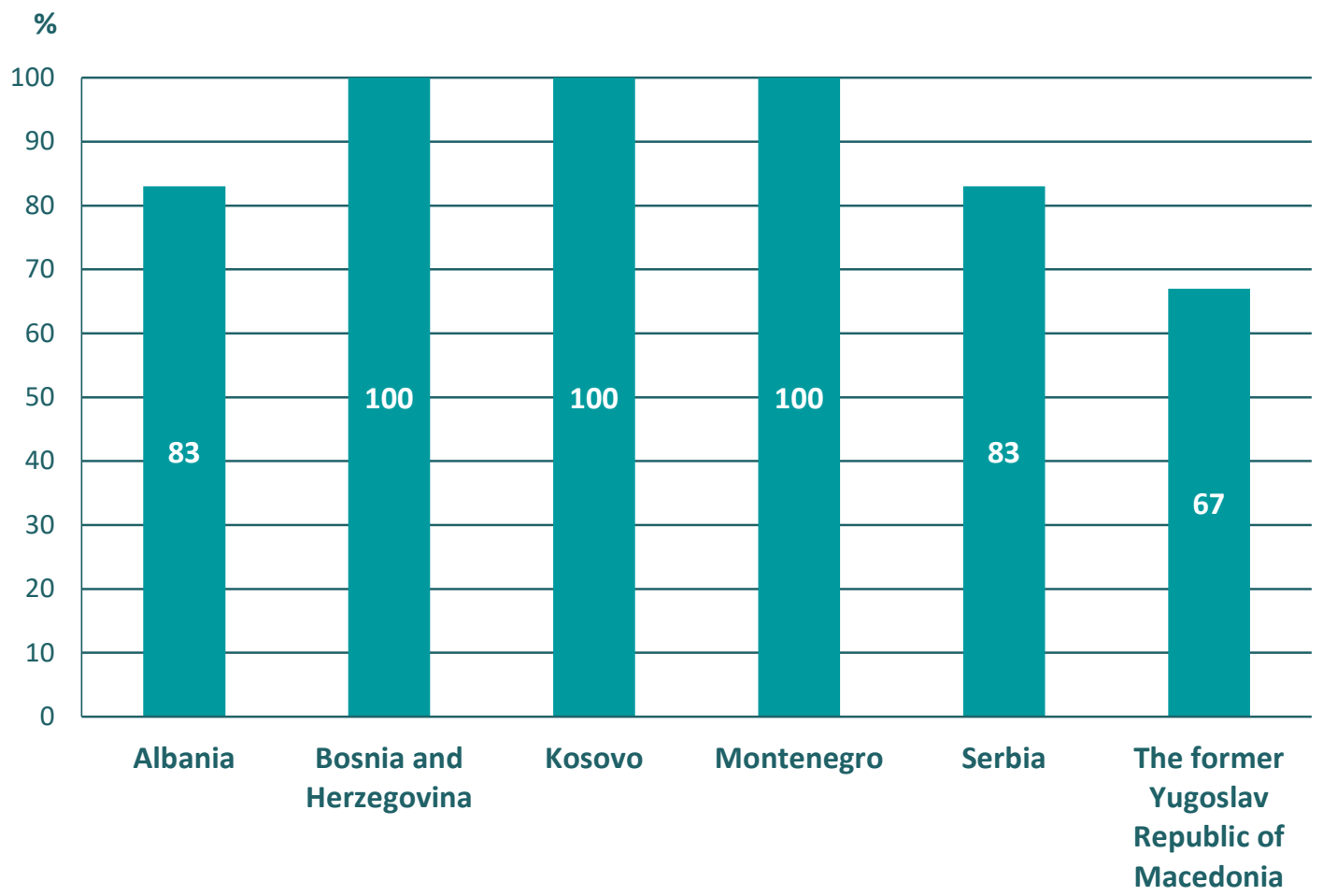

Source: Data in respect of sub-indicator 3.3.2.1, collected for the 2017 SIGMA assessment.

Nevertheless, involuntary terminations are generally not widely used by managers across the region, except in cases where they are imposed for political reasons. Albania has been reported as an example where on several occasions political decisions to downsize the administration have resulted in forced dismissals, but apart from managers not being in the driving seat of such processes, in some cases, even the line ministers were not consulted ${ }^{153}$. Otherwise, even large-scale political drives for downsizing end in voluntary severances as a predominant form (a recent example is found in Serbia, where most of the downsizing has been achieved through retirement).

Even in cases where the legal requirements are not too demanding, such as in Serbia and the former Yugoslav Republic of Macedonia, where the legal provisions allow termination to result rather swiftly from a repeated negative performance appraisal, these options are not widely used by managers, either because they are unpopular in the local administrative culture or because of the generally improper application of the performance appraisal procedures ${ }^{154}$. In fact, the general propensity to award high grades in performance appraisals (discussed in Section 2.2.2) renders performance-based dismissal decisions

${ }^{153}$ Interviews with experts and government officials during the 2017 SIGMA assessment.

${ }^{154}$ For a discussion of the problems with the application of performance appraisal procedures, see Section 2.2.2. 
unable to stand up to judicial scrutiny in the case of appeals to the courts, which are generally guaranteed across the region ${ }^{155}$.

Since in most administrations demotion is not foreseen by civil service legislation (except as a result of disciplinary proceedings for severe violations in the case of $\mathrm{BiH}$, the former Yugoslav Republic of Macedonia and Serbia), and termination is procedurally difficult and unpopular, managers often resort to less fair or effective ways of dealing with nonperforming staff. For example, they "reward" top performers by giving them more responsibilities and effectively more work, whereas the low performing members of the team are left behind or ignored, with little work and responsibility (a practice reported particularly by managers from $\mathrm{BiH}$, Kosovo and Serbia in the focus groups). However, this can be quite counterproductive, especially when combined with the fact that in most cases managers cannot financially compensate those who have been given extra responsibility.

\subsubsection{Budget planning}

\section{Why it is important}

The budget is in practice the most relevant planning document for most public sector organisations. Budget processes form a core part of regular management processes and should matter to everyone who considers themselves a manager. If funding from year to year is sufficiently predictable, ministries and other organisations are more likely to make multi-annual plans and commit to these. If the budgetary ceilings agreed within the MTBFs are largely retained for the annual budget bill, and if there is sufficient time for the ministries to plan and discuss the budget proposal internally, the line managers (such as heads of department, director generals and the heads of subordinate bodies) are more likely to get involved in a genuine discussion about funding priorities and feel more accountable for the end result.

Budget formulation is always partly a top-down process but it is equally important to leave room for bottom-up proposals. The objective of top-down budgeting is to achieve fiscal consolidation. To this end, the finance ministry focuses its energy on setting expenditure ceilings and maintaining fiscal discipline, delegating the details of resource allocation to line ministries. Therefore, this system will produce positive results only when the manager is at its centre ${ }^{156}$.

Managers at all levels need to know their budget and they need to be able to influence the level of funding at their disposal, by providing input and justifications, for example. In addition, a results-oriented budget system creates more opportunities for the development of comprehensive managerial accountability, as it encourages thinking about aspects of economy, efficiency and effectiveness in the use of budget funds to achieve the set objectives and the expected budget results. At the very least, thinking about the content of the work while planning financial resources develops the conditions for outcome-oriented accountability. Programme budgeting initiatives can help to move the focus of managers to outputs and outcomes, but these efforts also need to feed into other key planning processes, and are themselves dependent on a good level of managerial accountability.

${ }^{155}$ In the 2017 assessment, all administrations received maximum points on sub-indicator 3.3.2.3. 'Right to appeal dismissal and demotion decisions to the courts'.

${ }^{156}$ OECD (2006), Top-down Budgeting as a Tool for Central Resource Management, OECD, Paris, pp. 120-121, http://www.oecd.org/governance/budgeting/43469596.pdf. 
Summary of SIGMA analysis

Despite the existence of MTBFs, budget planning is primarily for one calendar year in all administrations of the region. Multi-annual commitments are only possible in exceptional cases. The annual budget planning cycle provides opportunities for all organisations to prepare and discuss their proposals and the procedures are largely kept to. However, the links between sector policy plans (strategies) and medium-term or annual budgetary plans are weak. In most of the administrations the rules for sector strategies setting out details about costing or estimating expenditure needs are missing. Costing of new policy proposals is in most cases not carried out in sufficient detail, and the necessary forms are filled in merely to satisfy the formal rules in place.

Line managers are mostly given an opportunity to provide initial inputs, but the outcomes of the budget formulation process are less clear for them. Most ministries in the region do not provide line managers (e.g. assistant ministers or director-generals) with a complete picture of the budget they can rely on during the year.

\section{Recommendations}

1. Governments should continue the reform efforts towards a more systematic programme budgeting approach with clear links between budget appropriations and institutional and managerial responsibilities, basic performance information and a clear medium-term perspective. For this budget planning approach to become serious, the MTBFs also need to become reliable planning documents which outline credible funding perspectives for the different sectors of the government ${ }^{157}$.

2. Managers (at least second level below the minister in the case of ministries) should have formally established budgets or budget envelopes, even if they do not have autonomy over the use of them in the budget execution phase ${ }^{158}$. This alignment need not be at the level of the budget law as approved by the parliament but can simply be established by the government or an individual budget organisation, to allow sufficient flexibility for reallocations.

3. Managers should be made accountable for the careful costing of new policy proposals by a stricter quality review by the ministry of finance or other competent bodies. Policy proposals without a credible estimate of budgetary impacts should not be allowed to be put forward for approval.

4. Actual donor funding to the governments (not referring to support in kind) should be included in the annual state budgets ${ }^{159}$, preferably to the budgets of ministries responsible for the respective policy areas, and the use of those funds should be monitored as if they were part of government expenditure, with managers being held as accountable for this expenditure as for domestically-sourced spending. This does not preclude the fulfilment of additional reporting obligations as agreed with individual international partners.

157 OECD (2017), SIGMA, The Principles of Public Administration, OECD, Paris, PFM Principle 1 , on a medium-term budgetary framework based on credible forecasts.

${ }^{158}$ Idem, PFM Principle 7, sub-principle 1, on internal regulations including establishing budgets for relevant managers, along with delegation and accountability arrangements.

159 Idem, PFM Principle 2, sub-principle 3, on the budget's coverage that is comprehensive and includes IPA funds and other donations. 
5. Finance departments should be strengthened by the introduction of new skills and responsibilities in the area of financial management, including the strategic financial planning needed to help the management avoid committing their organisation to expenditure that will not be met by the resources available in the medium and long term.

6. Moving to more sophisticated programme budgetary procedures should be an incremental development, depending on the capacities of the line ministries for policy planning, strategic financial planning, fiscal impact analysis and so on. The addition of complexity to budgetary procedures should be in accordance with the ability to plan policies in a credible manner and ensure that the capacities of the central budget departments and the budget and finance units in the line ministries are able to respond adequately to the established procedures.

\section{Detailed regional analysis}

In all the Western Balkan administrations, ministries and agencies that are the first-level budget organisations have the opportunity to put forward their proposals for the annual budget. This is embedded in regulation and followed in practice, at least for the annual budget. Also, the ministries provide multi-annual inputs for the MTBFs. Only in Montenegro is the medium-term budget planning document prepared largely by the MoF without explicit inputs from the line ministries.

In situations where the MTBF does not include sectoral or ministry-level ceilings (the former Yugoslav Republic of Macedonia), and where the sector-level ceilings already for the first year are significantly amended during the budget negotiations (in Bosnia and Herzegovina ( $\mathrm{BiH})$, Kosovo and Montenegro), there is a resulting reduction in the predictability of sector-level funding for the next calendar year. This has a negative effect on the level of managers' accountability for their policy areas within the ministry or in relation to the wider range of stakeholders. This carries forward to the level of sectors and departments, as well as subordinate bodies of the ministries.

The links between sector policy plans (strategies) and medium-term or annual budgetary plans are weak. In most of the administrations, there are no detailed rules on costing or estimating expenditure needs for sector strategies. In practice, costing is carried out in some cases, even in the absence of rules, but the links between the sector strategies and budget planning are weak and not systematic.

Costing of legislative proposals is formally regulated in most cases, but the rules are not substantially applied, and the required forms are very often filled in at the last stage to comply with the procedures and satisfy the formal requirements of the quality control bodies. The ministries of finance rarely challenge inadequate costing of proposals prepared for government decisions ${ }^{160}$.

The former Yugoslav Republic of Macedonia has set up a system for institutional strategic planning that is designed to provide direct three-year planning information for the budgetary process. In Albania and at the $\mathrm{BiH}$ State level the managers provide a mediumterm framework for links between policy goals and objectives for the MTBF, with budget resources allocated at the programme level. The roles and responsibilities for budget planning in Montenegro are set by internal procedures for budget planning.

${ }^{160}$ OECD (2017), SIGMA, Monitoring Reports, OECD, Paris. 
In practice, the role of managers in contributing to the medium-term or annual budget proposal within budget organisations such as ministries and agencies varies across the region and according to the particular type of organisation. In a typical ministry, the budget and finance department (or equivalent) is tasked with the preparation of budget proposals. The heads of sectors or departments within ministries are normally asked for direct inputs into the next year's budget plan, but they frequently lack tangible information about the outcomes of the budget debates or how their inputs have been interpreted or applied.

In better cases, the internal debates involve all key managers within the organisation, but since the budget proposals of the organisations are almost always higher than the actual ceilings, many of the ideas will not be funded. This information is not available in detail to public sector managers and the arbitration is done at the political level (in better cases involving the head of administrative affairs and/or the head of the budget department). Managers are not included in the budget hearings/negotiations with the MoF or asked to defend their budget within the parliamentary debates. The problem for managers is that they are not part of the final proposals on which expenditure lines are to be cut or safeguarded.

Although there are recurring problems with keeping to the annual calendar for budget preparations, the 2016 data shows that most administrations left six weeks or more for the line ministries to prepare their budget proposals. Only in Serbia, BiH State level and the $\mathrm{FBiH}$ were ministries left insufficient time to prepare the budget proposals following the central instructions.

One of the basic problems for line managers' involvement in budget management is that there is little or no systematic alignment between the budget structure and the management structures ${ }^{161}$. The former Yugoslav Republic of Macedonia has a procedure whereby budget organisations adopt the decision on the internal allocation of the approved budget. (Most ministries had done this for 2017.) In Kosovo, nearly a third of ministries, and in Montenegro some ministries have ensured that all senior managers have clear budget allocations. In Albania, most ministry line managers have a budgetary allocation but none of the ministries have ensured that this is the case for all of their senior managers.

Even in cases where managers have their own budget programme, in many public administration organisations, it is very often mostly concerned with staff salaries. The budgets for training, travel, events and other similar relatively regular activities are mostly centralised within budget organisations. Some kind of formal internal breakdown of these budgets between departments or sectors would be beneficial for managerial accountability. Furthermore, in Montenegro, the capital budget is a separate part of the budget, blurring the overall alignment between policy and management responsibilities.

The perspective in budget planning in the region is in practice only for one calendar year. Multi-annual commitments are only possible in exceptional cases and the formal rules do not encourage the commencement of procurement procedures before the start of a calendar year. It is therefore difficult for managers to plan for longer than a year for anything other than salaries, premises and other recurrent costs.

To get things done, many managers work with donors, but since in most administrations the donor resources are not part of the state budget (the former Yugoslav Republic of

${ }^{161}$ Ibid. 
Macedonia is an exception with all IPA funding being part of the state budget) ${ }^{162}$, the budget planning is effectively fragmented and does not follow the overall lines of responsibility in the organisation. For instance, managers may in practice agree on a significant amount for ICT investment by the European Union (EU) or another donor even though the project is not considered a priority under the national budget. Investment planning has the potential to be more transparent with the recently established National Investment Committees and the respective single project pipelines, but the links with national policy planning and budget deliberation procedures are still weak.

\subsubsection{Budget execution}

\section{Why it is important}

If the managers at different levels know the amount of financial resources they can rely on during the year, they are better able to make plans and prioritise their use of resources. Furthermore, predictability of funding over a period of two to three years affects managerial accountability in a positive way by allowing the planning of policies and reforms.

The OECD Recommendations on Budgetary Governance ${ }^{163}$ call for clear regulation of the roles, responsibilities and authorisations of each institution and accountable person, allowing some limited flexibility for ministries and agencies to reallocate funds throughout the year in the interests of effective management and value for money. Centralised ex ante controls are part of normal practice in public sector organisations and often necessary, but if they are excessive they may slow down decision making and reduce the accountability of individual managers in charge of the substance. Therefore, managers need to be able to influence timing and operational choices when using financial resources during the year.

\section{Summary of SIGMA analysis}

Most managers in the ministries do not have a complete picture of the budget they may expect to use during the year. Their responsibility in budget execution is limited to initiating expenditure (without sufficient predictability or control over the outcomes) and to specific verifications of the supplies and services received. In almost all public organisations overall accountability is centralised in the heads of administration and the financial or administrative services of the organisation.

The provision of regular budget spending data is mostly not designed with managers' needs in mind. The treasury information systems are typically tailored around the needs of the ministries of finance themselves for reporting against the budget using their system of budget categorisation. Since the budget categorisation and management structures are not aligned, line managers get useful data on commitments and spending only when they have a budget programme covering their area of work.

\footnotetext{
${ }^{162}$ In Montenegro IPA funding is also part of the state budget, but under the Ministry of Finance, regardless of the ministry to whose policy it contributes.

${ }^{163}$ OECD (2015), Recommendations of the Council on Budgetary Governance, OECD, Paris, p. 9, http://www.oecd.org/gov/budgeting/Recommendation-of-the-Council-on-Budgetary-

Governance.pdf.
} 


\section{Recommendations}

1. Managers should be given delegated responsibility for individual spending decisions within their budgets, with administrative and not overly burdensome ex ante verification by the relevant internal financial control officials or, where the information systems are mature enough, automatic controls and regular monitoring by the relevant internal financial control officials ${ }^{164}$.

2. All key managers (such as those at the second level below the minister in the case of ministries) should be provided detailed regular spending information at least on commitments and actual spending against the budget for their part of the organisation $^{165}$.

Delegation in budget execution should only be allowed if the underlying information systems enable constant or frequent monitoring of the actual situation. Central controls and automatic alerts over commitments need to be operational to allow delegation of decisionmaking authority in budget execution. Otherwise, the risk for arrears increases further.

\section{Detailed regional analysis}

In all the administrations in the region, responsibility for the use of budget resources lies primarily within the individual organisation ${ }^{166}$. The ministries of finance and treasuries are part of the payment procedures but their verification is not on substance. Nevertheless, in Montenegro for example, of the four key steps in a payment process (approval, verification, confirmation and authorisation) only the first two are within the competencies of the budgetary organisation while the last two are handled by the Treasury (part of the MoF). In Kosovo, the recent changes in the budget categorisations mean that the MoF monitors and controls actual spending in great detail (including the spending on mobile phones of a department within a ministry - a budget item less than EUR 100 per year).

Most managers in the ministries do not have a portion of the budget at their disposal, neither do they have a complete picture of the amount of funds that they can rely on (though they can count on the salaries of the staff and very general recurring resources, such as premises and access to general utilities). While most managers (75\%) feel that they are authorised to take decisions in line with their official level of responsibility, only $42 \%$ of them perceive that they have authority to manage the budget of their units ${ }^{167}$. In many cases, the head of the general administration service (e.g. the secretary of the ministry) is the "grey eminence" making decisions affecting the programmes of a ministry, and of whom the other managers must inquire regarding the possibility of funding an activity. In a similar fashion, neither

164 OECD (2017), SIGMA, The Principles of Public Administration, OECD, Paris, PFM Principle 7, sub-principle 1 , on internal regulations including the appointment of a finance officer and establishing budgets for relevant managers.

$165 \mathrm{Ibid}$. Internal regulations ensure that management information is regularly provided to the appropriate levels of the organisation.

166 As set out in the organic budget laws (laws specifying the rules, procedures and schedule of budget management for all budget organisations).

${ }^{167}$ According to a 2018 survey carried out in all six Western Balkan administrations by the Western Balkan Enabling Project for Civil Society Monitoring of Public Administration Reform (WeBER) in co-ordination with SIGMA, www.par-monitor.org. 
other managers nor departments are involved in estimating the cash flows for their programmes ${ }^{168}$.

In Kosovo, the role of the managers in budget execution is not defined by any regulation or any procedure. Delegation of this responsibility to other managers is at the discretion of the Secretary-General. The practice varies between institutions. Some institutions, such as the Ministry of Education, Science and Technology, have developed internal rules about the roles and responsibilities for budget execution.

Many senior civil servants do not even consider it necessary to know what their budget is. According to them, one can be a successful manager without knowing the budget ${ }^{169}$. This perception is understandable where a manager is leading a small team of professionals where the staff are the sole direct resource. But even in these cases, there are other needs, such as business travel, translation etc., where managers need to plan their resources during the year.

There are managers who would like to take the responsibility for their financial planning work more seriously. The following is an illustrative quote from a senior manager from $\mathrm{BiH}$ : "We don't know whether we have underestimated the workload of translators. But ministers always say 'don't worry, we can get more money if we ask for that, this is important'. But we need to know the available amounts to start public procurement."

The focus in past years on cutting budget deficits (with low or no budget growth) has meant strict central controls over spending. This has led to situations where some spending categories have been frozen or scheduled for a later quarter of the year without consultation or even prior notice for the budget organisations and the managers affected. This is in addition to the practice where the MoF determines centrally the pace of budget expenditures based on the availability of funds. In $\mathrm{BiH}$ and some other administrations, only certain organisations, such as the parliament or the supreme audit institution, have autonomy regarding the timing of spending throughout the year.

The role of managers in budget execution is mostly at the verification stage, where they confirm that the service has been provided, or that goods have been delivered, as a basis for the payment to be made. Due to the high formality of the process of public procurement, managers are often powerless to reject sub-optimal quality of service. The lack of documentation and systems that might serve in court proceedings as evidence that the contract has not been fully implemented, means companies are successful in challenging the state when a manager decides to decrease the value of the contract.

The provision of regular budget spending data is mostly not designed with managers' needs in mind. The treasury information systems are typically tailored around the needs of the ministries of finance and treasuries themselves for reporting against the budget using their system of budget categorisation, i.e., mainly to control cash flow and ensure that monthly cash limits are not exceeded. Since the budget categorisation and management structures are not aligned, sector managers get useful data on commitments and spending only when they have a budget programme covering their area of work. Sector managers in Kosovo receive monthly spending information based on the budget structure, while the former

${ }^{168}$ In most cases the cash flow requirements are determined centrally, and often a simple calculation of $1 / 12$ of the annual total is used to determine monthly cashflows.

${ }^{169}$ SIGMA focus group meetings. 
Yugoslav Republic of Macedonia receives this quarterly. In Montenegro, Serbia and $\mathrm{BiH}$ the information is given on request. In Albania, the managers who are in charge of a budget programme also receive regular financial updates ${ }^{170}$.

\subsubsection{Public procurement}

\section{Why it is important}

In an environment where managers want to achieve the best possible result, public procurement plays a critical role in many areas of public administration. Public procurement is a key procedure for obtaining the necessary external competencies and capacities for achieving their objectives. Organisation-specific procurement is often directly linked with the annual and medium-term objectives (e.g. improvements in infrastructure, ICT development and outsourcing of service delivery) and is therefore of strategic importance for accountability. In addition, procurement is used to pursue specific horizontal goals, such as those on innovation, the environment or gender equality. Centralised procurement can add value to managers in the public sector by relieving them of the need to buy basic, regularly required tools, as long as the central procurement services can provide the necessary resources in a flexible and timely manner.

Procurement is also a source of many failures. In the EU member states around half of all irregularities under EU-funded programmes are related to procurement operations ${ }^{171}$. Procurement is prone to corruption, therefore clear procedures and transparency are important ${ }^{172}$. It is equally important that managers should have the ability to purchase what is needed without being unduly afraid of the potential legal consequences of any miscalculation or mistakes that occur.

\section{Summary of SIGMA analysis}

Currently, the national administrations in the Western Balkans are not focussing on the creation of easy to handle public procurement procedures that help organisations and managers to achieve their objectives. The role of managers is limited to specific inputs, the selection and evaluation criteria used are not tailored to the overall objective of the work, and procurement procedures are not predictable - there can be several rounds of procurement review, and it is not unusual for the entire procedure to be cancelled.

Managers responsible for sectors or individual departments are usually only involved in the first stage of public procurement and in the monitoring of contract execution. They are prevented from initiating procurement procedures early due to the time taken to plan annual procurement. In the remaining phases of the procedure, it is usually the officers in charge of public procurement who run the procedure, with the involvement of the representatives of the relevant policy units. Managers with specific knowledge of the business needs are

\footnotetext{
${ }^{170}$ Data provided by the CHUs to a SIGMA questionnaire on managerial accountability.

${ }^{171}$ European Court of Auditors (2017), Special Report: Protecting the EU from irregular spending, European Court of Auditors, Luxembourg, p. 38. The conclusion is based on the statistics of the European Court of Justice.

172172 On the integrity of the public procurement system see: OECD (2015), Recommendation of the Council on Public Procurement, OECD, Paris, p. 7, https://www.oecd.org/gov/ethics/OECD-Recommendation-on-Public-Procurement.pdf.
} 
not responsible for the procurement outcomes and therefore they are not much involved in the design of the evaluation criteria.

Lower level managers cannot enter into contracts, even those with a low value of EUR 5000 or less, without the approval of the higher levels of management. In most cases, even small procurement contracts are signed either by the minister or secretary of the ministry or by the head of an agency or another government body.

\section{Recommendations}

1. The national procurement legislation should be reviewed and any explicit or implicit requirements that foresee the heads of organisation formally authorising the key steps in public procurement processes should be removed. Delegation should be both permitted and practised, while substance inputs and closer monitoring by organisation heads should be restricted to procurements which have a more strategic impact on the organisation's objectives.

2. Annual procurement plans should be prepared in such a way that these are ready and agreed by the end of January or, even better, before the start of the budget year, as soon as the annual budget is adopted by the parliament ${ }^{173}$. Ex ante controls over the procurement plans by the MoFs and other institutions should be gradually replaced by targeted monitoring.

3. The procurement review procedures and capacities should be reviewed to shorten first-instance complaint resolution and the share of cases which go back and forth between the procurement review body and the courts ${ }^{174}$. In specific circumstances, the procedures should allow the procurement process to be continued while disputes are settled.

4. Managers should be encouraged, perhaps by pressure from central procurement services, to avoid the automatic use of the lowest price criterion alone ${ }^{175}$. This could be done by setting up procedures whereby, for example, each time only the lowest price criterion is applied in more complex purchases justification has to be provided.

5. Detailed guidelines on contract management should be prepared ${ }^{176}$, actual responsibility among line managers for the outputs of the contract made more specific and systematic training for various level managers provided ${ }^{177}$.

${ }^{173}$ OECD (2017), SIGMA, The Principles of Public Administration, OECD, Paris, PFM Principle 13 , sub-principle 1 , on the planning and preparation of public procurement.

${ }^{174}$ Idem, PFM Principle 12, on the remedies system that provides for rapid and competent handling of complaints and sanctions.

${ }^{175}$ SIGMA Public Procurement Brief No. 32, on Market analysis, Preliminary Market Consultations and Prior Involvement of Tenderers may provide useful reference material.

${ }^{176}$ OECD (2017), SIGMA, The Principles of Public Administration, OECD, Paris, PFM Principle 13, sub-principle 7 , on the instruments to evaluate contract performance and benchmark contract management by an individual contracting authority or entity.

177 SIGMA Public Procurement Brief No. 22, on Contract management may provide useful reference material. 
Public procurement operations need to be based on clear, predictable and transparent procedures, and therefore public sector organisations or individual managers cannot be given full freedom to experiment. Standardisation and the use of central legal and technical expertise remain critical. Therefore, steps taken to increase the tangible responsibility of managers for procurement outcomes need to be well specified, and audit trails of the decisions need to be kept. In many cases merely involving managers in the key stages of an organisation's public procurement, internal procedures will help to ensure that their responsibility for the achievement of policy objectives is not negated.

\section{Detailed regional analysis}

In the Western Balkans, the primary focus in developing the public procurement systems has been on achieving better alignment between the national public procurement legislation and the EU public procurement directives. There have been attempts to make specific aspects of the procurement regime more effective and efficient. For example, centralised procurement obligations have been introduced and the conditions created for framework agreements. However, there have not been more systematic efforts to simplify and rationalise the existing procedures.

In all of the Western Balkan administrations, the central government organisations are obliged to prepare and publish annual plans for public procurement. In most cases, these also need to be agreed with the ministries of finance. The fact that the ministries of finance have to approve the public procurement plans is generally not seen as limiting the autonomy of the ministries since the ministries of finance rarely change the plan substantially: the limits are provided in the budget, and therefore there is rarely a difference of opinions. This extra procedure takes time, however. As the authorities usually do not start formal proceedings before January each year, a month, or in the worst cases two months, has been lost from the time for procurement procedures and contracts implementation, which again limits the opportunities for managers to manage the procedures, do the work and have sufficient contingency allowances to achieve meaningful objectives.

Public procurement legislation in the region does not explicitly hinder delegation of decision making in procurement operations. The most common practice is that operational duties within public procurement are delegated to a central unit either in the general affairs or budget and finance departments. Nevertheless, the key decisions, such as the award of a contract or a decision to suspend a procedure, are signed only by the head of the organisation (e.g. the minister) or, in some cases, the head of administration (e.g. secretary of the ministry or general secretary). In the ministries, the manager typically responsible for public procurement procedures is the secretary of the ministry (in Montenegro and Serbia) or the general secretary or the agency director (in Kosovo). Often the more operational activities are delegated to the heads of general affairs departments, but the signing off of procurement contracts and other key decisions are left for the manager with delegated functions directly from the minister.

The role of managers in the ministries varies. In most cases, managers responsible for the relevant area initiate the process but the formal responsibility is with a specialised unit in the general affairs department or its equivalent. The entire procurement process is normally managed by the procurement unit within the organisation, but specific requirements are defined by the respective unit for which the procurement of goods and services is taking place. 
Based on a survey carried out among public sector managers in Serbia ${ }^{178}$, two-thirds of assistant ministers $(66.7 \%)$ claim they have no role in public procurement procedures. At the same time, all secretaries of ministries who completed the survey replied positively to this question. However, the survey reveals a discrepancy between actual authority and the feeling of responsibility for the public procurement procedures among managers. Senior managers appear to have a particularly high level of responsibility, with almost $80 \%$ claiming to be highly responsible for public procurement. This means that, even when they are not formally in charge or responsible for the procedures, they feel responsibility for the outcomes and the implementation of the contracts.

Managers responsible for a sector or a work area within a ministry cannot enter into contracts, even those with a low value of EUR 5000 or less, without the approval of the higher levels of management. Only in Albania did the CHU report that managers (i.e. those managing a separate spending unit within a ministry) may enter into small procurement contracts within their unit without getting any prior approval ${ }^{179}$. In most cases, even small procurement contracts are signed either by the minister or secretary of the ministry or by the head of an agency or another government body ${ }^{180}$.

For EU funds management the system in the ministries differs from the national procedures. In most cases, the general affairs or finance and budget departments are not involved at all and their role is fulfilled by the project implementation units and central contracting authorities, established primarily for the management of EU funded programmes. The role of line managers and their expert staff is mostly limited to providing input to the terms of references and technical specifications. With multiple layers of management and ex ante controls, the ability of interested managers to influence the pace of the procedure and the selection/evaluation criteria is limited or depends on the activeness of the persons in position.

In practice one of the key problems for line managers is the unpredictable length and end result of the procurement process ${ }^{181}$. A significant share of the public procurement processes is cancelled without an award of contract (10\% in Serbia, $15 \%$ in the former Yugoslav Republic of Macedonia, 20\% in Montenegro and 25\% in Kosovo) ${ }^{182}$. When judging procurement cases, the actual time taken by the first-instance review body to resolve complaints varied across the region in 2016 from 10 days in the former Yugoslav Republic of Macedonia to an average of 64 days in Serbia ${ }^{183}$. A number of those cases are taken to court and the share of cases that are changed or returned by the courts is high in the region (in all administrations but Albania the share of cases sent back by the court was more than $20 \%$ in 2016) ${ }^{184}$. As a result, public procurement appeals may easily take more

178 Survey of Serbian senior civil servants carried out in 2016 by the European Policy Centre, Belgrade.

${ }^{179}$ Albanian CHU response to SIGMA questionnaire.

${ }^{180}$ Data collected by SIGMA for the 2017 assessment.

181 This unpredictability is common for national public procurement procedures and IPA funded tenders.

${ }^{182}$ OECD (2017), SIGMA, Monitoring Reports, OECD, Paris, data from 2016.

183 Ibid.

${ }^{184}$ Ibid. Data from 2016. 
than half a year, which has direct consequences for the ability to plan objectives for the year and sometimes for the medium term.

Managers with specific knowledge of the business needs are not responsible for the procurement outcomes and therefore they are not much involved in the design of the evaluation criteria. The share of competitive procedures having lowest price as the one and only award criterion is above $95 \%$ in the Western Balkans ${ }^{185}$. Public sector managers commonly complain about the use of lowest price criteria ${ }^{186}$ but even when there is an opportunity to offer more relevant criteria, this is either not done or the suggestions of sector departments are not taken up. This is due in part to a lack of skills and understanding of the market but also an unwillingness to take reasonable risks, reinforced by the general rigidity of the control bodies (public procurement legislation often provides penalties for mismanagement of procedures). Regardless of the reasons, the result is that the supplies or services, for example, translation services, do not meet the expectations, and therefore the objectives of the managers will not be achieved as intended and the overall accountability for results is lower.

As noted in the previous section, managers are often given responsibility for confirming whether the supplies or services have been received and meet the expected quality. This means that these individual departments/sectors and their managers are responsible for monitoring the implementation of the contracts, even in cases when they were not involved in the procedure itself. In the Western Balkan administrations, the central guidelines, tools and training typically focus on the procurement procedures up until the contracts are signed. Managers do not have access to detailed guidelines and good practice examples of contract management to complement the provisions of the legislation. Similarly, practical training for contract management is lacking.

\subsection{Reporting}

Reporting is the other side of the coin in relation to the role of objectives in managerial accountability. Reporting lines and processes are an indispensable and inalienable ingredient of any accountability framework (either internal within organisations or external towards other institutions and the public). The key element of reporting which constitutes the difference between administrative and managerial accountability is reporting on performance and results, as opposed to activity reporting. Reporting provides feedback on how the authority delegated down from parliament, government or minister has been used. Delegation of authority cannot serve its purpose if there is no way of learning how the delegation has been used. Moreover, when managers have financial resources put at their disposal, financial reporting needs to be assured, and institutional reports should be made public to be fully effective.

\subsubsection{Reporting on government and institutional objectives}

\section{Why it is important}

For a strong managerial accountability system, it is important that managers should make a contribution to their institution's reporting on the wider government objectives and priorities as well as on the more immediate, institutional objectives, including the

\footnotetext{
185 Ibid.

${ }^{186}$ SIGMA focus group meetings on managerial accountability.
} 
objectives of their own directorate/department/unit. By supporting reporting on government objectives, senior managers fulfil their fundamental role in supporting the government in place and its political accountability.

To steer an organisation towards the achievement of results, reporting needs to be regular, though not too frequent. Imposing overambitious monitoring and reporting cycles can lead to an unnecessary bureaucratic burden on managers, and this will eventually undermine the very purpose of reporting in a performance system. Reporting should impose minimum administration and ensure the maximum possible useful and meaningful information for the assessment of achievement against different levels of objectives and targets.

Reporting in the public sector also needs to be published, since it is only where reports are publicly available that they can stimulate a general accountability culture and create the pressure of public scrutiny of political leaders ${ }^{187}$. Such pressure will, in turn, create positive pressure on managers to deliver against the set objectives and targets.

\section{Summary of SIGMA analysis}

As far as the overall government reporting practices are concerned, even where frameworks for the planning and formulation of objectives have been set, they are not accompanied by the corresponding monitoring and reporting practices. The entire region shares a common problem that government reports mainly provide information about activities and outputs, and very rarely outcomes.

The reporting of individual administrative authorities is in place in most administrations, but such reports are often not made publicly available. The lack of reporting against objectives and targets remains a key challenge to developing managerial accountability. Failure to set targets in the first place means that even quantified reporting does not support development of managerial accountability, as it will be impossible to know whether a manager or a unit has underperformed or overperformed. A prevailing practice is that institutions prepare reports as part of the government's reporting processes, most frequently through reporting on the GAWP implementation. Reporting is often seen as a burden and not as a tool for management and better planning. The system is such that the achievement of objectives does not bring about any particular consequences from the managers' perspective.

Another important obstacle to nurturing managerial accountability through reporting is the lack of visibility of line managers, or at least their units, in those reports. Even if they are visible in the reports, they are only stated as responsible for the implementation of activities, never for the achievement of results.

\section{Recommendations}

1. In line with the improvements which need to be made in the planning and objective-setting processes, all governments should clearly establish and regulate an obligation for its organisations to regularly report against individual organisational targets and to publish those reports ${ }^{188}$. Such requirements should

\footnotetext{
${ }^{187}$ See also OECD (2017), Recommendation of the Council on Open Government, OECD, Paris, p. 3, https://www.oecd.org/gov/Recommendation-Open-Government-ApprovedCouncil-141217.pdf.

${ }^{188}$ OECD (2017), SIGMA, The Principles of Public Administration, OECD, Paris, PDC Principle 5 , on regular monitoring of the government's performance, sub-principle 3, on regular reporting.
} 
prioritise reporting against results and concrete targets, as well as minimise redundant activity-level information. Similar systems of regular reporting should be established within organisations.

2. Given the lack of training on strategic and operational planning (which should be an obligatory part of the professional development programmes for managers) governments should develop user-friendly templates, guidelines and examples for managers to use when developing reports. Care should be taken that reporting cycles and requirements are made simple and lean, avoiding duplication, minimising the administrative burden, while maximising outcome information.

3. Reports should make the crucial link between objectives and individual managers or their units. For this, the managers must be made responsible for objectives in the first place, which goes back to the planning requirements - plans need to ensure that responsibilities for implementation are formally assigned. The next step would be to ensure that the reporting templates clearly correspond to the planning templates, linking the organisations and units to the same objectives and targets as the plans do.

In order to turn reporting practices into a vehicle for managerial accountability, it is clearly necessary to ensure that high-quality, specific and measurable objectives are set in the first place. Moreover, a strong performance measurement system is an important prerequisite for managerial accountability.

The reader is also referred back to the risks and caveats given in Section 2.1.2, which are equally applicable here.

\section{Detailed regional analysis}

The reporting rules and practices across the region were assessed critically in the 2017 SIGMA assessments ${ }^{189}$, with the partial exception of Montenegro. Even where frameworks for the planning and formulation of objectives have been set, they are not accompanied by the corresponding monitoring and reporting practices. The entire region shares a common problem that government reports mainly provide information about activities and outputs, and very rarely outcomes. The assessment report for Albania states that reports on the analytical programme and on operational plans provide mainly statistical information on the actual number of measures completed, with only limited information on the policy objectives of the implemented policies or laws ${ }^{190}$. For $\mathrm{BiH}$, the 2017 Monitoring Report states that "the implementation reports do not follow consistently the structure and logic of the GAWPs. For example, although the state GAWP includes output-level indicators, those indicators are not discussed and presented in the annual implementation report" ${ }^{191}$. Moreover, information on achievement of objectives is largely missing at all levels.

One of the rare reports which recognises individual organisational units is that of the Government of the $\mathrm{FBiH}$, but even in this case, organisational units are only recognised as

\footnotetext{
${ }^{189}$ OECD (2017), SIGMA, Monitoring Reports, OECD, Paris.

${ }^{190}$ OECD (2017), SIGMA, Monitoring Report: Albania, OECD, Paris, p. 37.

${ }^{191}$ OECD (2017), SIGMA, Monitoring Report: Bosnia and Herzegovina, OECD, Paris, p. 44.
} 
responsible for specific activities ${ }^{192}$. Reports on the GAWP in Serbia, similarly, do not report on any objectives, but only activities contained in the plan (though, as explained in the previous section, objectives do not constitute a part of the adopted and published GAWP, despite being formulated and entered into the planning software).

In Kosovo, "the annual report on the GAWP is a 119-page document divided into sections describing achievements under the five strategic priorities and separate chapters containing the reports of each line ministry" ${ }^{\prime 193}$. The quality of the report is internally uneven, with some sections (on Sustainable Economic Development, Employment and Welfare) addressing certain outcomes and others not. Moreover, since targets are not set in the planning phase, it is not possible to assess whether the outcomes were satisfactory. Furthermore, chapters vary in terms of whether they include budget spending information, level of implementation of activities, etc.

Finally, both in the former Yugoslav Republic of Macedonia (where reports are irregular) and in Montenegro (where they are regular), reports only provide information on outputs.

The reporting of individual administrative authorities is in place in most administrations, but such reports are often not made publicly available. Indeed, in Albania and Serbia, almost no reports are publicly available ${ }^{194}$. The most regular practice of publishing annual institutional reports is found in Montenegro, whereas in $\mathrm{BiH}$ (State level) and Kosovo, institutions publish reports only sporadically, and the practice is uneven across institutions. On the other hand, institutional reports are contained in the Government's reports in Kosovo, which are regularly published.

A prevailing practice across the region is that institutions prepare reports as part of the government's reporting processes, most frequently through reporting on the GAWP implementation. In Albania, ministries are obliged to report annually on the activities undertaken to implement the Government Programme ${ }^{195}$, whereas institutions regularly report to the Office of the Prime Minister on the implementation of their work plans ${ }^{196}$. The reporting obligations and responsibility of managers is also clearly recognised in the FMC Law, though it is unclear to what extent these obligations are enforced in practice. In $\mathrm{BiH}$, Serbia and Kosovo, ministries report to the government as part of GAWP reporting ${ }^{197}$, whereas in the former Yugoslav Republic of Macedonia reports for the previous period are usually contained in the institutions' mid-term strategic plans ${ }^{198}$. It should be noted,

192 Report on the Work of the Government of the FBiH for 2016.

193 OECD (2017), SIGMA, Monitoring Report: Kosovo, OECD, Paris, p. 34.

${ }^{194}$ Based on the monitoring of proactive accountability of public institutions implemented within the WeBER project.

195 OECD (2017), SIGMA, Monitoring Report: Albania, OECD, Paris, p. 37.

${ }^{196}$ Combined analysis based on CHU questionnaire and SIGMA 2017 assessment results.

${ }^{197}$ Institutional objectives are usually set as part of the government planning process and individual institutions' plans feed directly into the GAWP.

${ }^{198}$ Based on the analysis of websites and strategic plans of the Ministry of Local Self-Government, Ministry of Labour and Social Policy and Ministry of Transport. 
however, that in Kosovo information on institutional achievements is included in the annual financial reports ${ }^{199}$.

The analysis of the published reports, however, shows that the quality of reports is poor across the region. First, in most cases, reports do not contain information about achievement of institutional objectives and are rather activity oriented. Second, in most cases, the responsibilities of individual sectors/units are not recognised in reports but rather given as for the whole institution. This is usually a direct effect of the fact that objectives are not cascaded down through the institutions.

A partial exception is Montenegro, where ministries produce annual work reports which do include reports of individual sectors/units, though these are focussed primarily on the implementation of activities ${ }^{200}$. Analysis of the published reports for $\mathrm{BiH}$ shows that they do include numerical data on the achievement of concrete targets (set at output level) ${ }^{201}$, but the information on achievements is not always cascaded down through the institutional structure. In the former Yugoslav Republic of Macedonia, although the strategic plans do recognise the responsibility of organisational units (at activity/output level), the reporting parts of the plans are not evenly structured, they do not contain matrices/tables which would provide uniform structure (they are written in a rather free form, as there are no templates for reporting) and the responsibilities of individual units are not apparent.

The administrations do not have uniform rules for reporting on sector strategies. In some cases, the strategies themselves or the strategy adoption decisions include annual and/or semi-annual reporting obligations. The actual quality of the reports also varies, and they rarely analyse progress against objectives in a systematic manner. In many cases, the reports are not made public, even when approved by the government.

A common problem recognised by senior managers across the region is that reporting is seen as a burden and not as a tool, as in many cases no one really asks if their objectives have been accomplished, except where there is external pressure to achieve objectives in specific policy areas (e.g. PFM and public administration reform, where sector budget support is received from the EU ${ }^{202}$. Ministers do not generally expect senior managers to formally report on the achievement of objectives, though there have been isolated efforts by ministers to introduce responsibility for results ${ }^{203}$. Regardless of the form of reporting,

${ }^{199}$ See, for example, the reports of the Ministry of Diaspora: http://gjuhaime.rksgov.net/Faqe.aspx?id=43\&l=0.

${ }^{200}$ Based on the analysis of annual reports of the Ministry of Finance, Ministry of Economy and Ministry of Health. However, the Ministry of Health had not at the time of writing published the report for 2016 (nor 2017).

201 See the 2016 report of the Directorate for European Integration: http://www.dei.gov.ba/dei/Akti Direkcije/Izvje\%C5\%A1tajioradu/Archive.aspx?langTag=sr-SPCyrl\&template $\mathrm{id}=120$ \&pageIndex $=1$, and the 2016 report of the Ministry of Finance and Treasury https://www.mft.gov.ba/srb/images/stories/ministarstvo/registar\%20propisa/dokumenti/izvjestajor aduzaweb.pdf.

202 SIGMA focus group meetings.

203 For example, one of the former Ministers of Public Administration in Serbia introduced an internal reporting practice as part of which every assistant minister had to report on their key achievements. However, following the change of minister, this practice has been abandoned (it was an informal practice). Based on the interview with the Secretary of the Ministry. 
the vast majority ( $85 \%$ ) of public sector managers in the Western Balkans however say that they are asked to report on the achievement of the objectives of their unit. While $68 \%$ of the surveyed managers reported that there are consequences when objectives are not achieved, only $36 \%$ responded that there are consequences upon achieving objectives ${ }^{204}$.

\subsubsection{Financial reporting}

\section{Why it is important}

Organisational and managerial authority needs to be accompanied by reporting both from the finance departments to the managers, on the actual financial situation compared with the budget, and by the managers to the higher levels of management and government, on the use of financial resources, ideally linked to the results. In order to increase the responsibility of key managers for results, links between financial reporting, managerial responsibilities and the outputs and outcomes of the public organisation need to be clear. To be fully effective, institutional reports need to be published.

\section{Summary of SIGMA analysis}

Financial reporting by organisations does exist. All public organisations provide their annual financial reports, and these are consolidated into an annual financial report of the government. They provide information about the spending outturn against the budget, but more analytical information, such as explanations for variations against the budget and links to the actual outputs or outcomes of the organisation's work, is not always provided.

Within public sector organisations, internal reporting is not as systematic. Reporting against the budget outturn is available for the management teams, but since the budget structure is more often not aligned with the management structure, most managers do not have regular information on their budgets. Because managers in the ministries do not have a complete picture of their budget they are also not involved in financial reporting. In most cases, financial reporting is not linked with the annual performance reports.

\section{Recommendations}

1. Align the required performance information with the financial and other annual reporting within organisations. Ideally, public organisations should prepare one single report capturing the elements of the annual financial report and the annual performance report. These reports need to be public.

2. Within public sector organisations, all managers need to be given regular information about the commitment and spending levels within their budgets. To facilitate this, financial management information systems need to cater for such information $^{205}$.

Integration of financial reporting with performance reporting needs to take into account the state of play in work planning and can be done incrementally, for example by aligning the

\footnotetext{
${ }^{204}$ According to a 2018 survey carried out in all six Western Balkan administrations by the WeBER project in co-ordination with SIGMA.
}

205 OECD (2017), SIGMA, The Principles of Public Administration, OECD, Paris, PFM Principle 7, sub-principle 1, on internal regulations ensuring that management information is regularly provided to the appropriate levels of the organisation. 
timetables for both reports and starting to request certain parameters from one part of the annual reporting cycle to be included or referenced in the other report.

\section{Detailed regional analysis}

All public organisations provide their annual financial reports which are consolidated into an annual financial report of the government. These are audited by the supreme audit institutions and published. However, the information provided in these generally does not interest the media or even the civil society organisations. They provide information about the spending outturn against the budget, but more analytical information, such as explanations for variations against the budget and links to the actual outputs or outcomes of the organisation's work, is not always provided.

There are a few notable exceptions to this. In the former Yugoslav Republic of Macedonia, for example, the public institutions prepare one single report combining financial and performance information. In Kosovo, the preparation of those reports is sequenced in time but still presented in separate documents. In Albania, all budget organisations must provide regular information to the Ministry of Finance and Economy on the achievement of objectives and outputs in line with the allocated annual budget. The managers of all institutions at the $\mathrm{BiH}$ State level are obliged to submit to the Ministry of Finance and Treasury an accountability statement on the implementation of institutional objectives, alongside the annual budget execution report.

Within the budgetary year, ministries of finance publish aggregate information on key revenue and expenditure categories but this information does not disclose the situation with spending by individual organisations.

In most administrations, managers responsible for different work areas are not required to submit any financial reports. In typical cases, budget and finance departments, or other designated units, provide the financial reports for the top management and the ministries of finance as required. In Albania, those managers within the ministries who are in charge of a separate spending unit or have a separate budget allocation provide regular financial reports. 


\section{The way forward}

Public sector managers in the Western Balkans are faced with several administrative barriers. Currently, it is all too easy for them to point to these barriers to managerial accountability as a reason for poor progress or a lack of achievement. At the same time, the concept of managerial accountability requires the implementation of demanding and sophisticated management approaches. The adoption of these approaches into current practice will not happen overnight, but work must continue and should focus increasingly on creating good conditions for the development of managerial accountability.

In order to advance the development of managerial accountability, various efforts will need to be led in parallel. Chapter 2 of this Paper provides detailed suggestions for the Western Balkan governments to consider when planning and implementing changes to the rules and practices of specific management processes. Chapter 3 presents a more strategic outline for the way forward.

\section{Clarity of roles and objectives}

A clear framework of roles and responsibilities throughout the levels of an organisation is critical. This needs to start from the top, as the relationship between the political leaders and senior civil servants is vital to the shaping of managerial accountability in practice. The authority to make decisions in the course of many routine management processes should not be reserved only for ministers and other heads of organisation. Their ability to focus on strategic issues will be significantly hampered if this is the case.

Strengthening managerial accountability requires the clear assignment of responsibility for actions and a focus on results, clear statements of objectives, transparency, open communication and the availability of the detailed information necessary for carrying out the work.

1. The roles of each key management position, both political and senior non-political, should be clearly defined within the hierarchy of public sector executive organisations. This should be established in legislation for the highest-level civil servants in the ministry and for the heads of bodies subordinate to the ministry. Political leaders need to be relieved of any operational management burden, and senior managers in the ministries and agencies need to be given clear decisionmaking authority in respect of the routine operational concerns of their organisation, including the financial and human resources they are accountable for.

2. The delegation permitted within general legislation should be used. To achieve this there needs to be clear and tangible procedures and guidelines, to support organisations seeking to make use of the legally defined delegation opportunities. Comparative information about delegation practices should be collected and used to encourage the delegation of decision-making authority in other organisations.

3. In order for objectives to become a vehicle for developing results-oriented managerial accountability, governments should consolidate planning systems and procedures and create a clear hierarchy of strategic and operational planning documents. The use of objectives and indicators should be a part of the minimum requirements for these planning documents, and central guidance and feedback needs to be available for the public sector organisations preparing them. Political- 
level prioritisation decisions and the political and strategic steering of objectives are desirable, but not at the expense of managerial involvement in these processes.

4. Governments should create conditions and incentives for public sector organisations to develop internal work planning and reporting systems that are aligned with the government's strategic plans, and which contribute to the implementation of government priorities by means of clear operational plans linked to specific managers and units within the ministries. Costing and budgeting should be an integral part of annual work planning. Internal reporting at the level of individual managers and their units should form the basis for higher-level reports and create a sound reporting and accountability culture.

\section{Managing resources}

Most managers in the Western Balkan administrations do not feel they can or even should be able to manage the key resources available to them. However, it is essential for the growth of managerial accountability that they are able to manage their staff and to predict and influence, to a certain extent, the operational budget for the year.

5. The political level should be removed from decisions about the recruitment and dismissal of individual non-managerial and middle-management staff members. Politicians should take overall policy decisions on increases in staffing levels or the downsizing of an administration, but they should not decide on individual appointments, promotions, bonuses (if any), reallocation, demotions or dismissals. These are all managerial decisions aimed at creating the bestperforming teams, so managers should have the maximum possible authority to make them.

6. Staff performance appraisal systems should be reviewed and redesigned to provide a simple but useful tool for managers, which supports to the maximum extent possible the building of a culture of trust. Practical solutions might involve performance dialogue, without a performance appraisal focus, in order to strengthen the relationship and increase trust between managers and their subordinates. The procedures and guidelines need to be supported by mandatory training in HRM. If managers are skilled in HRM, termination of employment will be the last resort, used only when performance appraisal, professional development and other tools have failed. This needs to go hand in hand with the professionalisation of organisations' HRM units.

7. Managers should have formally established budgets or budget envelopes, even if during the budget execution phase, they currently do not have autonomy over their use. This alignment between budget and management structures need not be at the level of the budget law as approved by parliament, but rather can simply be established by the heads of individual budget organisations, to allow sufficient flexibility for reallocations. All managers should be provided with detailed regular information on at least commitments and actual spending against their budget.

8. When the management and monitoring systems are sufficiently established, at least all senior managers should be given responsibility for individual spending decisions within their budgets (including the key decision for public procurement), with administrative ex ante verification by the relevant internal financial control officials. Ex ante verification by higher levels of management or at the political level should be replaced by adequate reporting by the finance departments. 


\section{Reporting}

9. Public sector organisations should publish reports on their achievement of objectives at least annually. Legislation needs to establish clear, centrally enforced minimum requirements for these reports, and governments should develop user-friendly report templates, guidelines and examples for managers to follow. Care should be taken that reporting cycles and requirements are made simple and lean, avoiding duplication and redundant information on detailed activities, in order to minimise the administrative burden, while at the same time maximising information about achievement of results. Reports should make the crucial link between the objectives of the organisation and those of individual managers or their departments/units.

10. The required performance information should be aligned with the organisation's internal and external annual financial reporting. Ideally, public organisations should prepare a single report capturing the elements of both the annual financial report and the annual performance report, but in the initial stages, the preparation and publication of these reports should at least be synchronised. It is important that these reports are made available to the public.

\section{Recruitment, selection and professional development of senior managers}

Good management cannot be achieved without competent managers. The governments need to focus their attention on the core group of senior managers within central government, as suggested in the SIGMA Paper on the professionalisation of the senior civil service $^{206}$. It must be understood that, in the long term, public sector senior managers can only be committed to and professionally prepared for the implementation of government programmes, creating organisations with the necessary capacities, if their own professional competence and independence are ensured from the start ${ }^{207}$.

11. Governments should develop and implement competency frameworks for senior managers to structure and guide the recruitment and testing of candidates, and to serve as a basis for professional development.

12. Candidates for senior management positions should be comprehensively tested for professional competence before a minister, the prime minister or any other decision maker is given the opportunity to take final selection decisions.

13. Central services for the development of senior civil servants need to invest more in enhancing the competence of managers, by offering personally tailored training and coaching activities, supporting networking opportunities and facilitating staff mobility, in order to retain talented senior civil servants and to contribute to the professionalism and stability of the senior civil service.

206 OECD (2018), "Analysis of the Professionalisation of the Senior Civil Service and the Way Forward for the Western Balkans”, SIGMA Paper No. 55, OECD Publishing, Paris.

207 See for more context the principles under development by the OECD Public Employment and Management Working Party (PEM) for public sector leadership [GOV/PGC(2018)10]. The PEM is working on identifying current trends and good practice regarding skills, competencies and performance. The PEM is a collaborative international forum of senior practitioners seeking to address current challenges affecting public services and civil service reform. It undertakes comparative analysis on issues related to strategic civil service management and compensation, which provides governments with unique data to inform their reform agendas 


\section{Managerial accountability as an integral part of other reforms}

The development of managerial accountability cannot be separated from other efforts to improve the functioning of public administration, including PFM. The development of better conditions for managerial accountability requires a shared understanding of what it means in the national context, and of the allocation of roles among the key state authorities leading public sector reforms. As long as the efforts to develop conditions for managerial accountability are restricted to PIFC laws and are promoted exclusively by the CHUs, whose political weight is limited, it will be challenging to make it work.

14. The lead ministries need to continue the key reforms in public governance and $\mathbf{P F M}^{208}$ while at the same time paying more attention to the role of public sector managers, particularly their incentives and ability to be accountable for the results and lawful performance of their teams. In other words, aspects related to the responsibility, authority and autonomy of public sector managers need to be carefully considered when planning structural changes in public governance. Key institutions need to be made more aware of the issue by a managerial accountability champion, designated from within the government administration, whose role would be to promote and safeguard the concept.

15. The management teams of public sector organisations need more support and direct incentives to develop effective internal control systems. When designing new rules and procedures for strategic planning, improving budgetary control information and creating modern HRM and financial management services, the needs of senior and middle managers need to be taken into account, while at the same time adhering to central guidelines. CHUs have a greater role to play in supporting the management teams in establishing robust internal control systems in key public sector institutions.

16. Each administration should carry out its own analysis of existing barriers to the development of managerial accountability in the public sector. This would help to take stock of the ongoing work, as well as guiding the detailed public governance reforms and facilitating the focus on managers and managerial accountability. These analyses should identify, among other things, those regulations that currently make it difficult for managers to properly fulfil their roles, and which it would, therefore, be desirable to change.

Administrations should not necessarily prepare additional, formally adopted action plans on the subject. Rather, the suggested dedicated, administration-specific analyses of the barriers to managerial accountability should feed into the longer-term design of individual reforms for better public governance.

${ }^{208}$ In line with the Principles of Public Administration, OECD (2017), SIGMA, The Principles of Public Administration, OECD, Paris. 


\section{Annex A. Management hierarchy of ministries in the region ${ }^{209}$}

\section{Legend}

Blue: Political positions generally not covered in civil service legislation

Yellow: Top civil service positions recognised by civil service law (CSL)

\section{Albania}
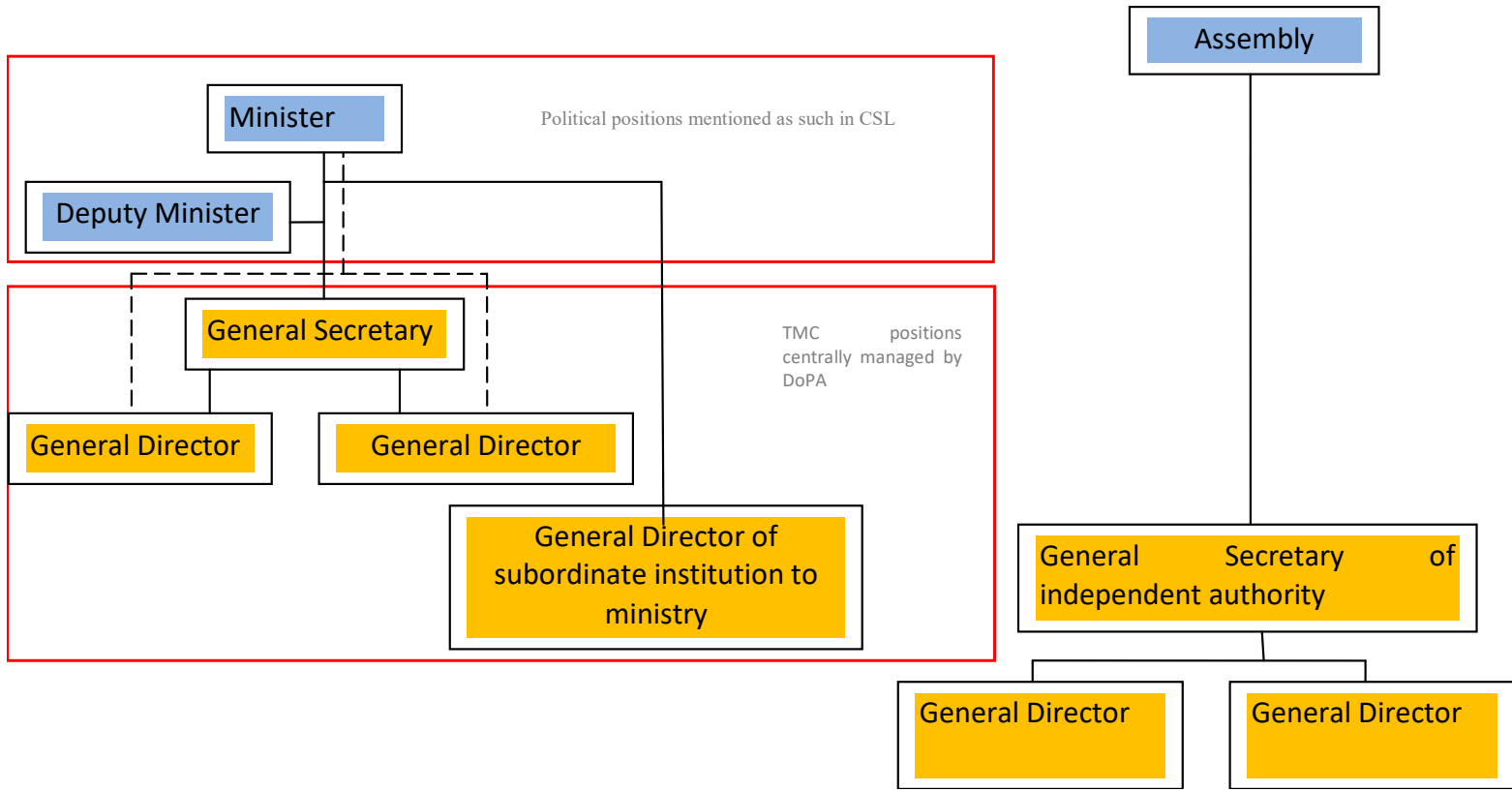

Note $: \mathrm{TMC}=$ Top Management Corps; DoPA $=$ Department of Public Administration.

209 OECD (2018), Analysis of the Professionalisation of the Senior Civil Service and the Way Forward for the Western Balkans, SIGMA Paper No. 55, OECD Publishing, Paris. 
Bosnia and Herzegovina State level

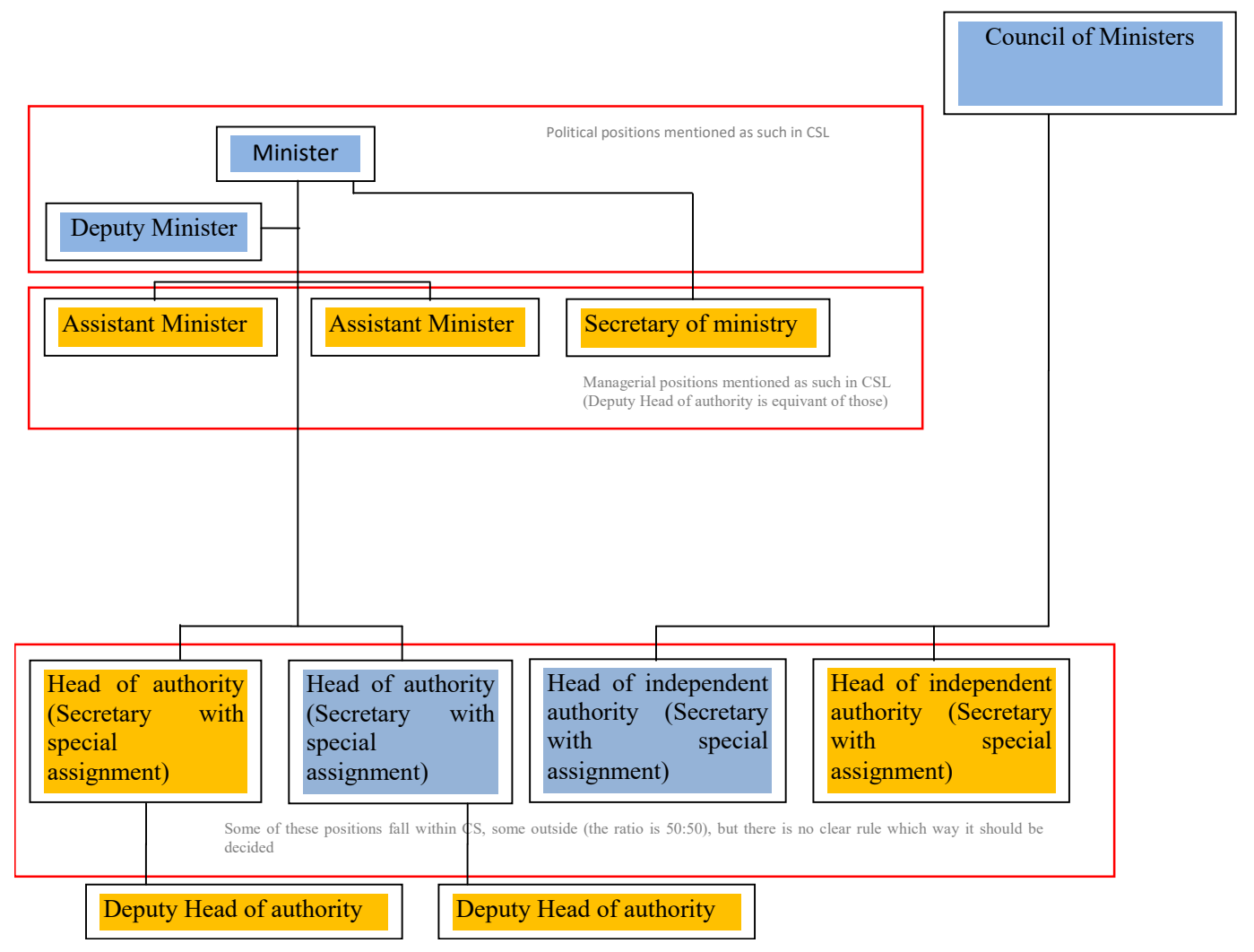

Federation of Bosnia and Herzegovina

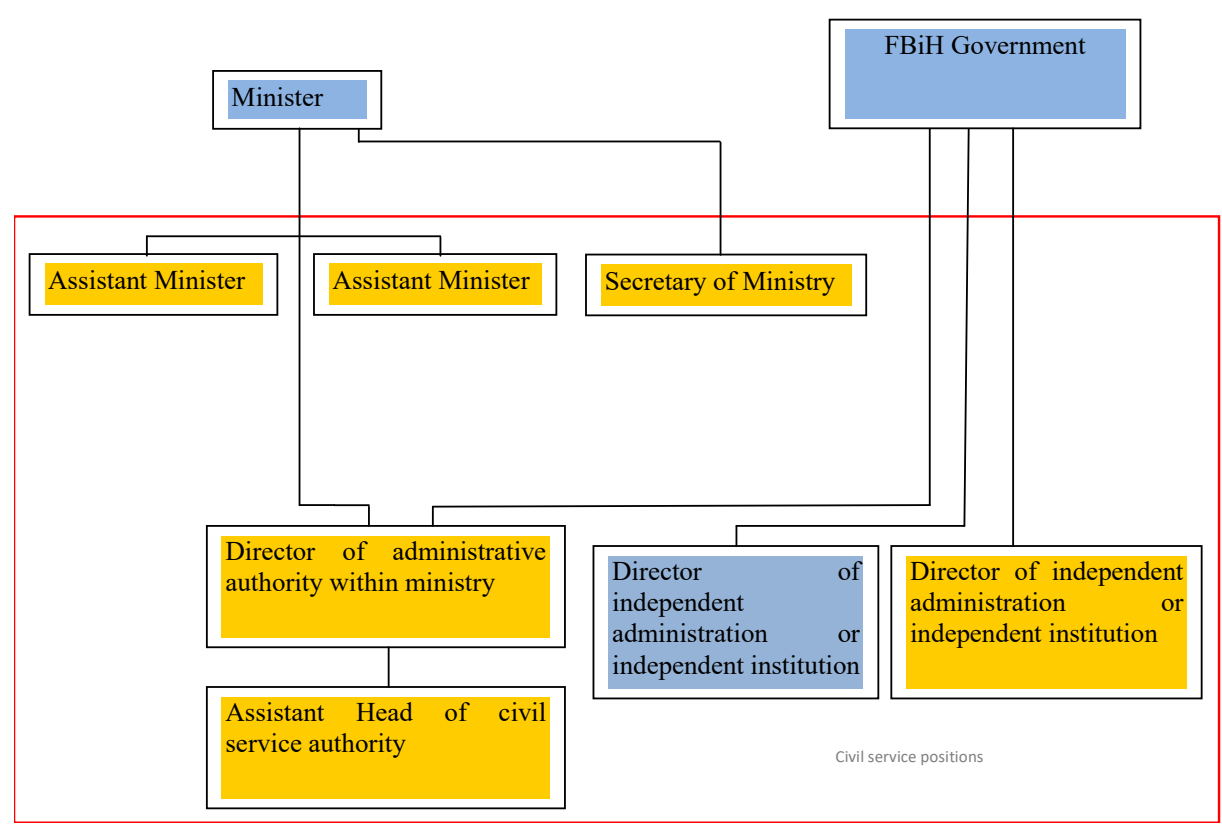


Bosnia and Herzegovina, Republika Srpska

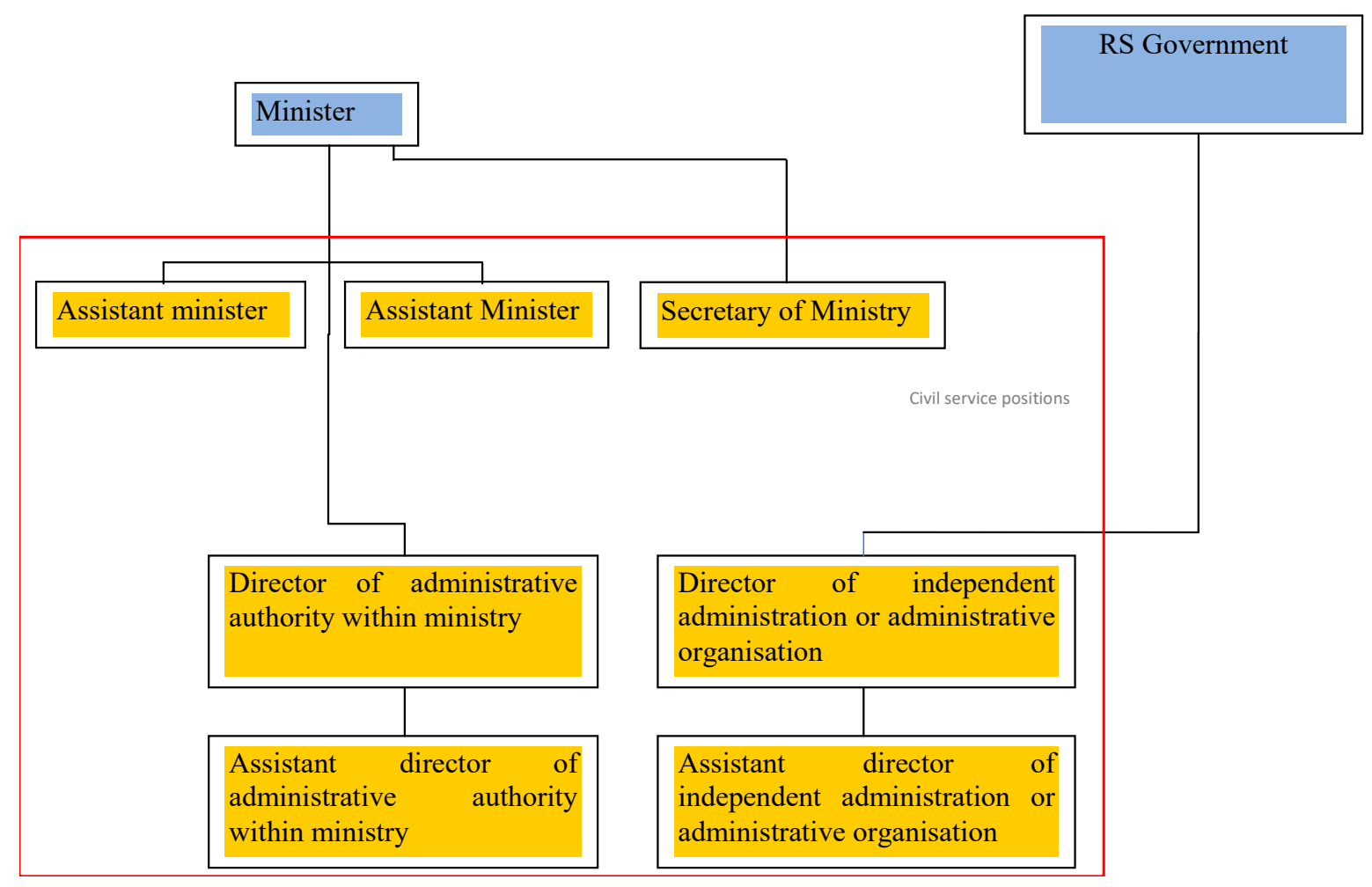

Kosovo
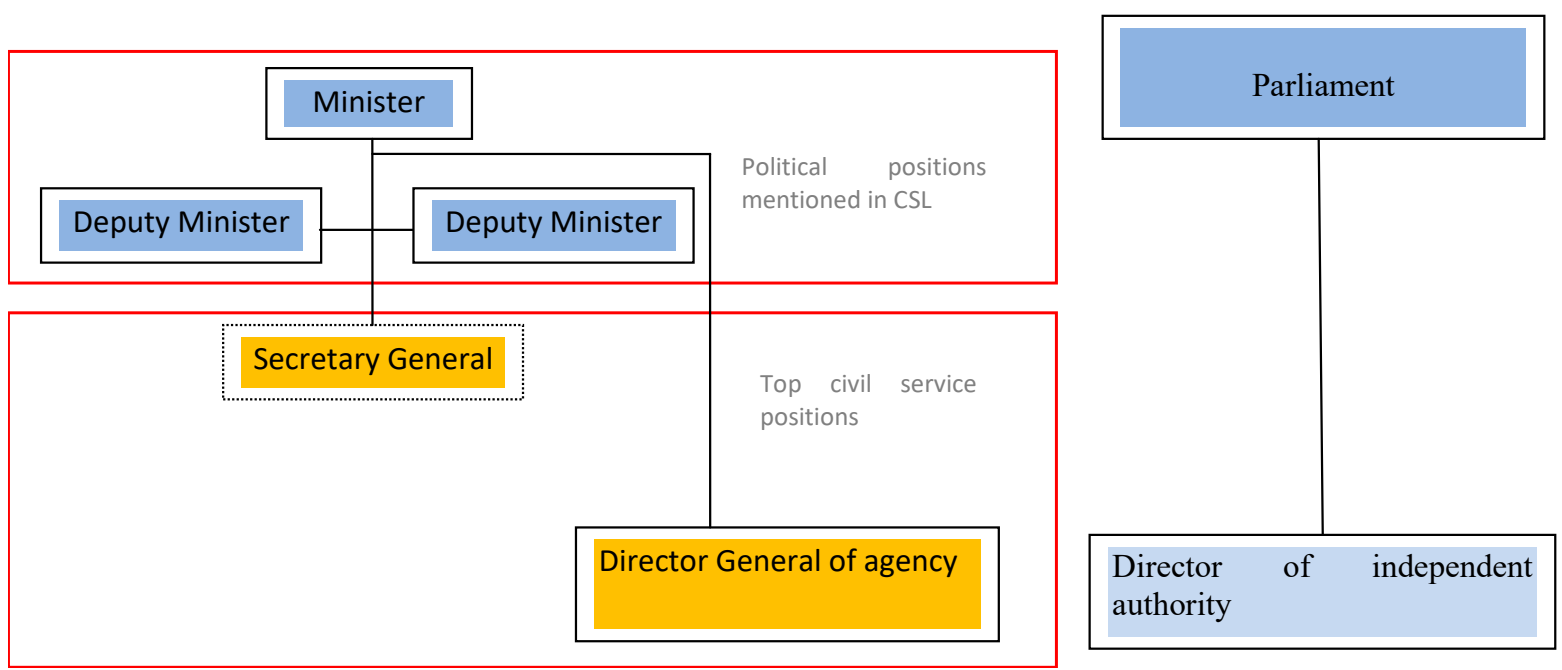
The former Yugoslav Republic of Macedonia

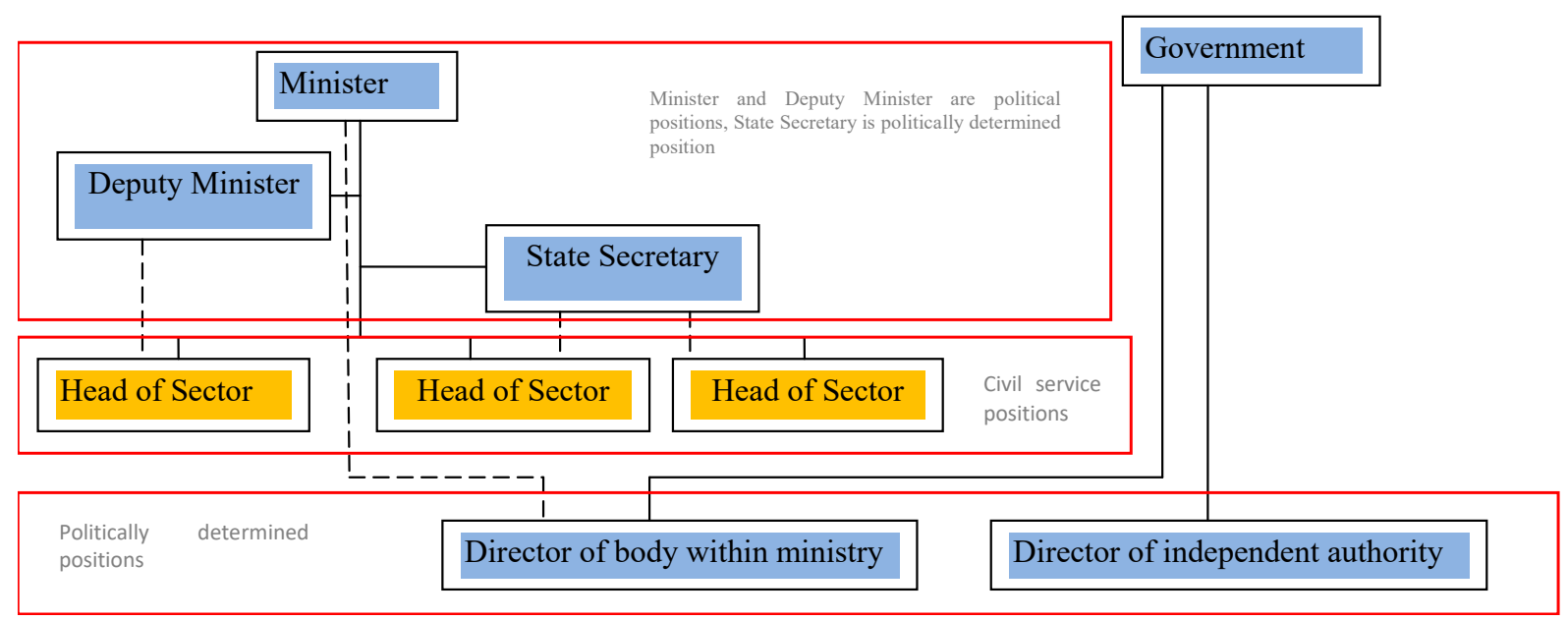

Montenegro

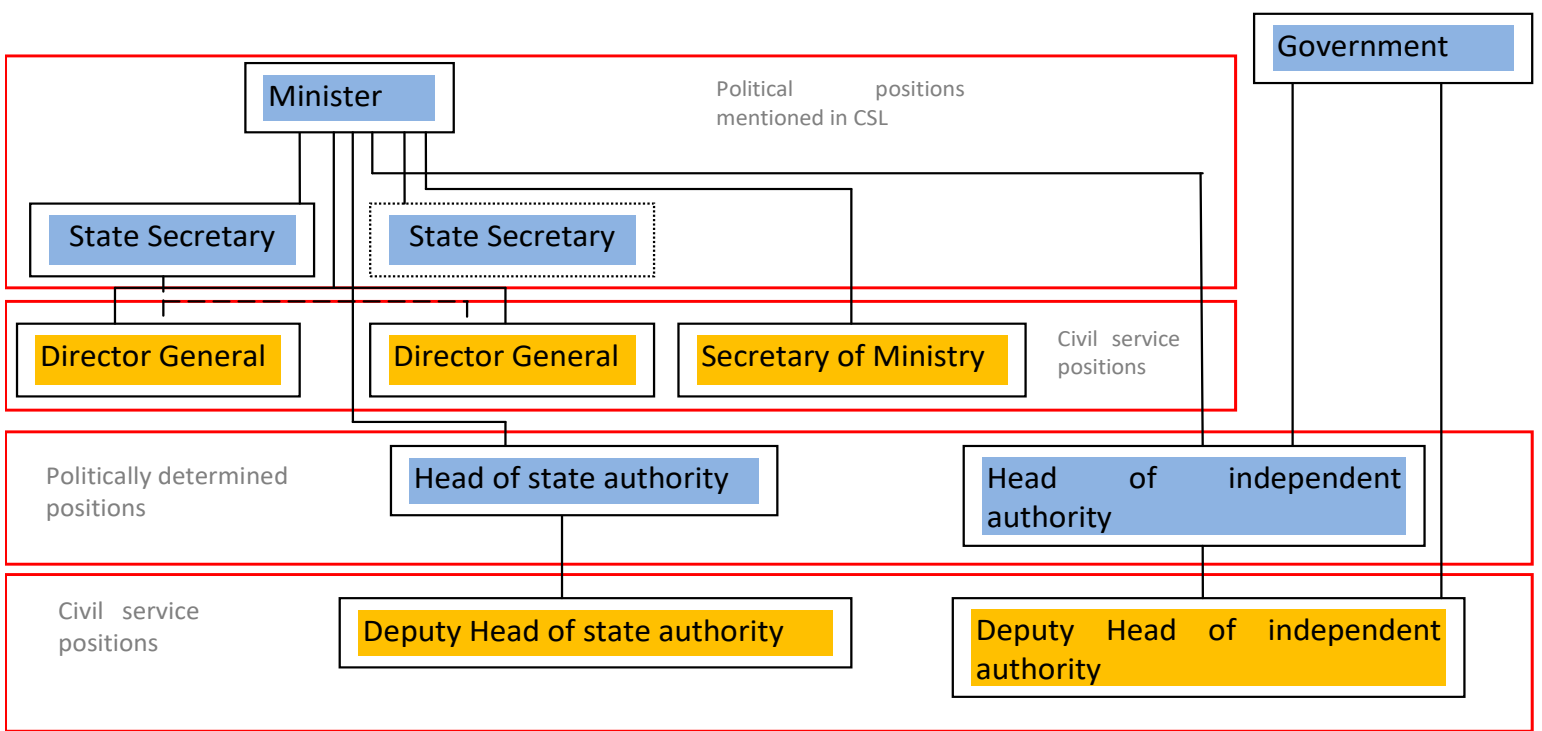

Note: In Montenegro the new Law on Civil Servants and State Employees brings the heads of state authorities and independent authorities closer to civil service positions. However, at the time of writing the law has not yet taken full effect. 
Serbia
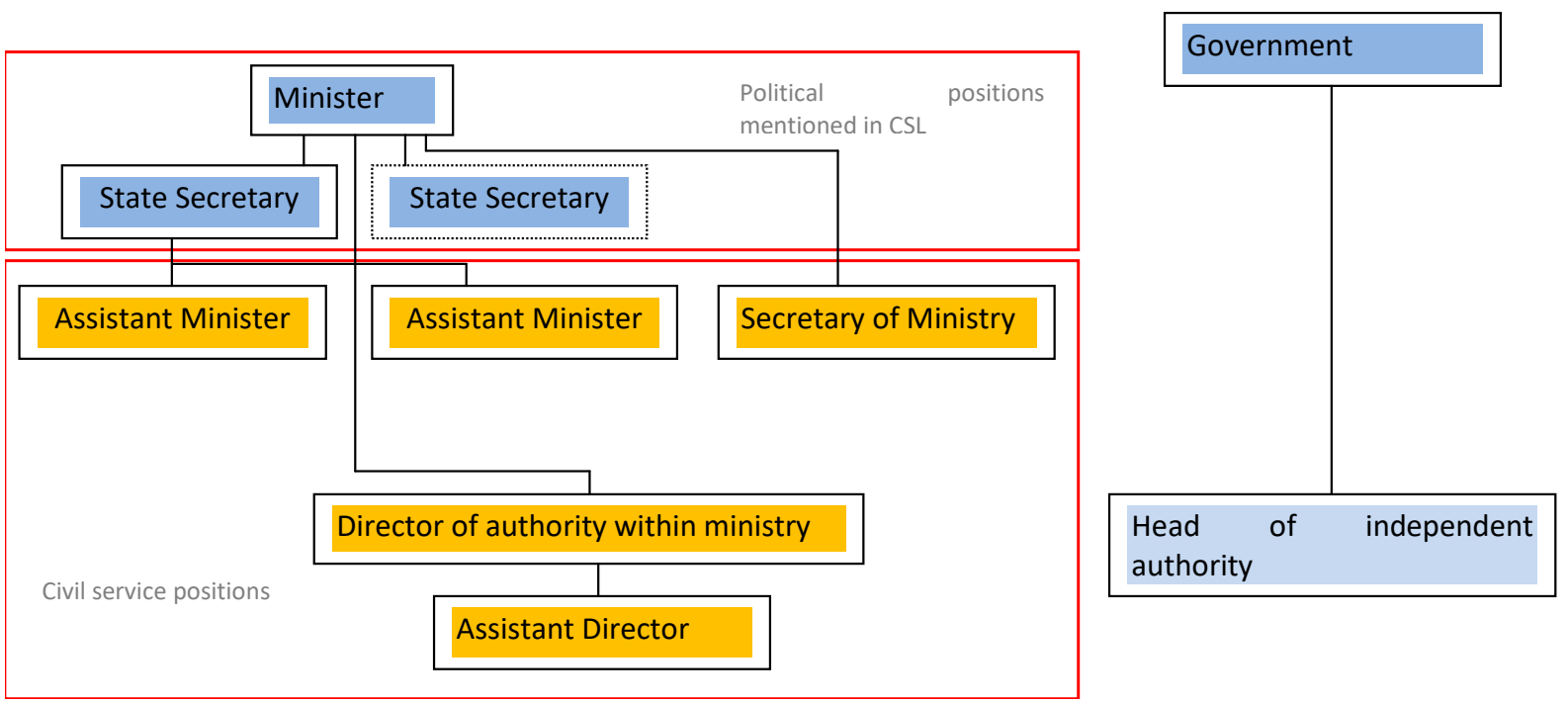


\section{Annex B. Delegation matrix - a generalised approach to the delegation of decision-making authority}

Why is delegation needed for the effective management of ministerial systems?

1. Initially, the minister holds all decision-making powers and is solely accountable within the ministerial system.

2. However, this model results in a number of significant inefficiencies: a) it distracts ministers from their core functions, i.e. higher-level policy making and strategy; $b$ ) it provides only delusive supervision over many decisions, since the minister is not truly able to make informed decisions on all matters falling within the remit of his/her ministry; c) it creates significant delays in decision-making; d) it hampers any shift towards managerial accountability, since the managers below the level of minister, deprived of decision-making powers, cannot be held fully accountable for their performance.

3. There is, therefore, a need to decentralise decision-making powers and cascade accountability mechanisms down to the lower levels of management in order to ensure an adequate level of managerial autonomy. 
Table 6. Delegation matrix

\begin{tabular}{|c|c|c|c|c|c|c|c|}
\hline $\begin{array}{c}\text { Delegation } \\
\text { from... }\end{array}$ & & Delegation to... & Legal form & $\begin{array}{c}\text { Nature of } \\
\text { delegation }\end{array}$ & $\begin{array}{l}\text { Option to withdraw } \\
\text { delegation }\end{array}$ & Potential scope (non-exhaustive list) & $\begin{array}{l}\text { Safeguards/control } \\
\text { measures }\end{array}$ \\
\hline \multirow[t]{2}{*}{ 1st level } & Minister & $\begin{array}{l}\text { Highest civil service } \\
\text { position, } \\
\text { i.e. secretary } \\
\text { general, state } \\
\text { secretary, secretary } \\
\text { of ministry, etc. }\end{array}$ & Legislation & $\begin{array}{l}\text { Not person-specific, } \\
\text { i.e. associated with } \\
\text { the function, not the } \\
\text { person }\end{array}$ & None & $\begin{array}{l}\text { Overall responsibility for all organisational } \\
\text { matters, including: } \\
\text { - HRM - management of (non-political) staff } \\
\text { and employer functions such as recruitment, } \\
\text { allocation of staff and provision of training, } \\
\text { sanctions and rewards } \\
\text { - financial management - budgeting, } \\
\text { contracting, spending commitments and } \\
\text { property disposal } \\
\text { - public procurement - exercising or oversight } \\
\text { of all contracting authority functions } \\
\text { - performance management - performance } \\
\text { plan drafting and oversight of the } \\
\text { implementation of agreed organisational } \\
\text { objectives and targets } \\
\text { - supervision of the performance of } \\
\text { subordinated bodies }\end{array}$ & $\begin{array}{l}\text { - Full administrative, } \\
\text { disciplinary and } \\
\text { criminal liability of the } \\
\text { top civil servant } \\
\text { - Ex ante approvals } \\
\text { (signatures required } \\
\text { for specific decisions, } \\
\text { such as the signing of } \\
\text { public procurement } \\
\text { contracts) }\end{array}$ \\
\hline & Minister & $\begin{array}{l}\text { Senior managers } \\
\text { such as directors or } \\
\text { assistant ministers }\end{array}$ & $\begin{array}{l}\text { OPTION 1: } \\
\text { Legislation (general } \\
\text { authorisation) + } \\
\text { individual act of } \\
\text { delegation, i.e. a } \\
\text { combination of } \\
\text { general and } \\
\text { specific } \\
\text { authorisation } \\
\text { OPTION 2: } \\
\text { Legislation (general } \\
\text { authorisation) + }\end{array}$ & $\begin{array}{l}\text { OPTION 1: } \\
\text { Person-specific, i.e. } \\
\text { terminates with the } \\
\text { dismissal or } \\
\text { resignation of the } \\
\text { persons involved } \\
\text { ('principal' or } \\
\text { 'agent') } \\
\text { OPTION 2: } \\
\text { Not person-specific }\end{array}$ & $\begin{array}{l}\text { OPTION 1: } \\
\text { Organisation may } \\
\text { withdraw delegation } \\
\text { at any time } \\
\text { OPTION 2: } \\
\text { Delegation may be } \\
\text { withdrawn via } \\
\text { amendments to the } \\
\text { ministry's internal } \\
\text { regulation }\end{array}$ & $\begin{array}{l}\text { Responsibilities such as: } \\
\text { - issuing administrative acts } \\
\text { - representing the ministry (... taking a formal } \\
\text { position on behalf of the ministry) on specific } \\
\text { policy matters } \\
\text { - functions relating to external stakeholders, } \\
\text { such as deciding on public information requests } \\
\text { and representing the ministry in official } \\
\text { communications with external parties } \\
\text { - initiating public procurement processes at } \\
\text { agreed values, signing procurement contracts } \\
\text { and overseeing the execution of contracts }\end{array}$ & $\begin{array}{l}\text { - Authorisation } \\
\text { includes value } \\
\text { thresholds } \\
\text { - Prior signatures } \\
\text { required } \\
\text { - Administrative acts } \\
\text { subject to appeal } \\
\text { procedure }\end{array}$ \\
\hline
\end{tabular}




\begin{tabular}{|c|c|c|c|c|c|c|c|}
\hline & & & $\begin{array}{l}\text { ministry's internal } \\
\text { regulation }\end{array}$ & & & & \\
\hline \multirow[t]{2}{*}{$2^{\text {nd }}$ level } & $\begin{array}{l}\text { Secretary } \\
\text { general }\end{array}$ & $\begin{array}{l}\text { Senior managers } \\
\text { often subordinate to } \\
\text { secretary general } \\
\text { (heads of } \\
\text { departments or } \\
\text { sectors such as } \\
\text { directors or } \\
\text { assistant ministers) }\end{array}$ & $\begin{array}{l}\text { OPTION 1: } \\
\text { Ministry's internal } \\
\text { regulation + } \\
\text { individual act of } \\
\text { delegation } \\
\text { OPTION 2: } \\
\text { Ministry's internal } \\
\text { regulation }\end{array}$ & $\begin{array}{l}\text { OPTION 1: } \\
\text { Person-specific } \\
\text { OPTION 2: } \\
\text { Not person-specific }\end{array}$ & $\begin{array}{l}\text { Delegation may be } \\
\text { withdrawn at any } \\
\text { time }\end{array}$ & $\begin{array}{l}\text { Organisational matters of sectoral relevance, } \\
\text { including: } \\
\text { - the setting of objectives and targets for staff } \\
\text { and the conducting of performance appraisals } \\
\text { (or the supervision of staff appraisals where } \\
\text { these are carried out by lower-level managers) } \\
\text { - advice and proposals regarding staff } \\
\text { sanctions and rewards } \\
\text { - proposals regarding the training of direct } \\
\text { subordinates } \\
\text { - the relocation of staff between sub-units } \\
\text { - the approval of low-value contracts and } \\
\text { payments within the budget allocated to the } \\
\text { department } \\
\text { - the day-to-day supervision of subordinated } \\
\text { bodies (i.e. agencies working within the specific } \\
\text { policy area) }\end{array}$ & $\begin{array}{l}\text { - Prior signatures } \\
\text { required, e.g. finance } \\
\text { department approval } \\
\text { prior to financial } \\
\text { commitments } \\
\text { - Regular reporting } \\
\text { - Review of a } \\
\text { random sample of } \\
\text { decisions } \\
\text { - Internal audit to } \\
\text { report directly to the } \\
\text { minister or secretary } \\
\text { general }\end{array}$ \\
\hline & $\begin{array}{l}\text { Senior } \\
\text { managers } \\
\text { (heads of } \\
\text { departments } \\
\text { or sectors } \\
\text { such as } \\
\text { directors or } \\
\text { assistant } \\
\text { ministers) }\end{array}$ & $\begin{array}{l}\text { Middle managers, } \\
\text { such as heads of } \\
\text { units, teams or } \\
\text { similar }\end{array}$ & $\begin{array}{l}\text { Ministry's internal } \\
\text { regulation }+ \\
\text { individual act of } \\
\text { delegation }\end{array}$ & $\begin{array}{l}\text { OPTION 1: } \\
\text { Person-specific } \\
\text { OPTION 2: } \\
\text { Not person-specific }\end{array}$ & $\begin{array}{l}\text { Delegation may be } \\
\text { withdrawn at any } \\
\text { time }\end{array}$ & $\begin{array}{l}\text { Organisational matters not directly associated } \\
\text { with the commitment of public funds or } \\
\text { decisions affecting the rights of the staff: } \\
\text { - staff management functions not carried out at } \\
\text { a higher level } \\
\text { - approval of annual leave } \\
\text { - staff training proposals } \\
\text { - approval of business trips } \\
\text { - the setting of objectives and targets for staff } \\
\text { and the appraisal of subordinates' performance }\end{array}$ & $\begin{array}{l}\text { - Regular reporting } \\
\text { - Review of a } \\
\text { random sample of } \\
\text { decisions } \\
\text { - Internal audit to } \\
\text { report directly to the } \\
\text { minister or secretary } \\
\text { general }\end{array}$ \\
\hline
\end{tabular}




\section{The SIGMA Programme}

SIGMA (Support for Improvement in Governance and Management) is a joint initiative of the OECD and the European Union (EU), principally financed by the EU. SIGMA has been working with partner countries on strengthening public governance systems and public administration capacities for 25 years.

In partnership with the European Commission (EC) Directorate-General for Neighbourhood and Enlargement Negotiations (DG NEAR), we currently work with:

Albania, Bosnia and Herzegovina, the former Yugoslav Republic of Macedonia, Kosovo, Montenegro, Serbia, and Turkey as EU candidate countries and potential candidates; and

Algeria, Armenia, Azerbaijan, Egypt, Georgia, Jordan, Lebanon, Moldova, Morocco, Tunisia and Ukraine as EU Neighbourhood countries.

SIGMA provides assistance in six key areas:

1. Strategic framework of public administration reform

2. Policy development and co-ordination

3. Public service and human resource management

4. Accountability

5. Service delivery

6. Public financial management, public procurement and external audit.

SIGMA reviews and gives feedback on:

- Governance systems and institutions

- Legal frameworks

- Reform strategies and action plans

- Progress in reform implementation.

SIGMA provides:

- Advice on the design and prioritisation of reforms

- Methodologies and tools to support implementation

- Recommendations for improving laws and administrative arrangements

- Opportunities to share good practice from a wide range of countries, including regional events

- Policy papers and multi-country comparative studies.

For further information on SIGMA, consult our website: www.sigmaweb.org

(C) OECD 2018

As SIGMA is part of the Organisation for Economic Co-operation and Development (OECD) the same conditions of use apply to its publications: http://www.oecd.org/termsandconditions. 